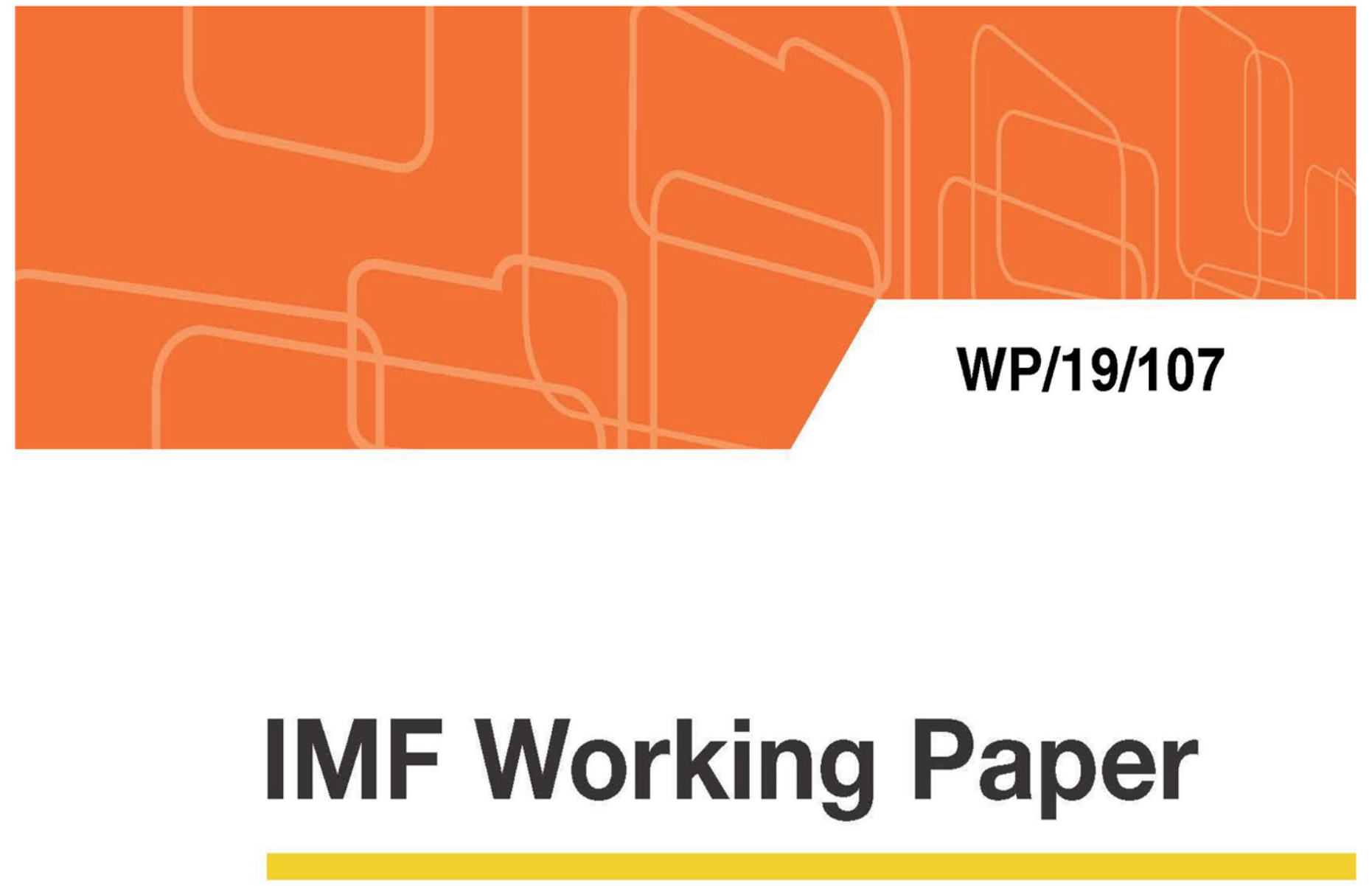

\title{
Credit Supply and Productivity Growth
}

by Francesco Manaresi and Nicola Pierri

IMF Working Papers describe research in progress by the author(s) and are published to elicit comments and to encourage debate. The views expressed in IMF Working Papers are those of the author(s) and do not necessarily represent the views of the IMF, its Executive Board, or IMF management. 


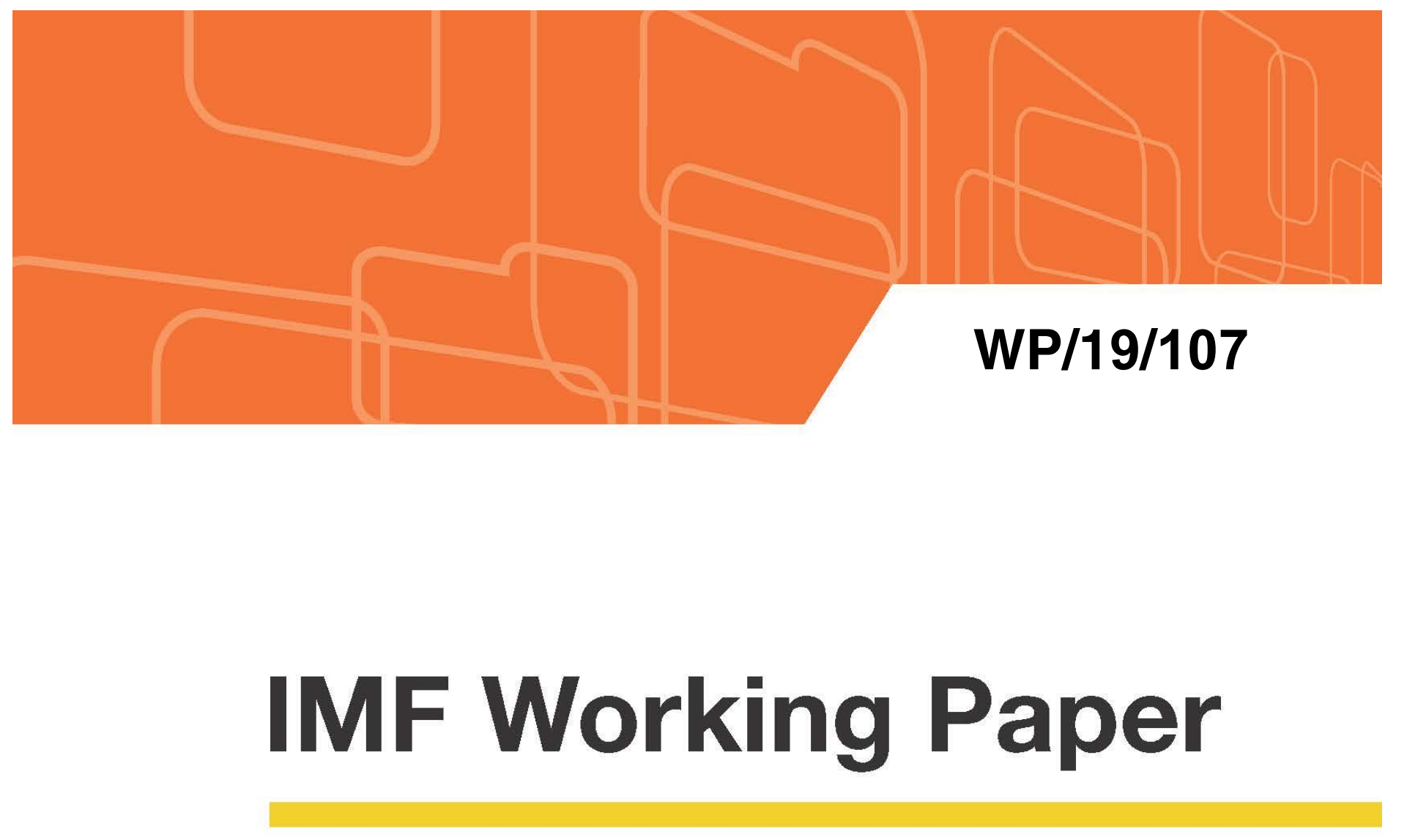

Credit Supply and Productivity Growth

by Francesco Manaresi and Nicola Pierri

IMF Working Papers describe research in progress by the author(s) and are published to elicit comments and to encourage debate. The views expressed in IMF Working Papers are those of the author(s) and do not necessarily represent the views of the IMF, its Executive Board, or IMF management.

$$
\text { I N T ER N A T I O N A L M O NETARY FU N }
$$




\title{
IMF Working Paper
}

Research Department

\section{Credit Supply and Productivity Growth}

\section{Prepared by Francesco Manaresi and Nicola Pierri ${ }^{1}$}

Authorized for distribution by Maria Soledad Martinez Peria

May 2019

IMF Working Papers describe research in progress by the author(s) and are published to elicit comments and to encourage debate. The views expressed in IMF Working Papers are those of the author(s) and do not necessarily represent the views of the IMF, its Executive Board, or IMF management.

\begin{abstract}
We study the impact of bank credit on firm productivity. We exploit a matched firm-bank database covering all the credit relationships of Italian corporations, together with a natural experiment, to measure idiosyncratic supply-side shocks to credit availability and to estimate a production model augmented with financial frictions. We find that a contraction in credit supply causes a reduction of firm TFP growth and also harms IT-adoption, innovation, exporting, and adoption of superior management practices, while a credit expansion has limited impact. Quantitatively, the credit contraction between 2007 and 2009 accounts for about a quarter of observed the decline in TFP.

JEL Classification Numbers: D22, D24, G21

Keywords: Credit Supply; Productivity; Export; Management; IT adoption

Author's E-Mail Address: francesco.manaresi@bancaditalia.it; npierri@imf.org;

\footnotetext{
${ }^{1}$ We thank, for their insightful comments, Nick Bloom, Tim Bresnahan, Liran Einav, Matt Gentzkow, and many seminar participants at Stanford, Bank of Italy, Bank of International Settlements, Banque de France, Italian Treasury Department, CompNet Annual Conference, University of Bologna, IMF, EIEF, BIS-IMF-OECD Conference, Kellogg School of Management, University of Cambridge, New Economic School, Swedish House of Finance, Atlanta FRB, and NBER Summer Institute 2018 - Macroeconomics and Productivity. We thank, for financial support, the Central Bank Research Fellowship program, the Bonaldo Stringher scholarship, the The Europe Center at Stanford University, and the Gale and Steve Kohlhagen Fellowship in Economics. Usual disclaimers apply.
} 


\section{Introduction}

Financial crises induce strong and persistent recessions, often followed by weak recoveries. ${ }^{1}$ Aggregate productivity fell sharply during the Great Recession in most OECD economies and it is still growing at a much slower pace than during the pre-crisis period, as illustrated by Figure 1. Yet, we still lack empirical evidence on the channels through which a disruption in financial markets and the resulting credit crunch may cause a long-lasting decrease in total factor productivity (TFP) of non-financial firms. In fact, most of the explanations currently proposed for the recent productivity slowdown are linked to long-term trends preceding the financial crisis. ${ }^{2}$

In this paper, we study the causal relationship between shocks to a major source of external financing and the firm-level component of aggregate productivity. Specifically, we estimate the impact of changes in the supply of bank credit faced by Italian firms on their TFP growth. We rely on detailed firm-bank matched data on credit granted by all financial intermediaries to all incorporated firms over the period 1997-2013. We find that a contraction in credit supply causes a decline of firm-level TFP growth by reducing productivity-enhancing strategies, while a credit expansion has only limited impact.

The causal impact of changes in credit supply on TFP is a priori ambiguous. Standard models of financial frictions assume that agents have an exogenous productivity, implying that lower credit supply affects only the scale of production. Richer models can generate either a negative or a positive relationship. On the one hand, lack of resources may spur productivity growth, if it forces firms to innovate to survive (Field, 2003), ${ }^{3}$ while abundance might aggravate agency problems and stifle managers' efforts (Jensen, 1986). Furthermore, firms may be more likely to invest first in the most profitable business opportunities: as credit constraints become slacker, the marginal project may be less productive (Ates \& Saffie, 2016). On the other hand, credit availability may have positive effects on firm productivity by supporting productivity-enhancing strategies. Firms facing tighter credit constraints might invest less in R\&D because of liquidity risk (Aghion et al. , 2010) and might acquire fewer intangible assets because it is more difficult to use them as collateral (Garcia-

\footnotetext{
${ }^{1}$ See, for instance, Cerra \& Saxena (2008), Reinhart \& Rogoff (2009), Reinhart \& Rogoff (2014), Jordà et al. (2013), and Oulton \& Sebastiá-Barriel (2013). A contrasting view is expressed by Stock \& Watson (2012).

2 They include lower business dynamism (Decker et al. , 2014; Davis \& Haltiwanger, 2014), the mismeasurement of digital goods (Mokyr, 2014; Feldstein, 2015; Byrne et al. , 2016), a slowdown in technological progress (Gordon, 2016; Gordon et al. , 2015; Bloom et al. , 2016; Cette et al. , 2016), and weak demand conditions (Anzoategui et al. , 2016). Adler et al. (2017) argue for the interaction of several factors, from greater uncertainty to an aging workforce. Focusing on Italy, Hall et al. (2008) underline the lack of product innovation as a pre-crisis productivity problem.

${ }^{3} \mathrm{He}$ documents that the years after the Great Depression were the most technologically progressive decade of modern American History, and argues that "the disruptions of financial intermediation [...] fostered a search for organizational innovations that enabled firms to get more out of what they had."
} 


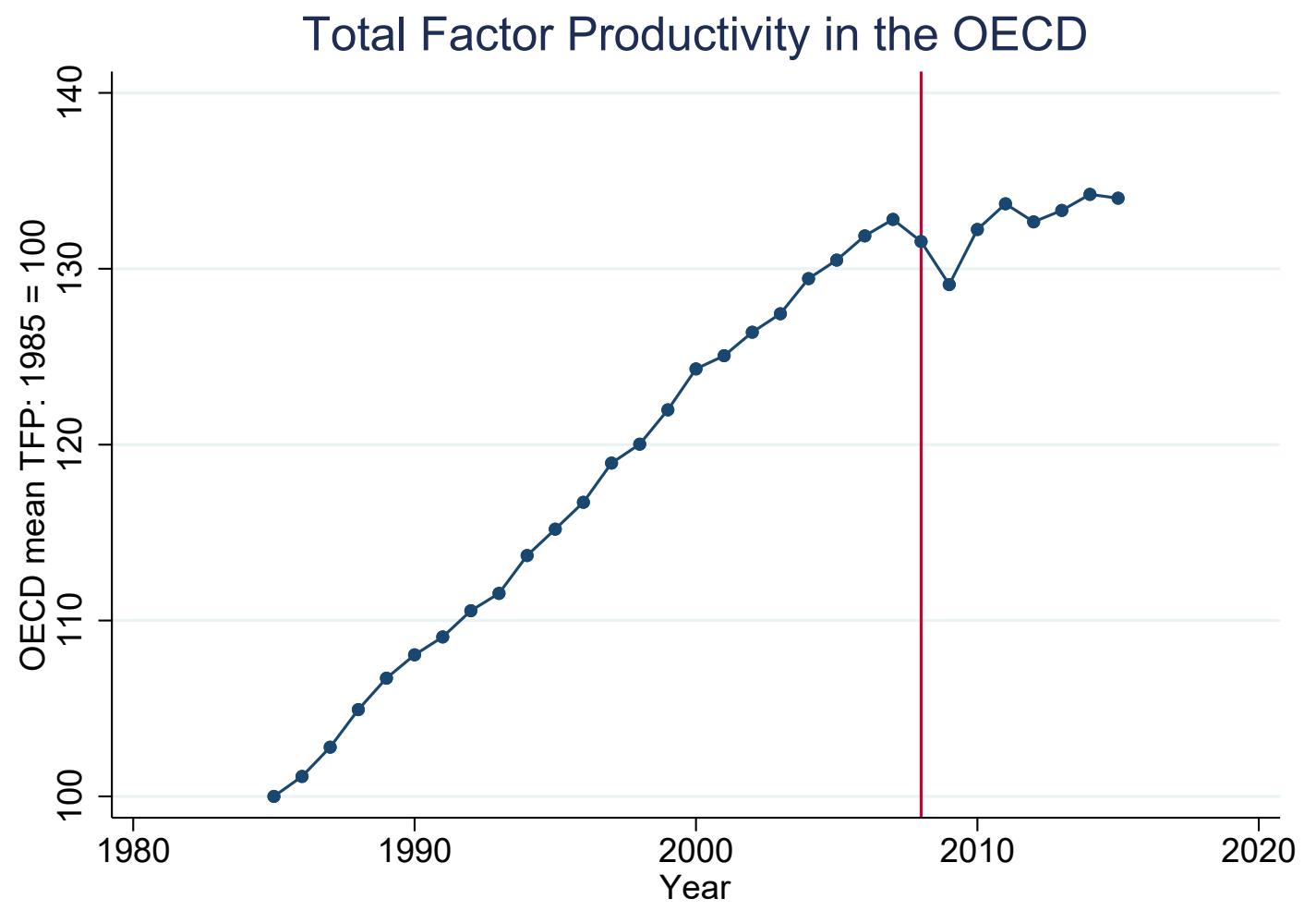

Figure 1: TFP provided by OECD (https://data.oecd.org/lprdty/multifactor-productivity.htm). Values in 1985 are normalized to 100 for each Country, with the (unweighted) average plotted. All countries with data since 1985 are included: AUS, BEL, CAN, DEU, DNK, ESP, FIN, FRA, GBR, IRL, ITA, JPN, KOR, NLD, PRT, SWE, and USA. The vertical line indicates year $=2008$.

Macia, 2015). Credit-constrained firms might undertake less radical innovation (Caggese, 2016), while Midrigan \& Xu (2014) emphasize the role of fixed costs. Additionally, negative credit shocks might exert immediate detrimental effects on small firms by forcing managers/entrepreneurs to divert time and effort away from productivity improvements in order to create relationships with new lenders ("managerial inattention").

To test these opposing predictions, we need to disentangle the effects of a change in credit supply from other confounding factors. For this purpose, we compare firms that operate in the same industry and location but have pre-existing lending relationships with banks that have heterogeneous changes in credit supply: because of relationship lending, one lender's expansion or contraction of credit disproportionally affects access to credit of its existing borrowers (Khwaja \& Mian, 2008; ChodorowReich, 2013).

We identify shifters of each bank's credit supply by exploiting two alternative empirical strategies. One decomposes the growth rate of credit of each bank-firm pair into firm-year and bank-year components, thus measuring in each year how different banks change the quantity of credit granted 
to the same firm and capturing shocks to bank supply. This additive decomposition, closely related to the ones developed by Amiti \& Weinstein (2017) and Greenstone et al. (2014), rests on restrictive assumptions related to the matching between banks and firms and the structure of substitution/complementarity between lenders. We develop novel tests for these hypotheses and show that they are met in our empirical application. A second empirical strategy focuses on the collapse of the interbank market driven by the skyrocketing perceived counterparty risk which followed the sub-prime crisis and the default of Lehman Brothers. Each bank was differentially exposed to this shock according to its pre-crisis reliance on interbank markets as a source of funding (Cingano et al. , 2016).

Bank shifters are aggregated at the firm-level according to the lagged share of credit granted by each lender. Therefore, the exclusion restriction required for a causal interpretation of our results is that firms borrowing from the same bank-within a group defined by industry and province-are not subject to correlated productivity shocks. We show empirical evidence supporting this assumption (see sections 5.1, 5.3, and 6). For instance, we find that lender exposure to the collapse of the interbank market is orthogonal to the pre-crisis observable characteristics of the borrowing firms, their growth potential, and their sensitivity to the business cycle.

Our two alternative empirical strategies to identify credit supply shocks are highly complementary. One methodology can be applied to all years of observation, allowing us to study the effect of credit on firm output and productivity both in "normal times" and during recessions. It also provides panel variation, which is necessary to estimate the structural model of firm production described below. The other strategy is based on a sudden and unexpected shock to bank liabilities providing a clean "natural experiment", but it cannot be exploited outside the Great Recession. The effects of credit supply on productivity estimated exploiting the collapse of the interbank market are larger than that estimated following the other empirical strategy. This suggests that reliable access to external financing is particularly valuable during financial turmoil.

To estimate sector-specific production functions and recover firm-idiosyncratic TFP, we propose a partial-equilibrium structural model of production with heterogeneous credit constraints. ${ }^{4}$ Lenders' credit supply can impact both the credit constraints faced by borrowing firms-affecting the quantity of inputs used in production for a given level of productivity-and the evolution of productivity itself.

\footnotetext{
${ }^{4}$ We build on the literature on estimation of the production function with control functions: Olley \& Pakes (1996), Levinsohn \& Petrin (2003), Ackerberg et al. (2015), De Loecker \& Warzynski (2012), De Loecker (2011), De Loecker \& Scott (2016), Gandhi et al. (2011). In particular, Shenoy (2017) studies estimation of the production function when firms face heterogeneous and unobservable constraints that distort input acquisition but not productivity. Ferrando \& Ruggieri (2015) and Peters et al. (2017a) are also related to our paper, since they estimate a production function and allow firm financial strength to affect productivity dynamics.
} 
Quantitatively, we find that a $1 \%$ decrease in credit granted decreases TFP growth, measured with value-added, by around $0.1 \%$ and TFP growth, measured with revenues, by $0.02-0.03 \%$. During the financial crisis of 2007-09, credit growth shrank by around $12 \%$ in our sample; our estimates imply that a similar supply-driven credit crunch would have induced between $12.5 \%$ and $30 \%$ of the average drop in firm TFP experienced by Italian firms during that period. The effect of credit on TFP growth lasts up to two years and does not revert afterwards, so that the impact on TFP is persistent over time and, therefore, it can contribute to explain the post-crisis low productivity dynamics. Moreover, we show that the relationship between credit supply and productivity is positive and concave: negative shocks have larger effects than positive ones. Consequently, the credit expansion of the recent years, due partly to the accommodative monetary policy stance, may only partially undo the consequences of the credit crunch. These empirical results highlight the fact that it is not only the quantity of credit that matters for productivity, but also its stability, as volatility of bank credit may be detrimental to firm productivity.

The effect of credit on productivity is found to be heterogeneous: large firms and firms with more lending relationships- that is, firms more easily able to substitute away from contracting lendersare largely unaffected by credit supply. Effects are stronger in sectors where bank credit is more important; that is, manufacturing and industries characterized by higher leverage.

We then enrich our dataset with information from administrative and survey-based sources to show that several productivity-enhancing activities, such as innovation, exporting, adoption of information technology (IT), and introduction of superior management practices, are stimulated by credit availability. These strategies increase productivity both in the short run (e.g., IT adoption) and in the long run (e.g., innovation). Therefore, their sensitivity to credit can explain the immediate effects of a credit supply shock on TFP and also suggests that there are additional effects over a longer horizon. We also show that firms exert more effort in creating new lending relationships when they are connected to banks which are contracting their credit supply; this finding is consistent with the "managerial inattention" hypothesis.

We contribute to the relevant literature on three dimensions. First, the database that we construct allows us to provide a complete picture of firm access to bank credit together with high-quality data on inputs acquisition and output for both large and small firms. Importantly, we are in a position to credibly study firm-level financial constraints without limiting our analysis to syndicated loans or public companies. Thanks to our data, we are also able to disentangle several channels for the estimated effect of credit on productivity. 
Second, we directly estimate credit supply from firm-bank matched data: unlike most previous studies of the link between finance and productivity, ours does not rely on self-reported measures of credit constraints, proxies for financial strength, or local and industry-specific shocks. ${ }^{5}$ We extend the previous literature on the impact of credit supply shocks on input accumulation by estimating their effect on firm ability to use these inputs to produce and sell output, by documenting its persistence, and by tracing its channels.

Third, we develop a methodology to estimate a production function in the presence of heterogeneous financial frictions affecting both TFP and inputs accumulation. Standard production function estimation methods, which rely on the assumption that firms operate at first-order conditions or, at least, face homogeneous frictions, would yield inconsistent results if idiosyncratic credit shocks have an effect on productivity. Our method does not, and thus it allows us to quantify the causal impact of credit supply on productivity. ${ }^{6}$

Our results imply that disrupting access to external funds depresses output above and beyond the observable contraction of investment. This contributes to the theoretical literature on the aggregate effects of financial frictions (Brunnermeier et al. ,2012) and to the empirical investigation of frictions and investment decisions (see Fazzari et al. (1988) and Rauh (2006)).

Our findings are also an important complement to the literature on the misallocation of production factors. This strand of research has been thriving in recent years; in particular, since the seminal paper by Hsieh \& Klenow (2009). ${ }^{7}$ It studies how frictions-financial ones in particular-affect overall productivity by shaping the allocation of capital and other inputs between firms for a given distribution of idiosyncratic productivity. We show that such financial frictions alter the location of productivity distribution. Therefore, any empirical investigation of the effect of a change in financial conditions on aggregate productivity ${ }^{8}$ should take into account jointly the impact on the allocative efficiency of inputs and the direct effect on firms' productive efficiency. Our results also imply that part of the vast heterogeneity in firms' productivity, which has been consistently found in several

\footnotetext{
${ }^{5}$ For instance, Krishnan et al. (2014) study the effect of State-level financial deregulation on small firms' TFP growth in the US.

${ }^{6}$ See De Loecker (2013) for a conceptually similar case regarding the effect of exporting on efficiency.

${ }^{7}$ A non-exhaustive list includes Bartelsman et al. (2013), Moll (2014), Asker et al. (2014), Midrigan \& Xu (2014), Chaney et al. (2015), Buera et al. (2011), Di Nola (2015), Gamberoni et al. (2016), Cette et al. (2016), Calligaris et al. (2016), Whited \& Zhao (2016), Borio et al. (2016), Besley et al. (2017), Hassan et al. (2017), Gopinath et al. (2017), Schivardi et al. (2017), Lenzu \& Manaresi (2018), and Linarello et al. (2018) . Review of Economic Dynamics had a special issue on "Misallocation and Productivity" in January 2013.

${ }^{8}$ For instance, Gopinath et al. (2017), Bai et al. (2018), and Neuhann \& Saidi (2017) analyze the consequences of changes in the financial system (respectively, the convergence of interest rates in the EU, the deregulation of US States banking, and the repeal of the Glass-Steagall Act) on the credit allocation and the consequent productivity impact; other papers (e.g. Whited \& Zhao (2016) or Catherine et al. (2018)) simulate the counterfactual aggregate productivity or investment gains from removing a financial friction using the estimates of a structural model.
} 
empirical works (Syverson, 2011), may be traced to unequal access to external funds.

A large literature is interested in the link between finance and firm productivity. For instance, see Schiantarelli \& Sembenelli (1997), Gatti \& Love (2008), Butler \& Cornaggia (2011), Ferrando \& Ruggieri (2015), Levine \& Warusawitharana (2014), and recent papers by Duval et al. (2017), Dörr et al. (2018), Cavalcanti \& Vaz (2017), and Mian et al. (2017). Huber (2018) and Franklin et al. (2015) are closer to our paper and examine the impact of the lending contraction of German and UK banks and present results on labor productivity. ${ }^{9}$ However, they provide evidence regarding the declining capital share and/or material inputs rather than declining TFP, which is our focus. Importantly, we estimate the impact of credit supply on firms' ability to produce output for a given level of investments and we study both "normal times" and the Great Recession. Other papers study the impact of credit on specific productivity-enhancing strategies, such as R\&D (Bond et al. (2005), Aghion et al. (2012), and Peters et al. (2017a)), innovation (Benfratello et al. (2008) and Caggese (2016)), intangible investments (Garcia-Macia (2015) and de Ridder (2016)), and exporting (Paravisini et al. (2014) and Buono \& Formai (2013)). Access to other sources of external funds, such as IPOs, can also affect productive investments (Bernstein, 2015).

The paper proceeds as follows. Section 2 presents the data sources, discusses sample selection, and provides descriptive statistics of the main variables. Section 3.1 describes the estimation of idiosyncratic credit supply shocks. Section 3.2 presents a partial-equilibrium model of firm production with heterogeneous credit constraints, which is used to recover firm-level productivity. Section 4 shows that credit supply affects firm input acquisition and output. Section 5 contains our main results and deals with their robustness, heterogeneity, and persistence. Section 6 presents additional evidence from the 2007-08 collapse of the interbank market. Section 7 investigates the mechanisms driving the effect of credit supply on productivity. Section 8 concludes.

\section{Data}

To perform our empirical analysis, we combine detailed balance-sheet data with loan-level data from the Italian Credit Register and survey-based information on productivity-enhancing activities.

\footnotetext{
${ }^{9}$ E.g., value added per worker - see column (3) in Table VI of Huber (2018).
} 


\subsection{Firm balance-sheets: The CADS dataset}

The Company Accounts Data System (CADS) is a proprietary database administered by CERVEDGroup Ltd. for credit risk evaluation. It has collected detailed balance-sheet and income statement information on non-financial corporations since 1982 and it is the largest sample of Italian firms for which data on actual investment flows are observed; net revenue of CADS firms account for about $70 \%$ of the total revenues of the private non-financial sector. Because this database is used by banks for credit decisions, the data are carefully controlled.

We estimate production functions for firms sampled in CADS from 1998 to 2013. Firm-level capital series are computed applying the perpetual-inventory method (PIM) on book-value of capital, investments, divestments, and sector-level deflators and depreciation rates. ${ }^{10}$ Operating value added and intermediate expenditures are recorded in nominal values in profit-and-loss statements; we convert them in real terms using sector-level deflators from National Accounts. The baseline measure of labor is the wage bill, deflated using the consumer price index (CPI). Expenditures on intermediate inputs are deflated using a combination of sector-level deflator and regional-level CPI. ${ }^{11}$ Throughout the paper, we use a Nace Rev.2 two-digit definition of industry. In addition, in a robustness exercise (section 5.1), we show that our main results are very similar if we use a finer four-digit definition.

From CADS, we also collect information on firm characteristics such as age, cash-flow, liquidity, assets, and leverage (total debt over assets). Their lagged values are used throughout the analysis in section 5 as firm-level time-varying controls.

\subsection{Firm-bank matched data: The Italian Credit Register}

The Italian Credit Register (CR), owned by the Bank of Italy, collects individual data on borrowers with total exposures (both debt and collateral) above $€ 30,000^{12}$ towards any intermediary operating in the country (including banks, other financial intermediaries providing credit, and special-purpose vehicles). ${ }^{13}$ The CR contains data on the outstanding bank debt of each borrower, categorized into loans backed by accounts receivable, term loans, and revolving credit lines. CR data can be matched

\footnotetext{
${ }^{10}$ See Lenzu \& Manaresi (2018) for details on PIM. We thank Francesca Lotti for providing capital series for an early version of this paper.

${ }^{11}$ Because some inputs might be bought on national rather than local markets, we assume that the price of intermediate inputs is the arithmetic mean of national price and national price deflated by local CPI.

${ }^{12}$ For instance, a borrowing firm with debt of $€ 20,000$ towards a bank appears in the CR if it also provides guarantees worth at least $€ 10,000$ to any another bank. The threshold was $€ 75,000$ before 2009 .

${ }^{13}$ Following previous literature (Amiti \& Weinstein, 2017), we include all financial intermediaries in the main analysis. We use the generic term "bank" for all of them. In a robustness exercise, available upon request, we show that our results are unchanged if we exclude firms which rely heavily on credit from non-bank intermediaries $(\approx 0.33 \%$ of total observations).
} 
to CADS using each firm's unique tax identifier.

For all the credit relationships of any Italian incorporated firm and any intermediary between 1998 and 2013, we measure net credit flows as the yearly growth rate (delta-log) of total outstanding debt. We do not differentiate between different kinds of credit (for instance credit line versus loan), because the choice of which type of credit to increase/decrease is ultimately the result of strategic bargaining between banks and firms. We also focus on credit granted rather than on credit used, as the latter is more strongly affected by credit demand.

\subsection{Additional data sources}

While the baseline estimate of the effect of credit supply on productivity exploits CADS and CR, further enquiries into the channels that drive this effect and several robustness checks of our analyses rely on additional data sources.

To test whether estimates of credit supply shocks are robust to assortative matching between firms and banks (see section 3.1), we control for past interest rates charged by banks to firms. This information is available from the TAXIA database, administered by the Bank of Italy, for a large sample of Italian banks (encompassing over $70 \%$ of all credit granted to the Italian economy). Interest rates are computed as the ratio of interest expenditures to the quantity of credit used.

For our study of the consequences of the 2007-2008 interbank market collapse as an exogenous change in credit supply (section 6), we obtain information on banks assets, ROA, liquidity, capital ratio, and their interbank liabilities and assets from the Supervisory reports.

In Section 7, we study the relevance of specific productivity-enhancing activities that are fostered by credit supply. These include IT-adoption, R\&D expenditures, patenting, and export. Such information is difficult to identify using balance-sheet data, because reporting by firms is generally non-compulsory. For this reason, we complement CADS with two sources of data. Data on ITadoption, R\&D, and export come from the INVIND Survey, administered by the Bank of Italy. INVIND is a panel of around 3,000 firms, representative of Italian firms with more than 20 employees and active in manufacturing and private services. For patent applications to the European Patent Office, we use the PatStat database. In particular, we exploit a release prepared by the Italian Association of Chambers of Commerce (UnionCamere), which matches all patent applications made during 2000-2013 with the tax identifiers of all Italian firms. We also obtain data on management practices for more than 100 manufacturing companies from the World Management Survey. 


\subsection{Sample selection and descriptive statistics}

Our main analysis is based on two samples. We use (a) a relationship-level dataset, in which an observation corresponds to a bank-firm-year triplet, to identify credit supply shocks and (b) a firm-level dataset, in which observations correspond to firm-year pairs and credit supply shocks are aggregated across banks, to estimate production functions.

The relationship-level dataset is based on the CR data. It consists of all relationships between incorporated firms and financial intermediaries during 1997-2013. The resulting dataset consists of $13,895,537$ observations and is composed of 852,196 unique firms and one 1,008 banks per year.

To estimate production functions, we consider all firms in CADS that report positive revenues, capital, labor cost, and intermediate expenditures, so that a revenue production function can be estimated. As a result, we exclude around one-fifth of the original CADS dataset: the final sample consists of 76,542 firms, corresponding to 656,960 firm-year observations. This dataset is used to estimate all the baseline regressions. Table 1 reports the main variables from the firm-level dataset for both the whole sample and for manufacturers.

To provide preliminary descriptive evidence that bank credit is a relevant source of finance for Italian firms, we study the credit intensity of firms' activity. We define the credit intensity of firm $i$ at time $t$ as the ratio of total credit granted at the end of year $t-1$ to the net revenue of year $t$. On average, manufacturers are granted 43 cents for each euro of revenues generated, while this figure is only 34 cents for non-manufacturers. Appendix figure A.1 shows that credit-intense companies are larger in non-manufacturing sectors, but not in manufacturing. Appendix figure A.2 shows that industries with a higher capital-to-labor ratio are more credit-intensive.

\section{Theoretical Framework}

We investigate the relation between credit supply and productivity. As a first step, we consider an empirical model to disentangle idiosyncratic shocks to credit supply from shocks to credit demand and shocks to the general economic context (section 3.1). We then build a model of production with heterogeneous credit constraints to recover firm TFP (section 3.2).

\subsection{Credit supply shocks}

We define a credit supply shock as any change in bank-specific factors affecting a bank's ability and willingness to provide credit to firms. Banks are heterogeneous in their exposure to different 
macroeconomic risks (Begenau et al. , 2015). This heterogeneity can arise because of differences in liabilities, assets or capital. ${ }^{14}$

Total credit granted to firm $i$ at the end of year $t$ equals the sum of credit granted by all existing intermediaries $b: C_{i, t}=\sum_{b} C_{i, b, t}$. We define firm $i$ and bank $b$ to have a pre-existing lending relation in period $t$ if and only if $C_{i, b, t-1}>0$. Credit granted $C_{i, b, t}$, is an equilibrium quantity which depends on both supply and demand factor, as well as on aggregate shocks. We collect all the observable and unobservable factors that determine the idiosyncratic supply of credit to corporations from bank $b$ in year $t$ into the vector $S_{b, t}$. For instance, bank-specific capital, cost of funds, and lending strategies may all be components of $S_{b, t}$. Similarly, let $D_{i, t}$ be the vector of observables and unobservables shaping firm $i$ 's demand for credit and its desirability as a borrower, such as productivity, size, and leverage. In addition, credit may be affected by firm-bank specific factors, such as the length of the pre-existing lending relationship or the quantity of credit previously provided by the bank to the firm (affecting the incentive to evergreen). We collect these match-specific covariates in the vector $X_{i, b, t}$. Finally, aggregate factors affecting all intermediaries and borrowers, such as aggregate demand or the monetary and fiscal stance, are collected in $J_{t}$.

Assumption 1: $\exists$ some smooth, unknown function $C(\cdot)$ such that:

$$
\frac{C_{i, b, t}}{C_{i, b, t-1}}=\frac{C\left(J_{t}, D_{i, t}, S_{b, t}, X_{i, b, t}\right)}{C\left(J_{t-1}, D_{i, t-1}, S_{b, t-1}, X_{i, b, t-1}\right)}
$$

While this assumption is very general, it nonetheless limits the substitution patterns amongst different lenders. Indeed, it rules out the impact of other banks' idiosyncratic shocks $S_{b^{\prime}, t}$ on credit granted by $b$ to $i$. In appendix A.1, we show that the exclusion of other banks' supply from equation (1) does not significantly affect our estimate of idiosyncratic credit supply shocks.

Log-linearizing equation (1) yields:

$$
\Delta c_{i, b, t}=j_{t}+\Delta d_{i, t}^{\prime} c_{1}+\Delta s_{b, t}^{\prime} c_{2}+\Delta x_{i, b, t}^{\prime} c_{3}+\operatorname{approx}_{i, b, t}
$$

We define the credit supply shock of bank $b$ in period $t$ to be $\Delta s_{b, t}^{\prime} c_{2}$. The idiosyncratic credit supply shock experienced by firm $i$ in period $t$ is a function of $\Delta s_{b, t}^{\prime} c_{2}$ for all the previously connected banks.

\footnotetext{
${ }^{14}$ For instance, Khwaja \& Mian (2008) show that the Pakistani banks that relied more on dollar deposits experienced stronger liquidity shocks after the unexpected nuclear tests in 1998. Chodorow-Reich (2013) uses US banks' connections to Lehman Brothers and exposure to mortgage-backed securities as an instrument for their financial health. In section 6, we exploit heterogeneity in reliance on the Interbank market as a source of exogenous variation during the credit crunch in Italy.
} 
Decomposition (2) can be written as:

$$
\Delta c_{i, b, t}=j_{t}+d_{i, t}+\phi_{b, t}+\epsilon_{i, b, t}
$$

where: $j_{t}$ is the mean growth rate of credit in the economy, $\phi_{b, t}$ is the change in credit granted explained by bank $b$ 's supply factors, $d_{i, t}$ is the change in credit granted explained by firm $i$ factors, and $\epsilon_{i, b, t}$ is the sum of a matching specific shock $\Delta x_{i, b, t}^{\prime} c_{t}^{3}$ and the approximation error approx $x_{i, b, t}$.

\section{Assumption 2: $\epsilon_{i, b, t} \perp \mathcal{D}_{i}, \mathcal{S}_{b}$}

where $\mathcal{D}$ and $\mathcal{S}$ are sets of dummy variables indicating the identities of the borrower and lender.

Furthermore, without loss of generality, we normalize $E\left[d_{i, t}\right]=E\left[\phi_{b, t}\right]=0$. We apply OLS to estimate equation (3). Under assumption 2, the bank $\times$ year fixed effects $\left(\phi_{b, t}\right)$ are unbiased estimates of $\Delta s_{b, t}$. We focus on corporations having multiple relations in order to estimate bank-idiosyncratic shocks by exploiting within-firm-and-time variability. This allows us to condition for time-varying observables and unobservables at the borrower level. ${ }^{15}$

Amiti \& Weinstein (2017) (AW hereafter) study the identification of model (3). They show that assumption 2 holds without loss of generality, as long as one is willing to conveniently "relabel" the firm and bank fixed effects. That is, one can write the idiosyncratic component $\Delta x_{i, b, t}$ as $\Delta x_{i, b, t}=$ $a_{i, t}+b_{b, t}+e_{i, b, t}$, where $a$ and $b$ are the linear projections of $\Delta x_{i, b, t}$ on dummies for bank and firm identity and $e_{i, b, t}$ is uncorrelated with these dummies by construction. Therefore, bank fixed effects in (3) correspond to $\phi_{b, t}^{A W}=\phi_{b, t}+c^{3} \cdot b_{b, t}$, which are the parameters of interest in AW's empirical analysis. In fact, AW show that the idiosyncratic match-specific terms do not affect the bank aggregate lending. In our study, however, we are interested in identifying the role of pure idiosyncratic supply-side factors, $\Delta s_{b, t}$, so that the orthogonality assumption (assumption 2) does not come without loss of generality. In particular, it limits the interaction between demand and supply shocks (which enter the approximation error) and restricts the correlation between match-level covariates and bank or firm factors.

We argue in appendix A.1 that this assumption is testable: we focus on two potential source of omitted variables in $\epsilon_{i, b, t}$ which may bias our estimate of supply-side shocks: substitution (or comple-

\footnotetext{
${ }^{15}$ Because we are using a delta-log approximation, the expected values are intended to be conditional on credit by bank $b$ to firm $i$ being positive in both $t$ and $t-1$. In a robustness exercise, available upon request, we compute the model by measuring growth rates as suggested by Davis et al. (1996) $\left(\Delta c_{i, b, t}=2 \cdot \frac{C_{i, b, t}-C_{i, b, t-1}}{C_{i, b, t}+C_{i, b, t-1}}\right)$, which we can compute as long as credit is positive in either $t$ or $t-1$ or both.
} 
mentarity) patterns (such as those discussed in assumption 1) and bank-firm relation characteristics. We show that our results on the impact of credit supply shocks on productivity are unaffected by the inclusion of these controls in the estimation of credit supply shocks. We therefore rely on the simpler specification in equation (3) for our main analysis.

In this paper, we study how borrowers' inputs acquisition and output production are affected by lenders' supply. Consequently, the cornerstone of the empirical strategy is a firm-level measure of credit supply shocks. To move from the bank-level measure of equation (3) to its firm-level counterpart, we rely on the intuition of the "lending channel" (Khwaja \& Mian, 2008): borrower-lender relationships are valuable because they help mitigate information asymmetry, limited commitment, or other problems which might generate credit rationing (Petersen \& Rajan, 1994). Consequently, they are sticky: changes in credit supplied by a bank have a disproportionally large effect on the firms with which it already has established credit relations. ${ }^{16}$ Obviously, a firm connected to a bank whose supply contracts can always apply to another bank for credit (see below). Yet, as long as credit from an unconnected bank is less likely or more costly, substitution between lenders will be imperfect. The empirical relevance of this phenomenon has been shown in several previous studies and we exploit it to identify firm-specific credit supply shocks.

As a simple benchmark, we assume that the strength of a firm-bank relationship is proportional to the amount of credit granted. Therefore, we measure the shock to credit supply faced by firm $i$ in period $t$ as

$$
\phi_{i, t}=\sum_{b} \phi_{b, t} \cdot \frac{C_{b, i, t-1}}{\sum_{b^{\prime}} C_{b^{\prime}, i, t-1}}
$$

A histogram of $\phi_{i, t}$ is provided in figure 2. Although the estimation of $\phi_{b, t}$ is performed considering only firms with multiple banking relations, the variable $\phi_{i, t}$ is defined for all firms which have some credit granted in year $t-1 .^{17}$

In appendix D, we show that this measure responds negatively to the freeze of the interbank

\footnotetext{
${ }^{16}$ Our analysis abstracts from any welfare consequences of relationship lending and focuses on one of its empirical implications.

${ }^{17}$ The credit supply shock is constructed similarly to a "Bartik" instrument. Rather than using it as an instrument for credit growth, however, we estimate the impact of $\phi_{b, t}$ directly in reduced form (as a broader measure of credit supply shocks). We refer to recent work by Goldsmith-Pinkham et al. (2018) (in particular, appendix A2) and Borusyak et al. (2018) for a discussion of pros and cons of the "Bartik" empirical approach. Some of the robustness exercises we present in section 5.1 (e.g. pre-trends analysis) are akin to those proposed by Goldsmith-Pinkham et al. (2018).
} 
market, which was the trigger of the credit crunch in Italy (see section 6 for details), suggesting that the additive growth rate model is able to capture credit supply factors. Furthermore, in appendix A.2, we study the relation between credit supply shocks and some determinants of bank lending and present results in line with economic intuition and previous literature. In particular, we show that banks entering the Great Recession with weaker balance-sheets decreased more sharply their credit supply (Jensen \& Johannesen, 2016), we document the crowding out effect of sovereign debt on corporate lending (Broner et al. , 2014), and we find that M\&A episodes are usually followed by a contraction of the credit supplied by the target (Buono \& Formai, 2013).

\subsection{Production with heterogeneous financial frictions}

We propose an empirical model to estimate firms' production functions and recover their idiosyncratic productivity. We augment the classical production function estimation framework with a control function (Ackerberg et al. , 2007) by adding two elements: a set of credit constraints and a modified law of motion for productivity dynamics. This section presents the main elements of the model; details can be found in appendix B. Uppercase letters denote variables in levels, while lowercase letters denote natural logarithms.

Firm $i$ operating in industry $s$, in year $t$, combines capital $\left(k_{i, t}\right)$, labor $\left(l_{i, t}\right)$, and intermediate inputs $\left(m_{i, t}\right)$-which are also referred to as "materials"-to generate sales, $\left(Y_{i, t}\right)$ according to an industry-specific production function $f(\cdot)$, known up to a set of parameters $\beta_{s}$. Each firm has an idiosyncratic Hicks-neutral productivity $\omega_{i, t}$ :

$$
Y_{i, t}=\exp \left\{\omega_{i, t}+f\left(l_{i, t}, k_{i, t}, m_{i, t}, \beta_{s}\right)\right\}
$$

As is common in the literature (Olley \& Pakes, 1996), we assume that productivity can be decomposed into a structural component $\left(\tilde{\omega}_{i, t}\right)$ and an i.i.d. error term $\left(\epsilon_{i, t}^{Y}\right)$, which is unknown to the firm when production decisions are made:

$$
\omega_{i, t}=\tilde{\omega}_{i, t}+\epsilon_{i, t}^{Y}
$$

Intermediate inputs are flexibly chosen every period in order to maximize variable profits (sales minus cost of labor and intermediate inputs). Then, if firm $i$ is unconstrained, the amount of materials $m^{u n c}$ will solve: 


$$
\frac{\partial \exp \left\{f\left(l_{i, t}, k_{i, t}, m^{u n c}, \beta\right)+\tilde{\omega}_{i, t}\right\}}{\partial m}=P_{p, t}^{M}
$$

where $P_{p, t}^{M}$ is the price of materials faced by firm $i$, which might depend on its location $p .^{18}$ In section 4 , we provide evidence that firms acquire less inputs when they receive negative credit supply shocks. Relying on the first-order condition in (5) would be misleading if firms face heterogeneous credit constraints. Therefore, we allow for the possibility that intermediate inputs (and other inputs) face financially generated constraints:

$$
m_{i, t} \leq m_{i, t}^{\max }=\log \frac{1}{P_{p, t}^{M}} K_{i, t-1} \cdot \Gamma\left(B_{i, t-1}, \phi_{i, t}, \tilde{\omega}_{i, t}\right)
$$

where $B_{i, t-1}$ is previous-period debt and $\Gamma$ is an unknown function. Similar constraints, usually applied only to capital accumulation, are standard in the literature on financial frictions, such as Moll (2014), Buera \& Moll (2015), and Gopinath et al. (2017), and they can be micro-founded by several market failures. We innovate by allowing them to depend on firm TFP and credit supply shocks. The results of the paper hold if we exclude credit rationing and, alternatively, if we assume that firms face heterogeneous costs of external funds. High-productivity firms might be considered more reliable borrowers and might therefore be allowed to borrow more, ceteris paribus. We thus assume that $\Gamma$ is strictly increasing in its third argument. The quantity of intermediate inputs acquired by firm $i$ is:

$$
m_{i, t}=\min \left\{m_{i, t}^{\max }, m_{i, t}^{u n c}\right\}:=m\left(x_{i, t}, \tilde{\omega}_{i, t}, \phi_{i, t}\right)
$$

where $m(\cdot)$ is unknown and $x_{i, t}$ is a vector containing firm-level inputs (capital, lagged capital, and labor), prices, and lagged debt. Under standard assumptions, the optimal value of materials is increasing in productivity $\tilde{\omega}_{i, t}$, equation 6 can therefore be "inverted" (Levinsohn \& Petrin, 2003).

\footnotetext{
${ }^{18}$ Gandhi et al. (2011) show that most of the estimation procedures based on the control function approach fail to identify the elasticity of output with respect to the flexible inputs (e.g., intermediate inputs). De Loecker \& Scott (2016) argue that a researcher can overcome this non-identification result under the assumption that firms face heterogeneous and autocorrelated input prices. The authors rely on firm-level wages to estimate their model. However, heterogeneity in wages might reflect heterogeneous worker quality or productivity. We, instead, allow local price shocks to affect real prices of input and recover all the production function parameters.
} 
That is, there exists an (unknown) function $h$ such that:

$$
\tilde{\omega}_{i, t}=h\left(x_{i, t}, m_{i, t}, \phi_{i, t}\right)
$$

Therefore, log sales can be written as:

$$
y_{i, t}=\Psi\left(x_{i, t}, m_{i, t}, \phi_{i, t}\right)+\epsilon_{i, t}^{Y}
$$

where $\Psi\left(x_{i, t}, m_{i, t}, \phi_{i, t}\right)=h\left(x_{i, t}, m_{i, t}, \phi_{i, t}\right)+f\left(l_{i, t}, k_{i, t}, m_{i, t}, \beta_{s}\right)$. Following the previous literature, we assume a law of motion for productivity:

$$
E_{t}\left[\omega_{i, t} \mid \mathcal{I}_{t-1}\right]=E_{t}\left[\omega_{i, t} \mid \omega_{i, t-1}, \phi_{i, t-1}\right]=g_{t}\left(\omega_{i, t-1}, \phi_{i, t-1}\right)
$$

where $\mathcal{I}_{t-1}$ is the firm information set at $t-1$ and $g_{t}(\cdot)$ is unknown. We innovate by allowing credit supply to affect productivity dynamics. It would not be correct to estimate the production function without including financial frictions in the productivity dynamics and regress the productivity residuals on financial variables. An analogous problem is highlighted in De Loecker (2013) discussion of the measurement of productivity gains from exporting. Let us also define the productivity innovation as $\zeta_{i, t}:=\tilde{\omega}_{i, t}-E\left[\tilde{\omega}_{i, t} \mid \mathcal{I}_{t-1}\right]$. Equation (7) implies moment conditions:

$$
E\left[\begin{array}{c}
E\left[\zeta_{i, t} \mid \mathcal{I}_{t-1}\right]=E\left[\zeta_{i, t} \mid z_{i, t-1}\right]= \\
\Psi_{i, t}-f\left(l_{i, t}, k_{i, t}, m_{i, t}, \beta\right)- \\
g_{t}\left(\Psi_{i, t-1}-f\left(l_{i, t-1}, k_{i, t-1}, m_{i, t-1}, \beta\right), \phi_{i, t-1}\right)
\end{array}\right]=0
$$

where $z_{i, t-1}$ contains lagged values of investments, labor, materials, and other variables. Estimation of the model is performed in two stages. In the first stage, we estimate the function $\Psi$ as $\Psi_{i, t}=E\left[y_{i, t} \mid x_{i, t}, m_{i, t}, \phi_{i, t}\right]$. In the second stage, we rely on (8) to estimate the structural parameter of interest $\beta_{s}$. Table A.1 presents some descriptive statistics. Finally, we can recover 
firm-level productivity as residuals from $\omega_{i, t}=y_{i, t}-f\left(k_{i, t}, l_{i, t}, m_{i, t}, \beta_{s}\right)$ or, in the value-added case, $\omega_{i, t}=v a_{i, t}-f\left(k_{i, t}, l_{i, t}, \beta_{s}\right)$.

As detailed in section 2, we observe balance-sheet and income statements but do not observe firm-level output prices. Therefore, this paper is about the ability of firms to transform inputs into sales and value added and not (only) about their technical efficiency. Our measure of productivity is referred to as "productivity" in several empirical studies, such as Olley \& Pakes (1996), and as $t f p r^{r r}$ (or "regression-residual total factor revenue productivity") in Foster et al. (2017). These studies find that this measure of productivity is predictive of firm survival and growth. Furthermore, it is proportional to the empirical estimate of (log) TFPQ (or "total factor quantity productivity") in Hsieh \& Klenow (2009), which is the relevant fundamental for aggregate welfare. See appendix C.1 for a more detailed discussion.

\section{Credit Supply Shocks and Firm Production}

Is a firm's production affected by the credit supply of its lenders? If credit frictions are not important, the amount of credit a firm receives should be unaffected by the supply shocks of its lenders. In a frictionless world, a firm's policy function might be affected by aggregate financial conditions but should not be shaped by the idiosyncratic shocks hitting any specific lender. Therefore, we estimate:

$$
\Delta x_{i, t}=\psi_{i}+\psi_{p, s, t}+\gamma \cdot \phi_{i, t}+\eta_{i, t}
$$

where $x_{i, t}$ is either the log of total credit granted to firm $i$, or a measure of output (log value added or net revenue) produced by firm $i$ during year $t$, or a measure of (log) input. The $\psi$ terms are firm and year $\times$ industry $\times$ province fixed effects. The former control for firm-specific unobserved heterogeneity which might affect both financial conditions and production. The latter capture local ${ }^{19}$ and sectoral demand and technology shocks, which might create spurious correlation between credit supply and firm dynamics. Results are presented in Table 2. Firms connected with banks contracting their supply of credit show lower growth of credit received, inputs acquired, and output produced than to other firms operating in the same market. The elasticity of credit granted with respect to the firm-level credit supply shock is approximately equal to 1 . This allows for simple interpretation of

\footnotetext{
${ }^{19} \mathrm{~A}$ province is a local administrative unit, approximately of the size of a US county. CADS reports the province in which each firm is headquartered.
} 
the magnitude of the main specifications of this paper: a one-percentage-point decrease in $\phi_{i, t}$ is the change of credit supply necessary to lower the average credit granted by one percent.

The impact of credit supply is stronger on value added than on capital accumulation. Net revenue responds almost as much as capital. Labor and intermediate inputs are found to be much less sensitive to credit supply shocks than output and capital are, from both the economic and the statistical point of view. Capital investments are likely to be fully paid up front, while expenditure for materials or labor can sometimes be delayed until some cash flow has been generated from the production. For instance, wages are usually paid at the end of the month. Therefore, it is not surprising that these inputs are less sensitive to changes in a firm's ability to access external finance.

To understand whether the effect on inputs is sufficiently large to rationalize the impact on output or, conversely, whether productivity is responding to credit shocks, we need to rely on the elasticities of output to inputs estimated in section 3.2.

We also investigate the effect of credit availability on firm efforts in creating new lending relationships. A borrowing firm is less likely to apply for credit with new lenders when it is already connected with banks expanding their credit supply. Columns (8) and (9) of Table 2 show that firms respond to a positive credit supply shock by decreasing their loan applications with previously unconnected lenders. This offers a further validation of the ability of the additive growth rate model (section 3.1) to disentangle demand and supply variation. In fact, if this model was severely misspecified, then the measure of credit supply shocks might be contaminated by demand-side factors and we would detect a positive correlation between these demand-side factors and loans applications.

\section{The Effect of Credit Supply on Firm Productivity Growth}

Does lenders' credit supply affect borrower firms' productivity growth? After identifying firm-level measures of credit supply shocks (section 3.1) and measuring TFP (section 3.2), we now tackle the main research question by estimating the model:

$$
\Delta \omega_{i, t}=\psi_{i}+\psi_{p, s, t}+\gamma \cdot \phi_{i, t}+\eta_{i, t}
$$

where: $\Delta \omega_{i, t}$ is the growth (delta $\log$ ) of the Hicks-neutral productivity for firm $i$ between years $t-1$ and $t$ and $\phi_{i, t}$ is the weighted average of credit supply shocks of $i$ 's previous-period lenders. The 
$\psi$ terms are firm and year $\times$ industry $\times$ province fixed effects. The latter capture local and sectoral demand and technology shocks, which might create spurious correlation between credit supply and firm dynamics. The former control for firm-specific unobserved heterogeneity which might affect both financial conditions and production, such as entrepreneur's wealth (Malacrino, 2016). Results are shown in Table 3. One observation is one firm per year in CADS for 1998-2013, subject to the selection criteria detailed in section 2.4. In each column, we consider productivity growth as obtained from a different production function estimation. The two columns on the left use value added as a measure of output, while productivity in columns 3 and 4 is based on net deflated revenues. Columns 1 and 3 are based on the Cobb-Douglas functional form, while 2 and 4 are based on Trans-Log production functions. The top panel presents results for the whole economy, while the bottom panel focuses on manufacturers. All specifications clearly show that a decrease in credit supply causes a decline of productivity growth. A credit supply shock of one percentage point induces an change in the growth rate of value-added productivity of approximately one-tenth of a percentage point for the whole economy and 0.13 points for manufacturing. ${ }^{20}$ The effect on the revenue-based measures of productivity is between 0.02 and 0.03 percentage points. The difference between the size of the effect of credit supply on value-added productivity growth and the size of its effect on revenue productivity growth can be partially explained by the fact that, in our sample, the standard deviation of the former is more than three times that of the latter.

The magnitude of the effects is economically large. ${ }^{21}$ For instance, the drop in the total growth rate of credit granted between 2007 and 2009 is around 12\% in our sample. Over the same period, (mean) value-added productivity growth declined by more than $8 \%$ and revenue productivity growth declined by $1 \%$. Therefore, if the drop in credit was fully driven by supply, it would explain between $12 \%$ and $30 \%$ of the productivity drop over the same period. These figures are likely to be conservative estimates; below we show that the productivity effects of credit shock are persistent and that credit supply is particularly valuable during financial turmoil.

These results have implications for the literature that measures the effects of financial frictions on the distribution of marginal returns of capital (MRPK) to study resources misallocation. Standard models assume that these frictions impact inputs allocation between producers without altering firm-level productivity. We find that productivity is also affected. Credit contractions have opposing

\footnotetext{
${ }^{20}$ As shown in Table 2, a $1 \%$ decrease in supply shock is the change in supply which causes credit granted to decrease by $1 \%$.

${ }^{21}$ When we weight observations by a lagged measure of size (unreported) we obtain coefficients in the same ballpark: although smaller firms suffer more from credit supply shocks (see below) the results are not entirely driven by the left tail of firms' size distribution.
} 
effects on MRPK: at one side they depress investments, raising MRPK, at the other they depress TFP, lowering MRPK. See appendix C.4 for details.

Appendix figure A.7 reports the bootstrapped distribution of the estimated effect of credit supply shock on productivity. The production functions are re-estimated for each bootstrap sample. All coefficients are above zero; therefore, the sampling error in estimating productivity dynamics does not distort statistical inferences based on Table 3 .

\subsection{Robustness}

This paper argues for a causal interpretation of the estimated relation between credit supply and firm productivity growth. We provide a broad set of robustness exercises to support this claim. Table 4 contains the relative results for the Cobb-Douglas revenue productivity case (see Tables A.8 and A.9 for value-added and translog TFP models). Column (1) reports the baseline estimate, as in Table 3. Column (2) adds a set of lagged controls: a polynomial in assets size and the ratios of value added, cash flow, liquidity, and bank debt to assets. The inclusion of such controls has negligible impact on the estimated coefficients.

Analogously to the "peer effect" literature (Bramoullé et al. , 2009), three main threats may hamper our identification strategy of credit supply shocks based on firm-bank connections: reverse causality, correlated unobservables, and assortative matching. That is, $\phi_{i, t}$ can be correlated with the error term in equation (10) because (a) connected agents are subject to correlated shocks, (b) lenders might decrease credit supply when expecting their borrowers to experience lower productivity growth, or (c) banks which are expanding their supply of credit are more likely to keep lending relations with firms that are increasing their performance (Bonaccorsi di Patti \& Kashyap, 2017). The productivity shocks received by sizable borrowers might be the very reason why their lenders contract the supply of credit. That is, if banks have information about the future profitability of some particularly significant borrowers, they might preemptively decrease the supply of credit to all borrowers. We define an "important" borrower as any firm which, at any point between 1997 and 2013, accounts for more than $1 \%$ of the credit granted by any of its lenders. We then estimate model (10) excluding such firms. Results are reported in column (3) of Table 4, which shows that the estimated effect of credit supply shocks on productivity growth is unaffected by the exclusion of the borrowers that are most likely to lead to reverse causality, thus mitigating this concern.

A further concern is that connected borrowers and lenders might be affected by correlated unobservable shocks. In particular, the output market of the borrower might overlap with the lender's 
collection or lending market. For instance, a drop in local house prices might contemporaneously lower consumption and also affect the value of collateral backing lenders' loans. Since we measure revenue-based productivity, any demand shock might affect markups and be picked up as a change in productivity. To investigate the relevance of correlated unobservables for our results, we compare specifications with two different fixed-effects structures. The first one (equation 10) includes industry $\times$ province $\times$ year fixed effects, which aim to control for demand and technology shocks. The second includes only industry, province, and year fixed effects; it therefore allows only for nationwide economic fluctuations. Results are reported in columns (1) and (5) of Table 4. The magnitude of the coefficient is remarkably stable across the two specifications, despite the fact that the inclusion of the finer grid of fixed effects doubles the $R^{2}$. This finding reveals that, if any unobservable is affecting both credit supply shocks and productivity, then it must be orthogonal with respect to location or industry. Since credit activity is indeed concentrated at the local (and/or industry) level, this is extremely unlikely to happen. A formal econometric treatment of this intuitive argument is provided by Altonji et al. (2005) and Oster (2016). In appendix C.2, we provide bounding sets for the coefficient of interest, following Oster (2016), and show that they do not contain zero. Therefore, our findings are "robust" to the presence of unobservable shocks and we can reasonably conclude that correlated unobservables are not driving our results. Furthermore, column (4) of Table 4 shows that firm fixed effects, while useful to control for firm-level unobservable characteristics, are not essential to our results.

Column (6) of Table 4 adopts an alternative measure of credit supply shocks, which controls for match-level characteristics, such as the interest rate charged and the type of credit instrument used (see appendix A.1 for more details). The estimated effect of credit supply on productivity growth is similar to that in the baseline specification of column (1), providing no evidence that assortative matching explains our results. Finally, section 6 exploits a natural experiment to confirm that credit supply affects productivity.

The bank-level credit supply shocks are computed using information on all borrowers. Therefore, if firm $i$ has a lending relation with bank $b$, then its credit supply is estimated from a linear regression including observations relative to the amount of credit granted by $b$ to $i$ (see section 3.1). This could generate problems in small samples. Therefore, we estimate an alternative set of bank-level credit supply shocks using a "cross-validation" procedure. ${ }^{22}$ Column (7) presents estimates of the baseline

\footnotetext{
${ }^{22}$ That is, we divide all firms into subsamples A and B. For each bank, we estimate two credit supply shocks, $\phi_{b, t}^{A}$ and $\phi_{b, t}^{B}$, using data about credit given to firms belonging to only one subsample at time. Then, we compute firm-level idiosyncratic shocks as the weighted average of the bank-level credit supply shocks estimated with data on firms of the other subsample. For instance, if firm $i$ belongs to subsample A, we estimate its credit supply shocks as
} 
specification using the "split sample" credit supply shock as an instrument. The similarity between estimates in columns (1) and (7) confirms that, since we rely on the universe of credit relations, this (potential) finite-sample bias is not a concern.

As an additional robustness test, we ask whether the distribution of firm observables predict future credit supply shocks. We define the innovation to the credit supply as:

$$
\zeta_{i, t}^{\phi}:=\phi_{i, t}-E\left[\phi_{i, t} \mid \phi_{t-1}\right]
$$

We estimate an empirical counterpart of $\zeta_{i, t}^{\phi}$ by OLS. We then divide the distribution of these shocks into quartiles and compare the averages of previous year firm observable characteristics, analogously to Chodorow-Reich (2013). Following Imbens \& Wooldridge (2009) we evaluate the "normalized differences" between groups, as reported in the top panel of Table A.2. We find these statistics are all well below the suggested rule-of-thumb threshold of 0.25 , raising no concern and supporting the causal interpretation of our results.

Estimation of production function parameters is a difficult exercise involving several (strong) assumptions, such as the absence of measurement error on inputs and a Markovian structure for the productivity dynamics. We perform several exercises to show that the specific modeling choices of section 3.2 do not affect the estimated effect of credit supply on productivity growth either qualitatively or in terms of its magnitude. First, we re-estimate both the production function and equation (10), using a finer four-digit industry classification (the baseline uses two-digit classification). Results are reported in column (8) of Table 4, which mitigates the concern that heterogeneity in the shape of the production function is a main driver of the baseline specification. Second, we re-estimate the production function by controlling for endogenous exit as in Olley \& Pakes (1996). Column (9) of Table 4 shows that the magnitude of the relation between credit supply shocks and productivity is unchanged. Furthermore, we compare our results to traditional estimation techniques. Column (10) of Table 4 reports results from the production function estimated with the cost-share procedure (Foster et al. , 2017). Results are in the ballpark of the baseline estimation.

An alternative approach is to refrain from estimating the production function and, instead, study how the estimated effect of credit supply shocks on productivity varies as a function of the unknown parameters of the production function. The simplest production function is a Cobb-Douglas in value

$\overline{\phi_{i, t}}=\sum_{b} w_{i, b, t-1} \cdot \phi_{b, t}^{B}$ where $w_{i, b, t-1}$ is the share of credit to firm $i$ granted by bank $b$ in the previous period. 
added:

$$
v a_{i, t}=\omega_{i, t}+\rho \cdot\left(\beta_{k} \cdot k_{i, t}+\left(1-\beta_{k}\right) \cdot l_{i, t}\right)
$$

where $\rho$ disciplines the returns to scale and $\beta_{k}$ is the (relative) elasticity of value added to capital. Then, given a pair $\left(\tilde{\rho}, \tilde{\beta}_{k}\right)$, we can recover productivity as

$$
\omega_{i, t}\left(\tilde{\rho}, \tilde{\beta}_{k}\right)=v a_{i, t}-\tilde{\rho} \cdot\left(\tilde{\beta}_{k} \cdot k_{i, t}+\left(1-\tilde{\beta}_{k}\right) \cdot l_{i, t}\right)
$$

and estimate $\gamma\left(\tilde{\rho}, \tilde{\beta}_{k}\right)$ as the coefficient of

$$
\Delta \omega_{i, t}\left(\tilde{\rho}, \tilde{\beta}_{k}\right)=\psi_{i}+\psi_{p, s, t}+\gamma\left(\tilde{\rho}, \tilde{\beta}_{k}\right) \cdot \phi_{i, t}+\eta_{i, t}
$$

We let $\rho$ vary from 0.3 to 2 and $\beta_{k}$ from 0.01 to 0.9 , so that our grid encompasses any plausible values of the return to scale and the elasticity of value added to capital. Results are presented in graphical form in figure 4, showing that we find a positive (and statistically significant) effect of credit supply shocks on value-added productivity growth for any point on the grid. Moreover, while higher values of the parameters tend to decrease the point estimates, $\gamma\left(\tilde{\rho}, \tilde{\beta}_{k}\right)$ stays between 0.07 and 0.1 within the whole support.

The collection of evidence reported in this section clarifies that any misspecification of the production function estimation, although it might bias the point-estimate of the effect of credit supply on productivity, is unlikely to change its magnitude significantly.

Concerns related to measurement error, adjustment costs (e.g. employment protection legislation), and factor hoarding (e.g. variable capital utilization) are discussed in appendix C.3.

\subsection{Heterogeneity}

Are all firms equally affected by credit supply shocks? To study the heterogeneous importance of credit availability for productivity growth, we estimate the equation: 


$$
\Delta \omega_{i, t}=\psi_{i}+\psi_{s, t, p}+\psi_{d} \cdot D_{i, t-1}+\gamma \cdot \phi_{i, t}+\gamma_{h e t} \cdot \phi_{i, t} \cdot D_{i, t-1}+\eta_{i, t}
$$

where the $D_{i, t-1}$ is a dummy variable taking value equal to one if and only if firm $i$ in year $t-1$ belongs to a certain part of the distribution according to some observable characteristics, and zero otherwise.

A firm's size might be a good predictor of its ability to find alternative sources of credit in case current lenders dry up and larger firms are less likely to be credit-constrained in the first place. For each year, we compute an indicator for whether or not a firm is in the top quartile of the (year-specific) size distribution in terms of asset value and estimate equation (13).

Results are reported in columns (1) of Table 5, which refer to Cobb-Douglas revenue productivity. The parameter $\gamma_{h e t}$ is estimated to be negative, indicating that large firms are less affected by credit supply shocks although the difference between the two groups is economically and statistically significant in manufacturing only.

Is the effect of credit supply on productivity driven by small or large banks? To answer to this question, we compute, for each borrower firm, the average size of its lenders, according to the formula LenderSize $e_{i, t-1}=\sum_{b} A_{s s e t} s_{b, t-1} \cdot \frac{C_{b, i, t-1}}{\sum_{b^{\prime}} C_{b^{\prime}, i, t-1}}$, where Assets $_{b, t-1}$ is the total asset size of bank $b$ and $C_{b, i, t-1}$ is the credit granted by $b$ to firm $i$. We re-estimate equation (13), dividing firms according to whether they belong to the bottom quartile quartile of the (year-specific) distribution of LenderSize $e_{i, t-1}$. Results are reported in columns (2) of Table 5. We find that the effect of credit supply shocks is twice as large for borrowers connected to smaller banks than for other firms. However, the impact of credit supply is statistically larger than zero for the rest of the sample as well.

Establishing a large number of lending relationships might help firms find alternative sources of finance in case of negative credit supply shocks. Therefore, we estimate the model by allowing the coefficient to be different for firms in the bottom quartile for number of lenders during the previous period. ${ }^{23}$ Results in column (3) document that the TFP growth of borrowers with fewer lenders is much more affected by credit supply shocks.

An potentially important dimension of firm heterogeneity is its reliance on external funds. We

\footnotetext{
${ }^{23} \mathrm{~A}$ few seminar participants suggested differentiating the effect of credit shocks between firms with one and with multiple lending relationships. Unfortunately, less than $5 \%$ of the observations in our baseline sample have only one lender, so the relative coefficient would not be reliably estimated.
} 
classify industries as above and below the median according to the mean leverage (debt over assets) in the sample. Column (4) of Table 5 shows that the effect of credit supply shocks on revenue productivity is stronger in sectors with high leverage.

Young firms might be more dependent from external financing. We define a firm as "young" if it belongs to the bottom quartile of the (year-specific) age distribution. On average, a young firm is 6.3 years old. Results of the relative heterogeneity specification are presented in column (4): we estimate a stronger effect for young firms (approximately $50 \%$ larger), but the difference between the two age-groups is not statistically different from zero.

We aim to understand whether the effect of credit availability on productivity growth might be driven by the impact on innovative activities. We divide 2-digit industries in high and low "patent frequency" according to the share of firm-year observations for which we observe at least one patent application. The two industries with highest likelihood of patent applications are R\&D services and pharmaceutical manufacturing. In column (6) of Table 5, we show that the productivity of firms in industries with above-the-median frequency of patent applications seem to be more sensitive to credit supply shocks. However, we cannot reject any null of zero effect when we focus on manufacturing. A more direct exploration of the effect of credit supply on productivity-enhancing activities is developed in section 7 .

To extend the literature which focuses on the effects of credit tightening during the Great Recession and other financial crises, we investigate whether idiosyncratic credit supply shocks affect real outcomes also during good times. We allow the coefficient of equation (13) to be different for years 2008 and 2009 (the Great Recession). Results are presenting in column (7). The estimated effect of credit supply shocks is about 16\% larger during the Great Recession (60\% in manufacturing). Yet, the productivity impact of credit supply is present even outside the financial crisis. $^{24}$

\subsection{Persistence}

The effect of credit supply on productivity is persistent. To test for such persistence, we estimate the model:

\footnotetext{
${ }^{24}$ Alternatively, we re-estimate the main equation (10) excluding years from 2008 or 2007 on (therefore excluding the sovereign debt crisis): we still find significant effects of credit shocks on productivity growth (results unreported).
} 


$$
\omega_{i, t}=\psi_{i}+\psi_{p, s, t}+\sum_{\tau=-T}^{T} \gamma_{\tau} \cdot \zeta_{i, t}^{\phi}+\eta_{i, t}
$$

where $\zeta_{i, t}^{\phi}$ an unexpected credit supply shock, as defined in equation (11). We set $T=3$, since our empirical strategy is not fit to estimate the regression at a longer horizon. ${ }^{25}$ Figure 3 graphically displays the coefficients, $\gamma_{\tau}$, for firms active in manufacturing (bottom panel) and all industries (top panel). They document that the peak in productivity is experienced one year after the shock and that the effect remains positive and significant for at least four years. This finding underlines that a temporary credit contraction can have persistent effects on productivity. It also rules out the potential concern that the effect we measure on revenue productivity is short-lived and due to factor hoarding caused by adjustment costs of labor and capital. Furthermore, we do not find any statistically significant (at 1\% confidence level) pre-trend.

\subsection{The asymmetric effect of credit supply shocks}

The main goal of this paper is to measure and explain the productivity effects of changes in the quantity of credit supplied, focusing on its first moment: is less credit bad or good? This section, instead, investigates the shape of the relation between productivity and credit supply shocks, in order to understand whether higher moments of the distribution of credit supply shocks might have an impact on average firm productivity.

We divide the credit supply shock $\phi_{i, t}$ into quintiles $q=1,2,3,4,5$ and estimate:

$$
\Delta \omega_{i, t}=\psi_{i}+\psi_{p, s, t}+\sum_{q=1, q \neq 3}^{5} \gamma^{q} \cdot \mathbf{1}\left(\phi_{i, t} \in q\right)+\eta_{i, t}
$$

where $\mathbf{1}\left(\phi_{i, t} \in q\right)$ is an indicator function taking value 1 iff the credit supply shock of firm $i$ in year $t$ belongs to the $q$ th quintile of its distribution; the third (or median) quintile $q=3$ is the omitted category with $\gamma^{3}=0$. Results are shown in graphical form in figure 5 . The relation between credit supply and revenue productivity is concave. That is, firms connected with banks with a relatively

\footnotetext{
25 The within-firm estimator, while allowing us to control for firm unobserved heterogeneity, creates a mechanical negative correlation between observation means at different lags. In fact, regression of firm productivity on past productivity yields a coefficient between .9 and .98 if no fixed effects are included and between .3 and .4 if the standard set of fixed effects is included. Therefore, a shock to productivity of magnitude $1 \cdot m$, is expected to show up as a change in productivity of only $0.03 \cdot m$ to $0.06 \cdot m$ after 3 years.
} 
low supply of credit experience lower revenue productivity growth than their competitors; firms connected to banks with a particularly strong increase in credit do not grow at a particularly high rate. It is important not to be connected with banks experiencing bad credit supply shocks, but it is not useful to be connected with banks increasing their supply of credit particularly quickly.

To strengthen this intuition, we re-estimate equation (14), which is used to study the persistence of credit supply shocks, by differentiating between positive and negative shocks. Figure 6 presents the results in graphical form. The coefficients relative to negative credit supply shocks are shown with negative values. The effect of credit supply shocks on productivity is driven by firms connected with banks experiencing relatively negative credit supply dynamics. Additionally, we argue in section 6 that credit supply shocks are particularly important when credit dries up.

These empirical findings imply that an increase in credit supply cannot undo the harm of a negative shock of the same size. Therefore, it is not only the quantity of credit that matters, but also the stability of its provision. This analogously suggests that a credit crunch followed (or preceded) by a credit expansion of the same magnitude leads to a net loss in average firm productivity. We conclude that the volatility of the banking sector's supply is detrimental to firm productivity.

\section{The Interbank Market Collapse as a Natural Experiment}

The credit supply shock derived in section 3.1 has the value of being general, in that it can be attributed to all firms (both multiple- and single-borrowers) and measured in any year for which there is bank-firm data on credit granted. This feature is exploited in section 7 and, for production function estimation, in section 3.2. However, its construction relies on the assumption that shocks to credit demand and bank supply have, approximately, additive effects on the quantity of credit granted. Moreover, bank lending ability is affected by several factors (see appendix A.2 for empirical evidence about some of these factors) and different shocks to credit supply may have different effects on firm productivity.

It is particularly important to study the effects of severe financial crises on the productivity growth of non-financial sectors. In this section, we therefore focus on the financial shock which triggered the credit crunch at the onset of the Great Recession. We use the 2007-2008 market collapse of the interbank market as a specific "natural experiment" in which credit supply contracted abruptly because of shocks to banks funding sources, arguably exogenous with respect to borrowers' observed and unobserved characteristics. In addition, such variation came unexpectedly both to lenders and 
to borrowers, thus overcoming the problem of assortative matching.

The interbank market is a critical source of funding for banks: it allows them to readily fill liquidity needs of different maturities through secured and unsecured contracts. Total gross interbank funding accounted for over $13 \%$ of total assets of Italian banks at the end of 2006. Market transactions began shrinking in July 2007, when fears about the spread of toxic assets in banks' balance sheets made the evaluation of counterparty risk extremely difficult (Brunnermeier, 2009); the situation worsened further after Lehman's default in September 2008. As a consequence, total transactions among banks fell significantly. In Italy, in particular, they plummeted from $€ 24 \mathrm{bn}$. in 2006 to $€ 4$.8bn. at the end of 2009. At the same time, the cost of raising funds in the interbank market rose sharply: the Euribor-Eurepo spread, which was practically zero until August 2007, reached over 50 basis points for all maturities in the subsequent year. It then increased by five times after the Lehman crisis and remained well above 20 basis points in the following years. Recent papers have exploited the collapse of the interbank market as a source of exogenous shock to credit supply in Spain (Iyer et al. , 2013) and Italy (Cingano et al. , 2016). They show that bank pre-crisis exposure to the interbank shock, as measured by the ratio of interbank liabilities to assets, was a significant predictor of a drop in credit granted and investments during the crisis.

We focus on the period 2007-2009, when credit dried up the most (while 2010 was a year of recovery). Subsequently, ECB interventions partially offset the impact of the interbank market shock. Our measure of firm exposure to the credit supply tightening is the interbank exposure of each Italian bank at the end of 2006, averaged at the firm level using firms' specific credit shares in 2006 as weights. Because firm exposure is time-invariant, we use cross-sectional variation. We include observations over a three-year window. Formally, for each firm $i$ active in industry $s$ and province $p$ over the years $t \in[2007,2009]$, we estimate the equation:

$$
\Delta \omega_{i, t}=\psi_{p, s, t}+\gamma \cdot I N T B K_{i, 2006}+\eta_{i, t}
$$

where $\omega_{i, t}$ is firm idiosyncratic productivity, $I N T B K_{i, 2006}$ is the pre-crisis reliance on the interbank market (winsorized at top 1\%), and $\psi$ is a set of province $\times$ industry $\times$ year fixed effects. Results are shown in Table 6. Firms whose lenders were more reliant on the interbank market in 2006 had significantly lower revenue and value-added productivity growth during the credit crunch. This strengthens the causal interpretation of the relations between credit supply and productivity growth documented in section 5. A $1 \%$ increase in average bank dependence on the interbank market results in an ap- 
proximately $.05 \%$ decrease in average value-added productivity growth and an approximately $.02 \%$ decrease in revenue productivity growth. Consequently, the same interbank shock which decreases credit growth by $1 \%$ also decreases value-added productivity growth of $0.25 \%$ and revenue productivity growth by one-tenth of a percent for the whole sample. These effects are between two and five times larger than the baseline estimate from Table 3, suggesting that accessing a reliable source of credit supply is particularly important during financial turmoil.

We perform several robustness exercises supporting the claim that the collapse of the interbank market provides a clean "natural experiment". These results are presented in appendix D and they all suggest that banks' exposure was not correlated with their borrowers' pre-crisis characteristics. For instance, we show that firms hit harder by the collapse of the interbank market were not more sensitive to business cycle before the 2007-08 crisis and they had similar productivity growth rates. We also perform a placebo test by estimating the impact of a fake interbank collapse during the early 2000s recession, finding no effect.

\section{Beyond Measurement: Channels}

How does credit supply impact productivity? In this section, we investigate the relationship between the credit supply shocks and several productivity-enhancing activities. As described in section 2, INVIND provides information about R\&D investment, export, IT-adoption, and self-reported "obstacles to innovation" for a sample of Italian companies in services and manufacturing. Because both questions and respondents vary between waves, each specification of this section relies on a different sample.

In section 5.3, we show that credit contractions affect productivity immediately. We detect lower productivity growth for at least two years and lower productivity for at least four years. Unfortunately, our empirical framework is not fit to investigate the effect at a longer horizon. Some of the productivity-enhancing strategies studied in this section, such as IT-adoption or better management practices, may affect productivity as soon as they are implemented. Others, such as innovation, are likely to take a few years to produce substantial improvement. Therefore, this section does not only explore the potential mechanisms behind the effect we measure in section 5 , but also suggests that a credit crunch might lead to additional productivity losses in the long run. 


\subsection{IT-intensity of capital}

The speed of adoption of IT technologies caused large differences in productivity between US and European companies (Bloom et al. , 2012). According to Pellegrino \& Zingales (2014), failure to take full advantage of the IT revolution is one of the main drivers of Italy's low productivity growth. Data on personal computers used is available from INVIND for 1999-2001. Purchases of PCs are accounted as investments. Therefore, they enter the computation of capital stock. Slacker credit constraints might allow firms to stay closer to the technological frontier. By making more technological investments, unconstrained firms might have a "better" capital stock. Since researchers do not have detailed information on "quality" or "closeness to the frontier" of inputs, this quality is picked up by the productivity residual. To test this hypothesis, we measure the "IT-intensity" of firm capital stock as (log) number of PCs per 1,000 euros of capital.

$$
I T_{i, t}=\psi_{i}+\psi_{s, p, t}+\gamma \cdot \phi_{i, t}+\eta_{i, t}
$$

Results are presented in column (1) of Table 7. Firms are more likely to increase the IT-intensity of their capital stock when they receive a positive credit supply shock. This finding suggests that financial frictions lower the quality of capital inputs used in production.

\subsection{Innovation and exporting}

Does credit availability impact innovation? Patenting activities have been extensively used as a proxy for firm-level knowledge creation (see Bernstein (2015) and Kogan et al. (2017) for recent examples). We obtain information for patent applications for a large fraction of Italian companies from PatStat, as described in section 2. In our sample, patent applications became much less common during (and after) the credit crunch. The share of firms applying for at least one patent was approximately $2 \%$ between 2002 and 2007. It declined to $1.5 \%$ in 2009 and went up to a bit more than $1.6 \%$ in the following two years. We observe approximately 5 patent applications per 100 firms per year before the Great Recession, but only around 3.4 in 2009. This pattern, of course, could be driven by lower demand and/or greater uncertainty. To investigate whether availability of credit has a causal impact on patent applications, we estimate the models: 


$$
\begin{aligned}
\text { PatentApp } p_{i, t+1} & =\psi_{i}+\psi_{p, s, t}+\gamma \cdot \phi_{i, t}+\eta_{i, t} \\
\text { GrowthPatentApp }_{i, t+1} & =\psi_{i}+\psi_{p, s, t}+\gamma \cdot \phi_{i, t}+\eta_{i, t}
\end{aligned}
$$

Following the literature on $\mathrm{R} \& \mathrm{D}$ and patents, we impose a lag between the credit shock and patent applications. The growth rate of patent applications is defined as GrowthPatentApp $p_{i, t+1}=$

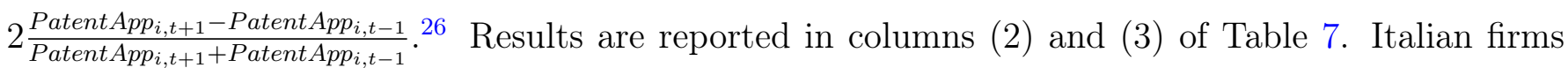
patent more when they have easier access to bank credit.

We then focus directly on the financial crisis and ask whether firms connected to lenders more exposed to the collapse of the interbank market (see section 6) contracted more their patent applications. Thus, we estimate the linear model:

$$
\text { PatentGrowt }_{i}=\psi_{p}+\psi_{s}+\gamma I N T B K_{i, 2006}+\eta_{i}
$$

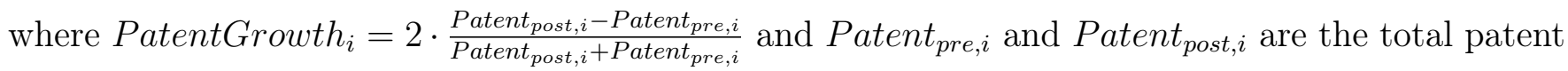
applications by firm $i$ before and during/after the credit crunch. The interbank market started collapsing in the late 2007, although general economic activity declined only afterwards. We thus use 2007 as the start of the "post" period and 2006 as the end of the "pre" period. We use 2010 (a short period of recovery) as the end of the "post" period and 2001 as start of the "pre" period, however results are unchanged if we modify these boundaries by excluding years 2010 and/or 2001 .

Results are reported in column (4) of Table 7. We find a negative impact of interbank exposure on patents. The effect is sizable: the average interbank exposure in the patenting sub-sample is $13 \%$, therefore a back-of-the envelope calculation would imply a decline of patent applications of approximately $22 \%$, which is more than half of the average contraction we observe in the data.

R\&D can increase firm productivity by improving both product quality and process efficiency. Similarly, export can have beneficial effects through two channels: it allows firms to access markets with higher margins and it can improve firm know-how through so called "learning-by-exporting." The sensitivity of international trade to financial frictions has been studied by several authors (Manova,

\footnotetext{
${ }^{26}$ In most of the analyses in the paper, we measures growth rates of credit, inputs, output, and TFP using a delta-log approximation. However, patent applications are rare, so we rely on the well-known formula by Davis et al. (1996), which can be calculated if patent applications are positive either in year $t+1$ or $t-1$ (or both).
} 
2012). We use the INVIND survey to identify firms that export and that have positive R\&D expenditures. Following previous literature (e.g. Peters et al. (2017b)), we focus on the extensive margin and estimate the linear probability model:

$$
D_{i, t}=\psi_{i}+\psi_{p, s, t}+\gamma \cdot \phi_{i, t}+\eta_{i, t}
$$

where $D_{i, t}$ is a dummy variable indicating whether firm $i$ engages in R\&D or exporting in year $t$. We find that firms are more likely to start (and/or less likely to stop) conducting R\&D (Table 7, column (5)) and exporting (Table 7, column (6)) when they have easier access to external finance. However, we cannot reject the null of no effect of credit shocks on R\&D.

Innovative effort is much broader than just formal R\&D or IT-adoption. The 2011 survey wave investigates the main constraints to innovative effort. One question asks how important, on a fouritem scale, the firm's difficulties in collecting external funds were in limiting innovation (in 2010). We define the variable FinCon $_{i, 2010}$, equal to 1 if and only if difficulty in getting external funds is reported to be "somehow important" or "very important" as an obstacle to innovation. Then, we estimate the linear probability model:

$$
\operatorname{FinCon}_{i, 2010}=\psi_{s, p}+\gamma \cdot \phi_{i, 2010}+\eta_{i}
$$

Results are presented in column (7) of Table 7, which documents that firms receiving positive credit supply shocks are less likely to consider external funds as a substantial obstacle to innovation. Since the question was asked for only one year of the survey, we cannot use panel variation. Nonetheless, this exercise is an indirect — yet insightful - test of the hypothesis that financial frictions dampen firms' innovative efforts.

\subsection{Management practices}

Management matters for firm performance, as shown by Bloom et al. (2013) for India and by Giorcelli (2016) for Italy. We use credit supply shocks to investigate whether firms improve their management when facing slacker financial constraints. The direction of the relation is not obvious. Scarcity of resources might push firms to improve their internal organization. Conversely, improvement in management practices might require stable financial resources; for instance, to hire professional 
consulting services or to restructure a production facility. Bhattacharya et al. (2013) propose a model in which frictions distort optimal investment in managerial skills.

We obtain firm-level data on management practices from the World Management Survey (WMS - http://worldmanagementsurvey.org/). As can be read from the website, WMS "developed an indepth survey methodology and constructed a robust measure of management practices in order to investigate and explain differences in management practices across firms and countries in different sectors." Information on data construction can be found in Bloom \& Van Reenen (2007). They state that the "practice evaluation tool defines and scores from one (worst practice) to five (best practice) across eighteen key management practices used by industrial firm." Merging WMS data on Italian companies by name, we obtain a sample of 183 observations. Because we have only one or two survey waves for each firm, we estimate the cross-sectional model:

$$
M S_{i, t}=\psi+\gamma \cdot \phi_{i, t}+\eta_{i, t}
$$

where $M S_{i, t}$ is the overall management score for firm $i$ surveyed in year $t$. Results are presented in column (8) of Table 7 and they indicate that an increase in credit supply stimulates the adoption of superior management practices. While the small sample size might cast doubt on the robustness of this result, the relation between credit supply shock and management is largely unaffected by the inclusion of a large set of firm-level controls.

\subsection{Managerial inattention}

Dealing with investors and creditors takes a substantial share of executive time. Bandiera et al. (2011) study the use of time by 94 CEOs of top-600 Italian companies. They document that finance is the topic on which the CEO spends the most time talking with others in the firm. Furthermore, of the outsiders with whom CEOs spend the most time, investors and bankers are, respectively, third and fifth. If this is true for Italian top-600 companies, which are all likely to have a professional $\mathrm{CFO}$ and other finance-related personnel, the time and effort required to establish and maintain relations with lenders might be even more demanding for the managers and entrepreneurs of smaller private companies which make up the bulk of our sample. Since their time is limited, if managerial delegation is difficult (Akcigit et al. , 2016), then the more difficult (or time-consuming) it is to find external funds, the less they can work on improving their core business. Entrepreneurs connected to 
lenders who contract their credit supply might need to spend more time and energy to establish new lending relations. Therefore, they might exert less effort in improving their firm's productivity.

As a colorful piece of anecdotal evidence to support this theory, the aunt of one of the authors was managing the family business during the credit crunch. When asked about the firm's performance, she used to reply, "I barely have time to go to the factory, I spend most of my mornings at banks trying to get some money." Results on firms' effort to search for new lenders, reported in columns (8) and (9) of Table 2, are consistent with this mechanism: firms receiving positive credit supply shocks are less likely to try to establish new lending relationships. The "managerial inattention" hypothesis may explain why the impact of credit supply on productivity growth is partly immediate (within a year). A more direct and complete investigation of this hypothesis is left to future research.

\section{Conclusion}

To grow and thrive, firms need reliable access to external funding. This paper carefully documents that bank credit is an important determinant of improvement to a firm's performance, both in the short run and the long run.

To study the impact of banks' credit supply on Italian firms, we exploit data on the universe of bank-firm credit relationships over the period 1997-2013. We estimate an additive growth rate model to separate credit demand from credit supply shocks. Then, we use the estimated bank-level supply shocks, together with the stickiness of lending relationships, to build a measure of firm-specific shocks to credit supply. We document that firms connected to banks which are contracting their supply of credit acquire less inputs and produce less output than their competitors. We find that the effect on output is stronger than the effect on inputs, suggesting that productivity is affected by credit availability.

We build a model of production with heterogeneous credit constraints in order to estimate an industry-specific production function and isolate firm idiosyncratic productivity dynamics. We show that credit supply boosts productivity growth and that these effects are sizable, persistent, and robust. They are stronger for smaller firms and for industries relying heavily on bank credit.

We show that a negative credit supply shock produces much stronger effects than a positive one of the same magnitude. Therefore, it is not only the quantity of credit supply that matters, but also its stability.

Our results imply that financial turmoil can have a persistent effect on aggregate output because 
it depresses firms' TFP in the short and long run. They also imply that financial frictions are harmful beyond their detrimental effects on allocative efficiency.

Finally, we find that several productivity-enhancing activities, such as adoption of IT, sound management practices, export orientation, and innovation, are stimulated by credit availability. We also conjecture that a reduction of credit supply might force borrowers (notably, managers and entrepreneurs) to consume time and energy in order to establish connections with additional lenders and, consequently, exert less effort in improving business performance. We document that firms' attempts to create new lending relationships are indeed more frequent when they experience negative credit shocks.

\section{References}

Ackerberg, Daniel, Benkard, C Lanier, Berry, Steven, \& Pakes, Ariel. 2007. Econometric tools for analyzing market outcomes. Handbook of econometrics, 6, 4171-4276.

Ackerberg, Daniel A., Caves, Kevin, \& Frazer, Garth. 2015. Identification Properties of Recent Production Function Estimators. Econometrica, 83(6), 2411-2451.

Adler, Gustavo, Duval, Mr Romain A, Furceri, Davide, Sinem, K, Koloskova, Ksenia, Poplawski-Ribeiro, Marcos, et al. . 2017. Gone with the Headwinds: Global Productivity. International Monetary Fund.

Aghion, Philippe, Angeletos, George-Marios, Banerjee, Abhijit, \& Manova, Kalina. 2010. Volatility and growth: Credit constraints and the composition of investment. Journal of Monetary Economics, 57(3), 246-265.

Aghion, Philippe, Askenazy, Philippe, Berman, Nicolas, Cette, Gilbert, \& Eymard, Laurent. 2012. Credit constraints and the cyclicality of R\&D investment: Evidence from France. Journal of the European Economic Association, 10(5), 1001-1024.

Akcigit, Ufuk, Alp, Harun, \& Peters, Michael. 2016. Lack of selection and limits to delegation: firm dynamics in developing countries. NBER working paper.

Altonji, Joseph G, Elder, Todd E, \& Taber, Christopher R. 2005. Selection on observed and unobserved variables: Assessing the effectiveness of Catholic schools. Journal of political economy, 113(1), 151-184.

Amiti, Mary, \& Weinstein, David E. 2017. How much do idiosyncratic bank shocks affect investment? Evidence from matched bank-firm data. Journal of Political Economy.

Anzoategui, Diego, Comin, Diego, Gertler, Mark, \& Martinez, Joseba. 2016. Endogenous Technology Adoption and $\mathrm{R} \& \mathrm{D}$ as Sources of Business Cycle Persistence. NBER working paper.

Asker, John, Collard-Wexler, Allan, \& De Loecker, Jan. 2014. Dynamic inputs and resource (mis) allocation. Journal of Political Economy, 122(5), 1013-1063.

Ates, Sina T, \& Saffie, Felipe Eduardo. 2016. Fewer but better: Sudden stops, firm entry, and financial selection. Working Paper.

Bai, John, Carvalho, Daniel, \& Phillips, Gordon M. 2018. The impact of bank credit on labor reallocation and aggregate industry productivity. The Journal of Finance, 73(6), 2787-2836.

Bandiera, Oriana, Guiso, Luigi, Prat, Andrea, \& Sadun, Raffaella. 2011. What do CEOs do?

Bartelsman, Eric, Haltiwanger, John, \& Scarpetta, Stefano. 2013. Cross-country differences in productivity: The role of allocation and selection. The American Economic Review, 103(1), 305-334. 
Begenau, Juliane, Piazzesi, Monika, \& Schneider, Martin. 2015. Banks' risk exposures. NBER working paper.

Benfratello, Luigi, Schiantarelli, Fabio, \& Sembenelli, Alessandro. 2008. Banks and innovation: Microeconometric evidence on Italian firms. Journal of Financial Economics, 90(2), 197-217.

Bernstein, Shai. 2015. Does going public affect innovation? The Journal of Finance, 70(4), 1365-1403.

Besley, Timothy, Roland, Isabelle, \& Van Reenen, John. 2017. Credit Market Frictions and the Productivity Slowdown. mimeo.

Bhattacharya, Dhritiman, Guner, Nezih, \& Ventura, Gustavo. 2013. Distortions, endogenous managerial skills and productivity differences. Review of Economic Dynamics, 16(1), 11-25.

Bloom, Nicholas, \& Van Reenen, John. 2007. Measuring and Explaining Management Practices Across Firms and Countries*. The Quarterly Journal of Economics, 122(4), 1351-1408.

Bloom, Nicholas, Sadun, Raffaella, \& Van Reenen, John. 2012. Americans do IT better: US multinationals and the productivity miracle. The American Economic Review, 102(1), 167-201.

Bloom, Nicholas, Eifert, Benn, Mahajan, Aprajit, McKenzie, David, \& Roberts, John. 2013. Does management matter? Evidence from India. The Quarterly Journal of Economics, 128(1), 1-51.

Bloom, Nicholas, Jones, Charles, Van Reenen, John, \& Webb, Michael. 2016. Are ideas getting harder to find? Unpublished paper, Stanford University.

Bonaccorsi di Patti, Emilia, \& Kashyap, Anil. 2017. Which Banks Recover From Large Adverse Shocks? NBER working paper.

Bond, Stephen, Harhoff, Dietmar, Van Reenen, John, et al. . 2005. Investment, R\&D and financial constraints in Britain and Germany. Annales d'Économie et de Statistique.

Borio, Claudio EV, Kharroubi, Enisse, Upper, Christian, \& Zampolli, Fabrizio. 2016. Labour reallocation and productivity dynamics: financial causes, real consequences. BIS working paper.

Borusyak, Kirill, Hull, Peter, \& Jaravel, Xavier. 2018. Quasi-Experimental Shift-Share Research Designs. NBER Working Paper.

Bramoullé, Yann, Djebbari, Habiba, \& Fortin, Bernard. 2009. Identification of peer effects through social networks. Journal of econometrics, 150(1), 41-55.

Broner, Fernando, Erce, Aitor, Martin, Alberto, \& Ventura, Jaume. 2014. Sovereign debt markets in turbulent times: Creditor discrimination and crowding-out effects. Journal of Monetary Economics, 61, 114-142.

Brunnermeier, Markus K. 2009. Deciphering the liquidity and credit crunch 2007-2008. The Journal of economic perspectives, 23(1), 77-100.

Brunnermeier, Markus K, Eisenbach, Thomas M, \& Sannikov, Yuliy. 2012. Macroeconomics with financial frictions: A survey. NBER working paper.

Buera, Francisco J, \& Moll, Benjamin. 2015. Aggregate implications of a credit crunch: The importance of heterogeneity. American Economic Journal: Macroeconomics, 7(3), 1-42.

Buera, Francisco J., Kaboski, Joseph P., \& Shin, Yongseok. 2011. Finance and Development: A Tale of Two Sectors. American Economic Review, 101(5), 1964-2002.

Buono, Ines, \& Formai, Sara. 2013. Bank Credit and Firm Export: Is there really a link? FREIT Working Paper.

Butler, Alexander W, \& Cornaggia, Jess. 2011. Does access to external finance improve productivity? Evidence from a natural experiment. Journal of Financial Economics, 99(1), 184-203.

Byrne, David M, Fernald, John G, \& Reinsdorf, Marshall B. 2016. Does the United States have a productivity slowdown or a measurement problem? Brookings Papers on Economic Activity, 2016(1), $109-182$. 
Caggese, Andrea. 2016. Financing constraints, radical versus incremental innovation, and aggregate productivity. Tech. rept.

Calligaris, S, Del Gatto, M, Hassan, F, Ottaviano, GIP, Schivardi, F, et al. . 2016. Italy's productivity conundrum. a study on resource misallocation in Italy. Tech. rept. Directorate General Economic and Financial Affairs (DG ECFIN), European Commission.

Carroll, Christopher Dixon. 2001. Death to the log-linearized consumption Euler equation!(And very poor health to the second-order approximation). Advances in Macroeconomics, 1(1).

Catherine, Sylvain, Chaney, Thomas, Huang, Zongbo, Sraer, David Alexandre, \& Thesmar, David. 2018. Quantifying Reduced-Form Evidence on Collateral Constraints. WP.

Cavalcanti, Tiago, \& Vaz, Paulo Henrique. 2017. Access to long-term credit and productivity of small and medium firms: A causal evidence. Economics Letters, 150, 21-25.

Cerra, Valerie, \& Saxena, Sweta Chaman. 2008. Growth Dynamics: The Myth of Economic Recovery. American Economic Review, 98(1), 439-57.

Cette, Gilbert, Fernald, John, \& Mojon, Benoit. 2016. The pre-Great Recession slowdown in productivity. European Economic Review, 88, 3-20.

Chaney, Thomas, Huang, Zongbo, Sraer, David Alexandre, \& Thesmar, David. 2015. Aggregate Effects of Collateral Constraints. mimeo.

Chodorow-Reich, Gabriel. 2013. The employment effects of credit market disruptions: Firm-level evidence from the 2008-9 financial crisis. The Quarterly Journal of Economics, 129(1), 1-59.

Cingano, Federico, Manaresi, Francesco, \& Sette, Enrico. 2016. Does credit crunch investment down? New evidence on the real effects of the bank-lending channel. The Review of Financial Studies, 29(10), 2737-2773.

Collard-Wexler, Allan, \& De Loecker, Jan. 2016. Production function estimation with measurement error in inputs. Tech. rept. National Bureau of Economic Research.

Correia, Sergio. 2016. Linear Models with High-Dimensional Fixed Effects: An Efficient and Feasible Estimator. Tech. rept. Working Paper.

Davis, Steven J, \& Haltiwanger, John. 2014. Labor market fluidity and economic performance. NBER working paper.

Davis, Steven J, Haltiwanger, John, \& Schuh, Scott. 1996. Small business and job creation: Dissecting the myth and reassessing the facts. Small business economics, 8(4), 297-315.

De Loecker, Jan. 2011. Product differentiation, multiproduct firms, and estimating the impact of trade liberalization on productivity. Econometrica, 79(5), 1407-1451.

De Loecker, Jan. 2013. Detecting learning by exporting. American Economic Journal: Microeconomics, 5(3), 1-21.

De Loecker, Jan, \& Scott, Paul T. 2016. Estimating market power Evidence from the US Brewing Industry. Tech. rept. National Bureau of Economic Research.

De Loecker, Jan, \& Warzynski, Frederic. 2012. Markups and firm-level export status. The American Economic Review, 102(6), 2437-2471.

de Ridder, Maarten. 2016. Investment in Productivity and the Long-Run Effect of Financial Crisis on Output.

Decker, Ryan, Haltiwanger, John, Jarmin, Ron, \& Miranda, Javier. 2014. The Role of Entrepreneurship in US Job Creation and Economic Dynamism. The Journal of Economic Perspectives, 28(3), 3-24.

Di Nola, Alessandro. 2015. Capital Misallocation during the Great Recession. Working Paper.

Dörr, Sebastian, Raissi, Mr Mehdi, \& Weber, Anke. 2018. Credit-Supply Shocks and Firm Productivity in Italy. Journal of International Money and Finance, 87, 155-171. 
Duval, Romain, Hong, Gee Hee, Timmer, Yannick, et al. . 2017. Financial Frictions and the Great Productivity Slowdown. Tech. rept. International Monetary Fund.

Fazzari, Steven M, Hubbard, R Glenn, Petersen, Bruce C, Blinder, Alan S, \& Poterba, James M. 1988. Financing constraints and corporate investment. Brookings papers on economic activity, 1988(1), 141-206.

Feldstein, Martin. 2015. The US underestimates growth. Wall Street Journal, 18.

Ferrando, Annalisa, \& Ruggieri, Alessandro. 2015. Financial constraints and productivity: evidence from euro area companies.

Field, Alexander J. 2003. The Most Technologically Progressive Decade of the Century. The American Economic Review, 93(4), 1399-1413.

Foster, Lucia S, Grim, Cheryl A, Haltiwanger, John, Wolf, Zoltan, et al. . 2017. Macro and Micro Dynamics of Productivity: From Devilish Details to Insights. NBER working paper.

Franklin, Jeremy, Rostom, May, \& Thwaites, Gregory. 2015. The banks that said no: banking relationships, credit supply and productivity in the United Kingdom. Bank of England Working Paper.

Gamberoni, Elisa, Giordano, Claire, \& Lopez-Garcia, Paloma. 2016. Capital and labour (mis) allocation in the euro area: some stylized facts and determinants.

Gandhi, Amit, Navarro, Salvador, \& Rivers, David A. 2011. On the identification of production functions: How heterogeneous is productivity?

Garcia-Macia, Daniel. 2015. The financing of ideas and the great deviation. IMF working paper.

Gatti, Roberta, \& Love, Inessa. 2008. Does access to credit improve productivity? Evidence from Bulgaria. Economics of Transition, 16(3), 445-465.

Giorcelli, Michela. 2016. The Long-Term Effects of Management and Technology Transfers.

Goldsmith-Pinkham, Paul, Sorkin, Isaac, \& Swift, Henry. 2018. Bartik Instruments: What, When, Why, and How. NBER working paper.

Gopinath, Gita, Kalemli-Özcan, Şebnem, Karabarbounis, Loukas, \& Villegas-Sanchez, Carolina. 2017. Capital allocation and productivity in South Europe. The Quarterly Journal of Economics, qjx024.

Gordon, Robert J. 2016. The rise and fall of American growth: The US standard of living since the civil war. Princeton University Press.

Gordon, Robert J, et al. . 2015. Secular Stagnation on the Supply Side: US Producivity Growth in the Long Run. Communications \& Strategies, 1(100), 19-45.

Greenstone, Michael, Mas, Alexandre, \& Nguyen, Hoai-Luu. 2014. Do credit market shocks affect the real economy? Quasi-experimental evidence from the Great Recession and 'normal'economic times. NBER working paper.

Hall, Bronwyn H. 2011. Innovation and productivity. NBER working paper.

Hall, Bronwyn H, Lotti, Francesca, \& Mairesse, Jacques. 2008. Employment, innovation, and productivity: evidence from Italian microdata. Industrial and Corporate Change, 17(4), 813-839.

Hassan, Fadi, di Mauro, Filippo, \& Ottaviano, Gianmarco IP. 2017. Banks credit and productivity growth. Working paper.

Hottman, Colin J, Redding, Stephen J, \& Weinstein, David E. 2016. Quantifying the sources of firm heterogeneity. The Quarterly Journal of Economics, 131(3), 1291-1364.

Hsieh, Chang-Tai, \& Klenow, Peter J. 2009. Misallocation and manufacturing TFP in China and India. The Quarterly journal of economics, 124(4), 1403-1448. 
Huber, Kilian. 2018. Disentangling the Effects of a Banking Crisis: Evidence from German Firms and Counties. American Economic Review, 108(3), 868-898.

Imbens, Guido W, \& Wooldridge, Jeffrey M. 2009. Recent developments in the econometrics of program evaluation. Journal of economic literature, 47(1), 5-86.

Iyer, Rajkamal, Peydró, José-Luis, da Rocha-Lopes, Samuel, \& Schoar, Antoinette. 2013. Interbank liquidity crunch and the firm credit crunch: Evidence from the 2007-2009 crisis. The Review of Financial Studies, 27(1), 347-372.

Jensen, Michael C. 1986. Agency costs of free cash flow, corporate finance, and takeovers. The American economic review, $\mathbf{7 6}(2)$, 323-329.

Jensen, Thais Lærkholm, \& Johannesen, Niels. 2016. The Consumption Effects of the 2007-2008 Financial Crisis: Evidence from Households in Denmark. American Economic Review.

Jordà, Òscar, Schularick, Moritz, \& Taylor, Alan M. 2013. When credit bites back. Journal of Money, Credit and Banking, 45(s2), 3-28.

Khwaja, Asim Ijaz, \& Mian, Atif. 2008. Tracing the Impact of Bank Liquidity Shocks: Evidence from an Emerging Market. American Economic Review, 98(4), 1413-42.

Kogan, Leonid, Papanikolaou, Dimitris, Seru, Amit, \& Stoffman, Noah. 2017. Technological innovation, resource allocation, and growth. The Quarterly Journal of Economics, 132(2), 665-712.

Krishnan, Karthik, Nandy, Debarshi K, \& Puri, Manju. 2014. Does financing spur small business productivity? Evidence from a natural experiment. The Review of Financial Studies, 28(6), 1768-1809.

Lenzu, Simone, \& Manaresi, Francesco. 2018. Do marginal products differ from user costs? Micro-level evidence rom Italian firms. mimeo.

Levine, Oliver, \& Warusawitharana, Missaka. 2014. Finance and productivity growth: Firm-level evidence. mimeo.

Levinsohn, James, \& Petrin, Amil. 2003. Estimating production functions using inputs to control for unobservables. The Review of Economic Studies, 70(2), 317-341.

Linarello, Andrea, Petrella, Andrea, \& Sette, Enrico. 2018. Allocative efficiency and finance. mimeo.

Malacrino, Davide. 2016. Entrepreneurs' Wealth and Firm Dynamics. Stanford mimeo.

Manova, Kalina. 2012. Credit constraints, heterogeneous firms, and international trade. Review of Economic Studies, $80(2), 711-744$.

Mian, Atif R, Sufi, Amir, \& Verner, Emil. 2017. How Do Credit Supply Shocks Affect the Real Economy? Evidence from the United States in the 1980s. NBER working paper.

Midrigan, Virgiliu, \& Xu, Daniel Yi. 2014. Finance and misallocation: Evidence from plant-level data. The American Economic Review, 104(2), 422-458.

Mokyr, Joel. 2014. Secular stagnation? Not in your life. Secular stagnation: Facts, causes and cures, 83.

Moll, Benjamin. 2014. Productivity losses from financial frictions: can self-financing undo capital misallocation? The American Economic Review, 104(10), 3186-3221.

Neuhann, Daniel, \& Saidi, Farzad. 2017. Do Universal Banks Finance Riskier but More Productive Firms? Forthcoming, Journal of Financial Economics.

Olley, G. Steven, \& Pakes, Ariel. 1996. The Dynamics of Productivity in the Telecommunications Equipment Industry. Econometrica, 64(6), 1263-1297.

Oster, Emily. 2016. Unobservable selection and coefficient stability: Theory and evidence. Journal of Business E Economic Statistics. 
Oulton, Nicholas, \& Sebastiá-Barriel, María. 2013. Long and short-term effects of the financial crisis on labour productivity, capital and output.

Paravisini, Daniel, Rappoport, Veronica, Schnabl, Philipp, \& Wolfenzon, Daniel. 2014. Dissecting the effect of credit supply on trade: Evidence from matched credit-export data. The Review of Economic Studies, 82(1), 333-359.

Pellegrino, Bruno, \& Zingales, Luigi. 2014. Diagnosing the Italian disease. Unpublished manuscript, September, 14.

Peters, Bettina, Roberts, Mark J, \& Vuong, Van Anh. 2017a. Dynamic R\&D choice and the impact of the firm's financial strength. Economics of Innovation and New Technology, 26(1-2), 134-149.

Peters, Bettina, Roberts, Mark J, Vuong, Van Anh, \& Fryges, Helmut. 2017b. Estimating dynamic R\&D choice: an analysis of costs and long-run benefits. The RAND Journal of Economics, 48(2), 409-437.

Petersen, Mitchell A, \& Rajan, Raghuram G. 1994. The benefits of lending relationships: Evidence from small business data. The journal of finance.

Pozzi, Andrea, \& Schivardi, Fabiano. 2016. Demand or productivity: What determines firm growth? The RAND Journal of Economics, 47(3), 608-630.

Rauh, Joshua D. 2006. Investment and financing constraints: Evidence from the funding of corporate pension plans. The Journal of Finance, 61(1), 33-71.

Reinhart, Carmen M, \& Rogoff, Kenneth S. 2009. This time is different: Eight centuries of financial folly. princeton university press.

Reinhart, Carmen M., \& Rogoff, Kenneth S. 2014. Recovery from Financial Crises: Evidence from 100 Episodes. American Economic Review: Papers and Proceedings, 104(5), 50-55.

Schiantarelli, Fabio, \& Sembenelli, Alessandro. 1997. The maturity structure of debt: Determinants and effects on firms' performance? Evidence from the United Kingdom and Italy. The World Bank, Policy Research Working Paper Series: 1699.

Schivardi, Fabiano, Sette, Enrico, \& Tabellini, Guido. 2017. Credit Misallocation During the European Financial Crisis. mimeo.

Shenoy, Ajay. 2017. Estimating the Production Function when Firms Are Constrained. Working paper.

Stock, James H, \& Watson, Mark W. 2012. Disentangling the Channels of the 2007-2009 Recession. Brookings Institute.

Syverson, Chad. 2011. What determines productivity? Journal of Economic literature, 49(2), 326-365.

Whited, Toni M, \& Zhao, Jake. 2016. The misallocation of finance. Working paper. 


\section{Figures}
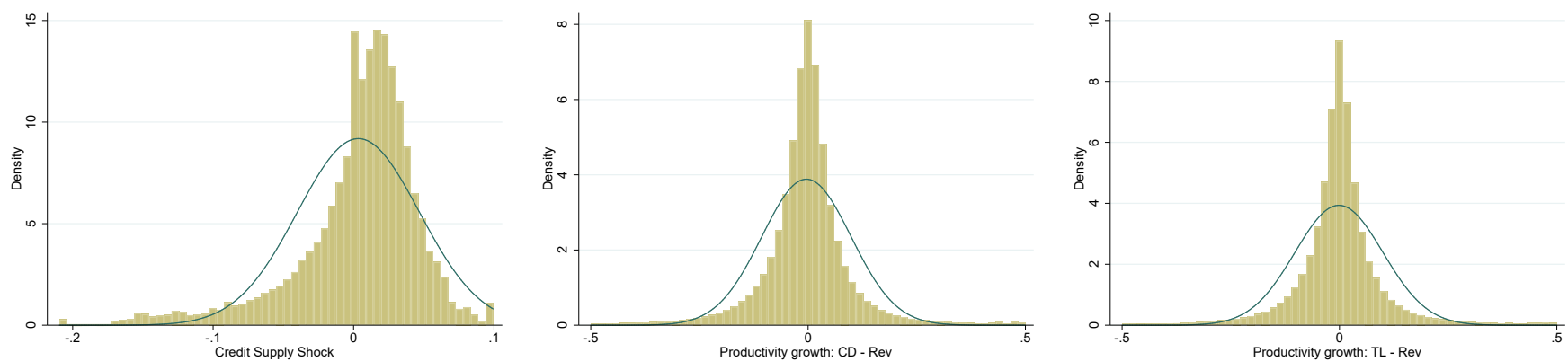

Figure 2: Histogram of credit supply shock (left panel) and productivity growth (central and right panel). Productivity is estimated as a residual from $(\log )$ revenues production function. CobbDouglas (central panel) or Trans-Log (right panel) functional form is assumed. Normal distribution is superimposed. See sections 3.1 and 3.2 for details.
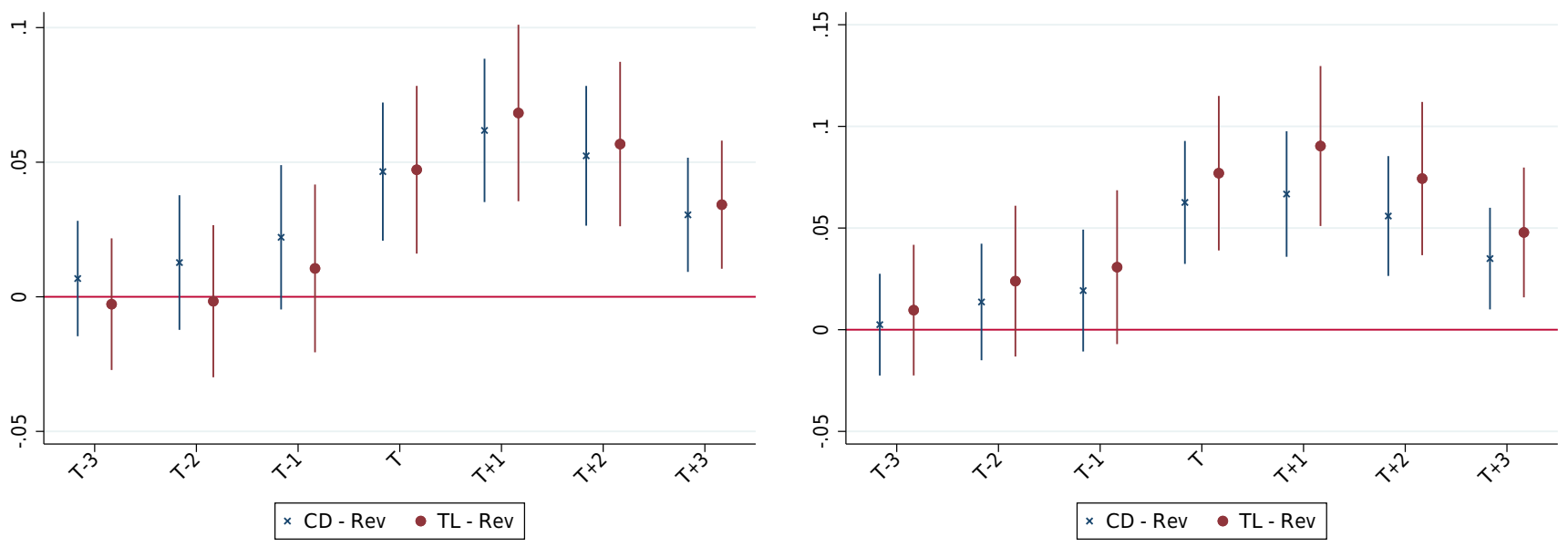

Figure 3: $\quad$ Productivity before and after an unexpected credit supply shock, see section 5.3 for details on the estimated equation. Top panel refers to all industries, while bottom panel refers to manufacturers. 99\% confidence intervals are displayed. Productivity is estimated as residual from a $(\log )$ revenue production function. Functional form is either Cobb Douglas or Trans-Log. Details on productivity estimation are in section 3.2. 

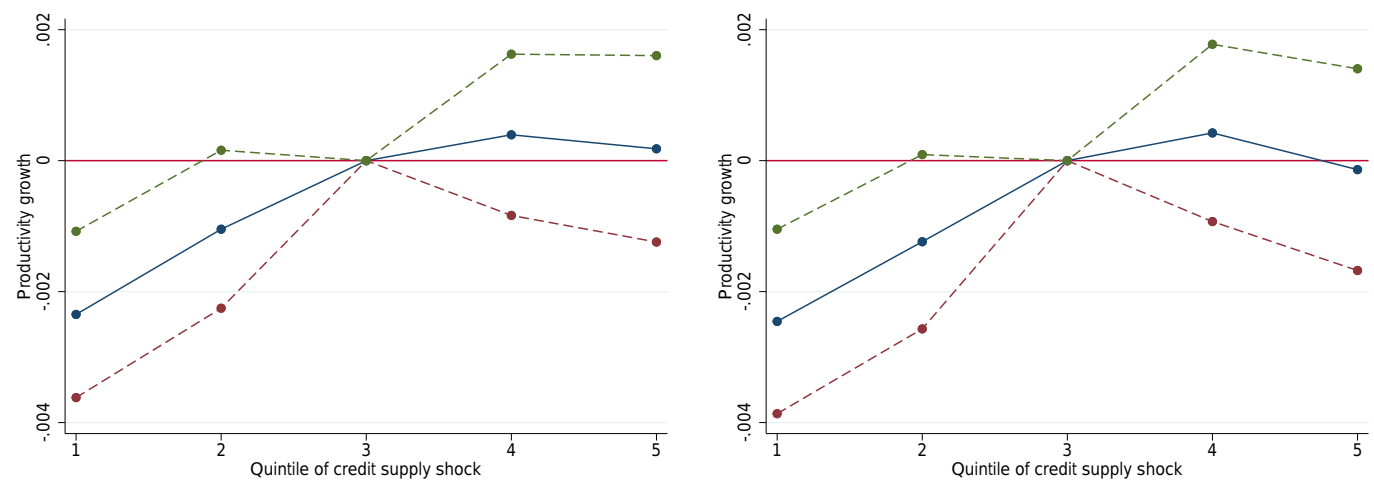

Figure 5: Growth rate of productivity in manufacturing per quintile of credit supply shock. The third quintile (which includes the median credit supply shocks) is normalized to zero. Productivity is residual from a Cobb-Douglas revenues production function (left side) or Trans-Logs revenues production function (right side).

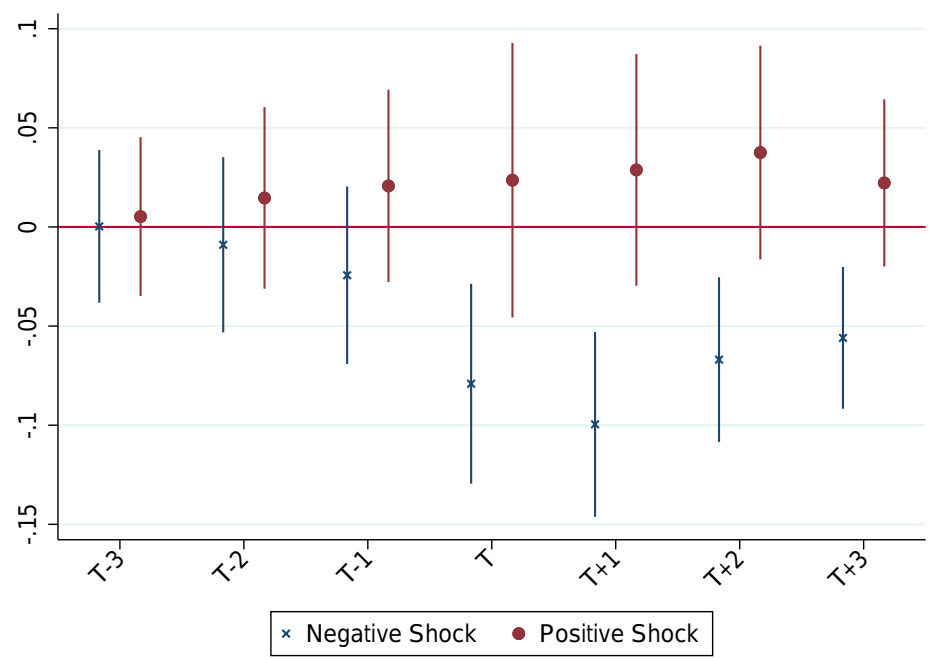

Figure 6: Revenue productivity before and after a credit supply shock - negative vs positive shocks 


\section{Tables}

Table 1: Descriptive Statistics - main firm-level variables

\begin{tabular}{lcccc|cccc}
\hline \hline VARIABLE & Mean & Std. Dev. & Median & $\mathrm{N}$ & Mean & Std. Dev. & Median & $\mathrm{N}$ \\
\hline \multicolumn{7}{c}{ All Industries } \\
Value Added & 5,312 & 33,819 & 1,641 & 656,960 & 5,409 & 21,699 & 1,943 & 347,990 \\
Net Revenues & 27,073 & 156,638 & 8,813 & 656,960 & 25,351 & 164,054 & 8,209 & 347,990 \\
Wagebill & 3,377 & 19,693 & 1,062 & 656,960 & 3,466 & 13452.4 & 1,299 & 347,990 \\
Capital Stock & 8,636 & 153,346 & 1,545 & 656,960 & 7,111 & 40,357 & 2,058 & 347,990 \\
Intermediate Inputs & 21,888 & 137,390 & 6,873 & 656,960 & 20,057 & 150,610 & 6,119 & 347,990 \\
Credit Granted & 7,924 & 3,6445 & 2,737 & 650,664 & 8,039 & 29,760 & 3,013 & 345,700 \\
Employees & 80 & 472 & 28 & 656,960 & 79 & 269 & 35 & 347,990 \\
\hline \hline
\end{tabular}

Notes: One observation is one firm for one year, between 1998 and 2013 (unbalanced panel). All variables (except for number of employees) are expressed as thousands of 2010 euros using sector-level deflators from national accounts.

Source: CADS and Credit Register. 
Table 2: Credit, Inputs, Outputs, and Loan Applications response to Credit Supply Shocks

\begin{tabular}{|c|c|c|c|c|c|c|c|c|c|}
\hline$\overline{\text { VARIABLES }}$ & $\begin{array}{c}\text { Credit } \\
\text { Received } \\
\text { (delta Log) } \\
(1)\end{array}$ & $\begin{array}{c}\text { Value } \\
\text { Added } \\
\text { (delta Log) } \\
(2)\end{array}$ & $\begin{array}{c}\text { Net } \\
\text { Revenues } \\
\text { (delta Log) } \\
(3)\end{array}$ & $\begin{array}{c}\text { Capital } \\
\text { Stock } \\
\text { (delta Log) } \\
(4)\end{array}$ & $\begin{array}{c}\text { Wagebill } \\
\text { (delta Log) } \\
(5)\end{array}$ & $\begin{array}{c}\text { Number of } \\
\text { Employees } \\
\text { (delta Log) } \\
(6)\end{array}$ & $\begin{array}{c}\text { Intermediate } \\
\text { Inputs } \\
\text { (delta Log) } \\
(7)\end{array}$ & $\begin{array}{c}\text { N. of Loan } \\
\text { Applications with } \\
\text { New Lenders } \\
(8)\end{array}$ & $\begin{array}{c}\text { Any Loan } \\
\text { Application with } \\
\text { New Lenders } \\
(9)\end{array}$ \\
\hline \multicolumn{10}{|c|}{ All Industries } \\
\hline$\phi_{i, t}$ & $\begin{array}{c}0.949^{* * * *} \\
(0.0196)\end{array}$ & $\begin{array}{c}0.123^{* * * *} \\
(0.0162)\end{array}$ & $\begin{array}{c}0.0474^{* * *} \\
(0.0109)\end{array}$ & $\begin{array}{c}0.0619^{* * *} \\
(0.0128)\end{array}$ & $\begin{array}{c}0.0154^{*} \\
(0.00926)\end{array}$ & $\begin{array}{c}0.00608 \\
(0.00889)\end{array}$ & $\begin{array}{l}0.0220^{*} \\
(0.0114)\end{array}$ & $\begin{array}{c}-0.537^{* * *} \\
(0.0796)\end{array}$ & $\begin{array}{c}-0.0780 * * * \\
(0.0173)\end{array}$ \\
\hline Observations & 609,195 & 656,960 & 656,960 & 656,960 & 656,960 & 656,960 & 656,960 & 656,960 & 656,960 \\
\hline$R^{2}$ & 0.239 & 0.224 & 0.302 & 0.259 & 0.324 & 0.319 & 0.302 & 0.500 & 0.348 \\
\hline \multicolumn{10}{|c|}{ Manufacturing } \\
\hline$\phi_{i, t}$ & $\begin{array}{c}0.966^{* * *} \\
(0.0253)\end{array}$ & $\begin{array}{c}0.134^{* * *} \\
(0.0201)\end{array}$ & $\begin{array}{c}0.0436^{* * *} \\
(0.0143)\end{array}$ & $\begin{array}{c}0.0610^{* * *} \\
(0.0169)\end{array}$ & $\begin{array}{l}0.00388 \\
(0.0116)\end{array}$ & $\begin{array}{r}-0.00892 \\
(0.0108)\end{array}$ & $\begin{array}{l}0.00716 \\
(0.0152)\end{array}$ & $\begin{array}{c}-0.424^{* * *} \\
(0.113)\end{array}$ & $\begin{array}{c}-0.0583^{* *} \\
(0.0242)\end{array}$ \\
\hline Observations & 324,926 & 347,990 & 347,990 & 347,990 & 347,990 & 347,990 & 347,990 & 347,990 & 347,990 \\
\hline$R^{2}$ & 0.224 & 0.241 & 0.309 & 0.253 & 0.326 & 0.317 & 0.308 & 0.491 & 0.349 \\
\hline
\end{tabular}

Columns (1) - (7), results of estimating model:

$$
\Delta x_{i, t}=\psi_{i}+\psi_{s, t, p}+\gamma \cdot \phi_{i, t}+\eta_{i, t}
$$

One observation is one firm for one year between 1998 and 2013 (unbalanced panel). $\Delta x_{i, t}$ is the delta-log of the variable described on top of each column, in real terms (2010 euros). $\phi_{i, t}$ is an idiosyncratic shock to firm credit supply, whose construction is detailed in section 3.1. Firm FEs and province $\times$ industry $\times$ year FEs are included. Singleton observations are dropped. A $1 \%$ increase in $\phi_{i, t}$ is the supply shock needed to increase the credit granted to firm $i$ by $1 \%$. The first column has less observation because some firms might have no credit granted in one year, and therefore delta logs are ill-defined. Columns (8) - (9), results of estimating model:

$$
\begin{aligned}
& \operatorname{App}_{i, t}=\psi_{i}+\psi_{p, s, t}+\gamma \cdot \phi_{i, t}+\eta_{i, t} \\
& \operatorname{Pr}\left(\operatorname{App}_{i, t}>0\right)=\psi_{i}+\psi_{p, s, t}+\gamma \cdot \phi_{i, t}+\eta_{i, t}
\end{aligned}
$$

where $A p p_{i, t}$ is the number of banks submitting a query about firm $i$ to the credit register, for the first time, in year $t$. It proxies for the number of firm $i$ 's applications with previously unconnected lenders. Standard errors, in parentheses, are (two-way) clustered at firm and main-lender $\times$ year level. ${ }^{* * *} \mathrm{p}<0.01,{ }^{* *} \mathrm{p}<0.05,{ }^{*} \mathrm{p}<0.1$ 
Table 3: Credit Supply Shocks and Productivity Growth

\begin{tabular}{lcccc}
\hline \hline $\begin{array}{l}\text { VARIABLES } \\
\text { (in delta Log) }\end{array}$ & Productivity & Productivity & Productivity & Productivity \\
Functional Form & $\begin{array}{c}\text { Cobb-Douglas } \\
\text { Output Measure } \\
\text { Value Added } \\
(1)\end{array}$ & $\begin{array}{c}\text { Trans-Log } \\
\text { Value Added } \\
(2)\end{array}$ & $\begin{array}{c}\text { Cobb-Douglas } \\
\text { Net Revenue } \\
(3)\end{array}$ & $\begin{array}{c}\text { Trans-Log } \\
\text { Net Revenue } \\
(4)\end{array}$ \\
\hline \multicolumn{5}{c}{ All industries } \\
$\phi_{i, t}$ & $0.0946^{* * *}$ & $0.109^{* * *}$ & $0.0190^{* * * *}$ & $0.0259^{* * *}$ \\
& $(0.0155)$ & $(0.0160)$ & $(0.00477)$ & $(0.00491)$ \\
Observations & 656,960 & 656,960 & 656,960 & 656,960 \\
$R^{2}$ & 0.172 & 0.185 & 0.178 & 0.195 \\
\hline \multicolumn{5}{c}{ Manufacturing } \\
$\phi_{i, t}$ & $0.115^{* * *}$ & $0.121^{* * *}$ & $0.0303^{* * *}$ & $0.0323^{* * *}$ \\
& $(0.0178)$ & $(0.0186)$ & $(0.00595)$ & $(0.00649)$ \\
Observations & 347,990 & 347,990 & 347,990 & 347,990 \\
R-squared & 0.186 & 0.200 & 0.144 & 0.180 \\
\hline \hline
\end{tabular}

Results of estimating model:

$$
\Delta \omega_{i, t}=\psi_{i}+\psi_{s, t, p}+\gamma \cdot \phi_{i, t}+\eta_{i, t}
$$

One observation is one firm for one year between 1998 and 2013 (unbalanced panel). Firm FEs and province $\times$ industry $\times$ year FEs are included. Singleton are dropped. $\phi_{i, t}$ is an idiosyncratic shock to firm credit supply, whose construction is detailed in section 3.1. A 1\% increase in $\phi_{i, t}$ is the supply shock needed to increase the credit granted to firm $i$ by $1 \%$. The LHS variable is the first difference of Hicks-neutral productivity residual: $\Delta \omega_{i, t}=\Delta y_{i, t}-\Delta f\left(x_{i, t}, \beta\right)$ where $y$ is $\log$ of net revenue (columns 3-4) or log of value added (columns 1-2) and $x$ is a set of inputs. Capital stock, labor, and (for the revenue case only) intermediate inputs are included in $x . f(\cdot, \beta)$ is either a first (Cobb-Douglas, columns 1 and 3 ) or second (Trans-Log, columns 2 and 4) order polynomial in $\log$ inputs. Estimation of parameters $\beta$ is described in section 3.2. Standard errors, in parentheses, are (two-way) clustered at firm and mainlender $\times$ year level. $* * * \mathrm{p}<0.01,{ }^{* *} \mathrm{p}<0.05,{ }^{*} \mathrm{p}<0.1$ 
Table 4: Credit Supply Shocks and Productivity Growth: Robustness - Cobb-Douglas Revenue Productivity

\begin{tabular}{|c|c|c|c|c|c|c|c|c|c|c|}
\hline $\begin{array}{l}\text { VARIABLES } \\
\text { (delta Logs) }\end{array}$ & Productivity & Productivity & Productivity & Productivity & Productivity & Productivity & Productivity & Productivity & Productivity & Productivity \\
\hline Model & $\begin{array}{l}\text { Baseline } \\
\text { (1) }\end{array}$ & $\begin{array}{c}\text { Firm } \\
\text { Controls } \\
(2)\end{array}$ & $\begin{array}{l}\text { Important } \\
\text { Borrowers } \\
\quad(3)\end{array}$ & $\begin{array}{c}\text { Pooled } \\
\text { Estimator } \\
\quad(4)\end{array}$ & $\begin{array}{c}\text { Alternative } \\
\text { FEs structure } \\
(5)\end{array}$ & $\begin{array}{c}\text { Match } \\
\text { Controls } \\
(6)\end{array}$ & $\begin{array}{c}\text { Split } \\
\text { Sample } \\
(7)\end{array}$ & $\begin{array}{l}4 \text { Digits } \\
\text { Sector } \\
(8)\end{array}$ & $\begin{array}{l}\text { Endogenous } \\
\text { Exit } \\
(9)\end{array}$ & $\begin{array}{l}\text { Cost } \\
\text { Share } \\
(10)\end{array}$ \\
\hline \multicolumn{11}{|c|}{ All Industries } \\
\hline$\phi_{i, t}$ & $\begin{array}{c}0.0190^{* * * *} \\
(0.00477)\end{array}$ & $\begin{array}{c}0.0248^{* * *} \\
(0.00534)\end{array}$ & $\begin{array}{c}0.0182^{* * * *} \\
(0.00540)\end{array}$ & $\begin{array}{c}0.0131^{* * *} \\
(0.00327)\end{array}$ & $\begin{array}{c}0.0171^{* * *} \\
(0.00471)\end{array}$ & $\begin{array}{c}0.0234^{* * *} \\
(0.00604)\end{array}$ & $\begin{array}{c}0.0197^{* * *} \\
(0.00503)\end{array}$ & $\begin{array}{c}0.0278^{* * *} \\
(0.00585)\end{array}$ & $\begin{array}{c}0.0166^{* * *} \\
(0.00465)\end{array}$ & $\begin{array}{c}0.0256^{* * *} \\
(0.00736)\end{array}$ \\
\hline Observations & 656,960 & 483,665 & 521,741 & 656,960 & 656,960 & 656,960 & 656,960 & 587,873 & 656,960 & 545,162 \\
\hline R-squared & 0.178 & 0.184 & 0.192 & 0.006 & 0.096 & 0.178 & 0.178 & 0.272 & 0.177 & 0.185 \\
\hline \multicolumn{11}{|c|}{ Manufacturing } \\
\hline$\phi_{i, t}$ & $\begin{array}{c}0.0303^{* * *} \\
(0.00595)\end{array}$ & $\begin{array}{c}0.0362^{* * *} \\
(0.00657)\end{array}$ & $\begin{array}{c}0.0330^{* * * *} \\
(0.00698)\end{array}$ & $\begin{array}{c}0.0188^{* * *} \\
(0.00443)\end{array}$ & $\begin{array}{c}0.0321^{* * *} \\
(0.00600)\end{array}$ & $\begin{array}{c}0.0331^{* * *} \\
(0.00739)\end{array}$ & $\begin{array}{c}0.0292^{* * *} \\
(0.00633)\end{array}$ & $\begin{array}{c}0.0401^{* * *} \\
(0.00731)\end{array}$ & $\begin{array}{c}0.0295^{* * *} \\
(0.00639)\end{array}$ & $\begin{array}{c}0.0537^{* * *} \\
(0.0104)\end{array}$ \\
\hline Observations & 347,990 & 262,308 & 280,346 & 347,990 & 347,990 & 347,990 & 347,990 & 309,887 & 347,990 & 291,071 \\
\hline R-squared & 0.144 & 0.153 & 0.150 & 0.004 & 0.071 & 0.144 & 0.144 & 0.259 & 0.166 & 0.161 \\
\hline
\end{tabular}

Results of estimating model:

$$
\Delta \omega_{i, t}=\psi_{i}+\psi_{s, t, p}+\gamma \cdot \phi_{i, t}+\eta_{i, t}
$$

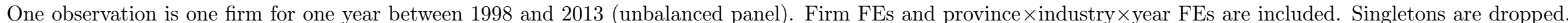

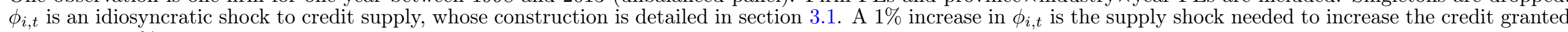

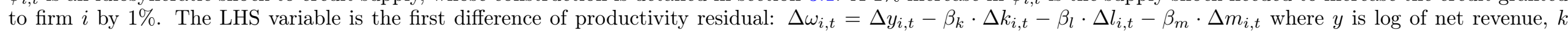

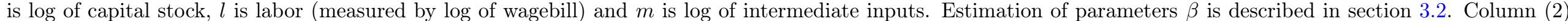

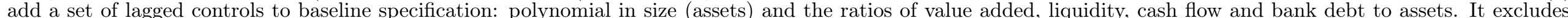

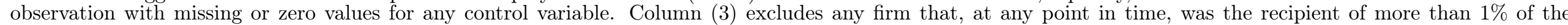

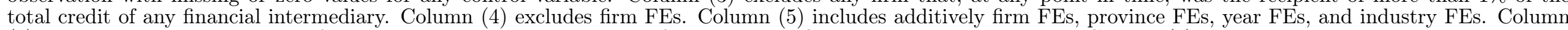

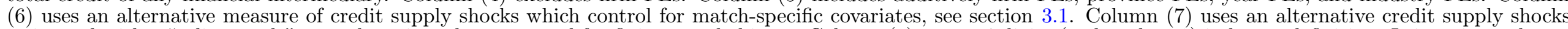

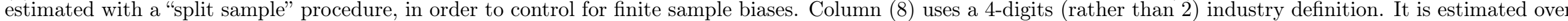

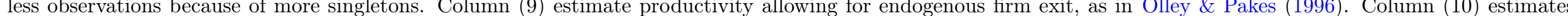

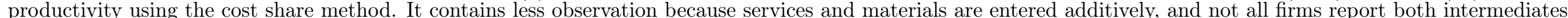
Standard errors, in parentheses, are (two-way) clustered at firm and main-lender $\times$ year level. ${ }^{* * *} \mathrm{p}<0.01,{ }^{* *} \mathrm{p}<0.05,{ }^{*} \mathrm{p}<0.1$ 
Table 5: Credit Supply Shocks and Productivity Growth - Heterogeneity - Cobb-Douglas Revenue Productivity

\begin{tabular}{|c|c|c|c|c|c|c|c|}
\hline $\begin{array}{l}\text { VARIABLES } \\
\text { (in delta } \log \text { ) }\end{array}$ & Productivity & Productivity & Productivity & Productivity & Productivity & Productivity & Productivity \\
\hline $\begin{array}{l}\text { Hetereogeneity } \\
\text { Dimension }\end{array}$ & $\begin{array}{c}\text { Large Firm } \\
\text { (Assets) } \\
(1)\end{array}$ & $\begin{array}{c}\text { Small Lenders } \\
\text { (Bank Assets) } \\
(2)\end{array}$ & $\begin{array}{l}\text { Few } \\
\text { Lenders } \\
(3)\end{array}$ & $\begin{array}{c}\text { High Sectoral } \\
\text { Leverage } \\
(4)\end{array}$ & $\begin{array}{l}\text { Young } \\
\text { Firm } \\
(5)\end{array}$ & $\begin{array}{c}\text { High Sectoral } \\
\text { Patent Frequency } \\
(6)\end{array}$ & $\begin{array}{c}\text { Years } \\
\text { (Great Recession) } \\
(7)\end{array}$ \\
\hline \multicolumn{8}{|c|}{ All Industries } \\
\hline$\phi_{i, t}$ & $\begin{array}{c}0.0208^{* * *} \\
(0.00520)\end{array}$ & $\begin{array}{c}0.0150^{* * *} \\
(0.00571)\end{array}$ & $\begin{array}{l}-0.0142 \\
(0.0187)\end{array}$ & $\begin{array}{c}0.00108 \\
(0.00839)\end{array}$ & $\begin{array}{c}0.0163^{* * *} \\
(0.00494)\end{array}$ & $\begin{array}{c}0.00726 \\
(0.00669)\end{array}$ & $\begin{array}{c}0.0185^{* * *} \\
(0.00496)\end{array}$ \\
\hline Interaction & $\begin{array}{c}-0.00385 \\
(0.0107)\end{array}$ & $\begin{array}{c}0.0169^{*} \\
(0.00926)\end{array}$ & $\begin{array}{l}0.0347^{*} \\
(0.0184)\end{array}$ & $\begin{array}{c}0.0253^{* * *} \\
(0.00951)\end{array}$ & $\begin{array}{c}0.00939 \\
(0.00995)\end{array}$ & $\begin{array}{c}0.0242^{* * *} \\
(0.00867)\end{array}$ & $\begin{array}{l}0.00313 \\
(0.0111)\end{array}$ \\
\hline Observations & 656,960 & 653,492 & 656,704 & 656,960 & 656,960 & 656,960 & 656,960 \\
\hline R-squared & 0.179 & 0.178 & 0.178 & 0.178 & 0.178 & 0.178 & 0.178 \\
\hline \multicolumn{8}{|c|}{ Manufacturing } \\
\hline$\phi_{i, t}$ & $\begin{array}{c}0.0391^{* * *} \\
(0.00719)\end{array}$ & $\begin{array}{c}0.0202^{* * *} \\
(0.00672)\end{array}$ & $\begin{array}{l}-0.0167 \\
(0.0245)\end{array}$ & $\begin{array}{c}0.000303 \\
(0.0129)\end{array}$ & $\begin{array}{c}0.0262^{* * *} \\
(0.00595)\end{array}$ & $\begin{array}{c}0.0231 \\
(0.0278)\end{array}$ & $\begin{array}{c}0.0263^{* * *} \\
(0.00651)\end{array}$ \\
\hline Interaction & $\begin{array}{c}-0.0313^{* *} \\
(0.0130)\end{array}$ & $\begin{array}{c}0.0380^{* * *} \\
(0.0124)\end{array}$ & $\begin{array}{c}0.0485^{* *} \\
(0.0246)\end{array}$ & $\begin{array}{c}0.0391^{* * *} \\
(0.0144)\end{array}$ & $\begin{array}{c}0.0164 \\
(0.0139)\end{array}$ & $\begin{array}{l}0.00756 \\
(0.0285)\end{array}$ & $\begin{array}{c}0.0164 \\
(0.0126)\end{array}$ \\
\hline Observations & 347,990 & 346,937 & 347,919 & 347,990 & 347,990 & 347,990 & 347,990 \\
\hline R-squared & 0.144 & 0.144 & 0.144 & 0.144 & 0.144 & 0.144 & 0.144 \\
\hline
\end{tabular}

Results of estimating equation:

$$
\Delta \omega_{i, t}=\psi_{i}+\psi_{s, t, p}+\psi_{d} \cdot D_{i, t-1}+\gamma \cdot \phi_{i, t}+\gamma_{h e t} \cdot \phi_{i, t} \cdot D_{i,-1 t}+\eta_{i, t}
$$

One observation is one firm for one year between 1998 and 2013 (unbalanced panel). Firm FEs and province $\times$ industry $\times$ year FEs are included. Singleton are dropped. $\phi_{i, t}$ is an idiosyncratic shock to firm credit supply, whose construction is detailed in section 3.1 . A $1 \%$ increase in $\phi_{i, t}$ is the supply shock needed to increase the credit granted to firm $i$ by $1 \%$. The LHS variable is the first difference of productivity residual: $\Delta \omega_{i, t}=\Delta y_{i, t}-\beta_{k} \cdot \Delta k_{i, t}-\beta_{l} \cdot \Delta l_{i, t}-\beta_{m} \cdot \Delta m_{i, t}$ where $y$ is log of net revenue, $k$ is log of capital stock, $l$ is labor (measured by log of wagebill) and $m$ is $\log$ of intermediate inputs. Estimation of parameters $\beta$ is described in section 3.2. Categorical dummy $D_{i, t-1}$ is equal to one if and only if: for column (1), firm is in the top quartile for size (according to previous year assets); for column (2), firm is in the bottom half according to previous year lenders' size (assets); for column (3), firm is in bottom half according to previous year number of lending relationships; for column (4), firm is in the top half according to sector mean leverage (debt over assets); column (5), firm is among the $25 \%$ youngest firms in calendar year $t$ (approx 10 years old); column (6), firm operates in a sector in the top half according to the likelihood of applying for a patent. In column (7) heterogeneity is across the time dimension: years of the Great Recession. Standard errors, in parentheses, are (two-way) clustered at firm and main-lender $\times$ year level. $* * * \mathrm{p}<0.01,{ }^{* *} \mathrm{p}<0.05,{ }^{*} \mathrm{p}<0.1$. 
Table 6: Exposure to Interbank Market and Productivity Growth

\begin{tabular}{lcccc}
\hline \hline $\begin{array}{l}\text { VARIABLES } \\
\text { (in delta Log) }\end{array}$ & Productivity & Productivity & Productivity & Productivity \\
$\begin{array}{l}\text { Functional Form } \\
\text { Output Measure }\end{array}$ & $\begin{array}{c}\text { Cobb-Douglas } \\
\text { Value Added } \\
(1)\end{array}$ & $\begin{array}{c}\text { Trans-Log } \\
\text { Value Added } \\
(2)\end{array}$ & $\begin{array}{c}\text { Cobb-Douglas } \\
\text { Net Revenue } \\
(3)\end{array}$ & $\begin{array}{c}\text { Trans-Log } \\
\text { Net Revenue } \\
(4)\end{array}$ \\
\hline \multicolumn{5}{c}{ All Industries } \\
ITBK $K_{i, 2006}$ & $-0.0412^{*}$ & $-0.0462^{*}$ & $-0.0171^{* *}$ & $-0.0209^{* * *}$ \\
& $(0.0220)$ & $(0.0257)$ & $(0.00799)$ & $(0.00734)$ \\
Observations & 110,070 & 110,070 & 110,070 & 110,070 \\
$R^{2}$ & 0.112 & 0.117 & 0.101 & 0.121 \\
\hline & \multicolumn{5}{c}{ Manufacturing } \\
ITBK & $-0.0675^{* *}$ & $-0.0815^{* *}$ & -0.0117 & $-0.0190^{*}$ \\
& $(0.0311)$ & $(0.0344)$ & $(0.0113)$ & $(0.0103)$ \\
Observations & 57,986 & 57,986 & 57,986 & 57,986 \\
$R^{2}$ & 0.134 & 0.140 & 0.096 & 0.124 \\
\hline \hline
\end{tabular}

Resulting of estimating model:

$$
\Delta \omega_{i, t}=\psi_{s, t, p}+\gamma \cdot \operatorname{ITB} K_{i, 2006}+\eta_{i, t}
$$

One observation is one firm for one year between 2007 and 2009. Provincexindustry $\times$ year FEs are included. Singleton are dropped. ITB $K_{i, 2006}$ is the weighted average of firm's $i$ lenders' liability on the interbank market over assets in 2006 (winsorized at top 1\%). The LHS variable is the first difference of Hicks-neutral productivity residual: $\Delta \omega_{i, t}=\Delta y_{i, t}-\Delta f\left(x_{i, t}, \beta\right)$ where $y$ is log of net revenue (columns 3-4) or $\log$ of value added (columns 1-2) and $x$ is a set of inputs. Capital stock, labor, and (for the revenue case only) intermediate inputs are included in $x . f(\cdot, \beta)$ is either a first (Cobb-Douglas, columns 1 and 3) or second (Trans-Log, columns 2 and 4) order polynomial in log inputs. Estimation of parameters $\beta$ is described in section 3.2. Standard errors, in parentheses, are (two-way) clustered at firm and main-lender $\times$ year level. ${ }^{* * *} \mathrm{p}<0.01,{ }^{* *} \mathrm{p}<0.05,{ }^{*} \mathrm{p}<0.1$. 
Table 7: Credit Supply Shock and Productivity-Enhancing Activities

\begin{tabular}{|c|c|c|c|c|c|c|c|c|}
\hline VARIABLES & $\begin{array}{c}\text { PCs per } \\
\text { unit of Capital } \\
(1)\end{array}$ & $\begin{array}{c}\text { No. of Patents } \\
\text { Applications } \\
(2)\end{array}$ & $\begin{array}{c}\text { Patent } \\
\text { Growth } \\
(3)\end{array}$ & $\begin{array}{c}\text { Patent } \\
\text { Growth } \\
(4)\end{array}$ & $\begin{array}{c}R \& D \\
(5) \\
\end{array}$ & $\begin{array}{c}\text { Export } \\
(6) \\
\end{array}$ & $\begin{array}{c}\text { FinCon }_{i, 2010} \\
(7)\end{array}$ & $\begin{array}{c}\text { Management } \\
\text { Score } \\
(8)\end{array}$ \\
\hline$\phi_{i, t}$ & $\begin{array}{c}0.672^{* *} \\
(0.269)\end{array}$ & & & & $\begin{array}{l}0.163 \\
(0.284)\end{array}$ & $\begin{array}{l}0.305^{*} \\
(0.159)\end{array}$ & $\begin{array}{c}-1.629^{* * *} \\
(0.594)\end{array}$ & $\begin{array}{l}2.166^{*} \\
(1.116)\end{array}$ \\
\hline$\phi_{i, t-1}$ & & $\begin{array}{c}0.0418^{* *} \\
(0.0195)\end{array}$ & $\begin{array}{c}1.759^{* *} \\
(0.771)\end{array}$ & & & & & \\
\hline$I T B K_{i, 2006}$ & & & & $\begin{array}{c}-1.703^{* *} \\
(0.835)\end{array}$ & & & & \\
\hline Model & Panel & Panel & Panel & Cross Section & Panel & Panel & Cross Section & Cross Section \\
\hline Observations & 3,913 & 497,376 & 9,322 & 3,199 & 2,868 & 6,094 & 506 & 183 \\
\hline$R^{2}$ & 0.967 & 0.756 & 0.342 & 0.049 & 0.872 & 0.843 & 0.421 & 0.020 \\
\hline
\end{tabular}

Columns (1)-(3), results of estimating model: $Y_{i, t}=\psi_{i}+\psi_{s, t, p}+\gamma \cdot \phi_{i, t}+\eta_{i, t}$ One observation is one firm for one year between 1999 and 2001 (unbalanced panel). Firm FEs and provincexindustry $\times$ year FEs are included. Singleton are dropped. $\phi_{i, t}$ is an idiosyncratic shock to firm credit supply, whose construction is detailed in section 3.1 . A $1 \%$ increase in $\phi_{i, t}$ is the supply shock needed to increase the credit granted to firm $i$ by 1\%. LHS of column (1) is the log of number of PCs per 1,000 euros of capital. The LHS variable in column (2) is the number of patent application made from company $i$ in year $t$. Column (3) is the growth rate of the number of patent applications made by company $i$ in year $t$ versus $t-2$. Columns (5) and (6), LHS is a dummy variable taking value 1 iff firm $i$ in year $t$ has positive investment in R\&D or positive export revenues. Column (4), results of

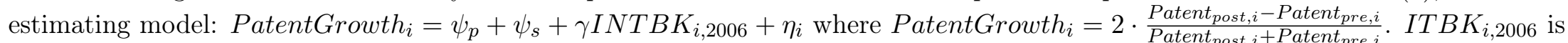
the weighted average of firm's $i$ lenders' liability on the interbank market over assets in 2006. Patent $t_{\text {post }, i}($ Patent pre,$i)$ is the total number of patent applications made by firm $i$ between 2001 and 2006 (2007 and 2010). Column (7), results of estimating model FinCon $_{i, 2010}=\psi_{s, p}+\gamma \cdot \phi_{i, 2010}+\eta_{i}$. One observation is one firm (cross section). ProvincexIndustry fixed effects are included. FinCon $i, 2010$ is a dummy taking value one iff firm $i$ reports "difficulties to get external funds" as an important or somehow important obstacle to innovation. Number of PCs, export activity, R\&D investments, and self-reported obstacle to innovation are taken from INVIND. Column (8), results of estimating model $M S_{i, t}=\psi+\gamma \cdot \phi_{i, t}+\eta_{i, t}$. One observation is one firm observed for one or two years (cross section). $M S_{i, t}$ is firm $i$ overall management score provided by the World Management Survey (Bloom \& Van Reenen, 2007). It takes value from 1-5. Standard errors (in parentheses) are clustered at firm level. ${ }^{* * *} \mathrm{p}<0.01,{ }^{* *} \mathrm{p}<0.05,{ }^{*} \mathrm{p}<0.1$. See section 7 for more details. 
For Online Publication Only

\section{A Additional Materials on Estimation of Credit Supply Shocks}

\section{A.1 Extensions of the additive growth rate model}

\section{A.1.1 Substitution Patterns}

Various forms of the empirical model (1) are widely used in the literature on borrower-lender relations and real effect of financial shocks. However, it does not come without loss of generality. Since many companies have multiple lending relationships, we can expect supply shocks of other connected banks to be included in (1). For instance, letting $b$ and $b^{\prime}$ be the lenders of firm $i$, a more complete model of credit is

$$
\frac{C_{i, b, t}}{C_{i, b, t-1}}=\frac{C\left(J_{t}, D_{i, t}, S_{b, t}, S_{b^{\prime}, t}, X_{i, b, t}\right)}{C\left(J_{t-1}, D_{i, t-1}, S_{b, t-1}, S_{b^{\prime}, t-1}, X_{i, b, t-1}\right)}
$$

which leads to

$$
\Delta c_{i, b, t}=j_{t}+d_{i, t}+\phi_{b, t}+\alpha \cdot \phi_{b^{\prime}, t}+\epsilon_{i, b, t}
$$

To assess the consequences of the exclusion of other banks' supply from (1), we firstly estimate the credit supply shock from such restricted model (equation 3): let $\widehat{\phi}_{b, t}^{0}$ be the resulting estimate. For each bank-firm pair, we define $b^{\prime}$ as the main substitute for $b$ : it is either the main lender of firm $i$ during period $t-1$ or, in case $b$ is the main lender, then $b^{\prime}$ is the second main lender. We then estimate an augmented version of equation (3) which includes the first-stage estimate of credit shock of bank $b^{\prime}$ as an additional controls:

$$
\Delta c_{i, b, t}=j_{t}+d_{i, t}+\phi_{b, t}+\alpha_{t} \cdot \widehat{\phi}_{b^{\prime}, t}^{0}+\epsilon_{i, b, t}
$$

Defining $\widehat{\phi}_{b, t}^{1}$ the estimate of $\phi_{b, t}$ from (17), the correlation between $\widehat{\phi}_{b, t}^{1}$ and $\widehat{\phi}_{b, t}^{0}$ is $\approx 0.99$ for all years $t$. This finding suggests that ignoring substitution and complementarity does not significantly affect our results.

\section{A.1.2 Loans and Relationships Characteristics}

We may relax Assumption 2, by imposing Assumption 2b:

$$
\epsilon_{i, b, t}=\alpha \cdot o_{i, b, t-1}+\dot{\epsilon}_{i, b, t}
$$

and

$$
\dot{\epsilon}_{i, b, t} \perp \mathcal{D}_{i}, \mathcal{S}_{b}
$$

where $o_{i, b, t-1}$ are observable characteristics of the lending relation between firm $i$ and financial intermediary $b$. Assumption $2 \mathrm{~b}$ allows us to estimate bank and firm factors from

$$
\Delta c_{i, b, t}=c_{t}+d_{i, t}+\phi_{b, t}+\alpha \cdot x_{i, b, t-1}+\dot{\epsilon}_{i, b, t}+\text { approx }_{i, b, t}
$$

As match-specific controls, we include: size of the loan relative to borrower's total credit received, size of the loan relative to lender's total credit granted, interest rate, ${ }^{27}$ length of the lending relations, type of credit instrument used, presence of past non-performing loans, and the share of credit covered by collateral. Supply shocks estimated from equations (18) and (3) have correlations above $94 \%$

\footnotetext{
${ }^{27}$ We need to impute interest rates for roughly a third of the observations.
} 
for most years, which mitigate concern that unobservable elements of $\epsilon_{i, b, t}$ are significantly affecting the estimated bank supply shocks. In section 5.1, we show that the main results of the paper are unaffected by using the alternative credit supply shocks derived from decomposition (18).

Summing-up, we develop new tests to estimate whether substitution and complementarity patterns between lenders, and bank-firm match-specific shocks affect our results on the impact of credit supply on productivity. In our data, this does not seem to be the case. Yet, notice that this may not be the case in other more specialized or concentrated markets, such as the one of syndicated loans. Given the widespread use of additive growth rate model, we suggest that our tests represent an important robustness test to be performed by researchers.

OLS computations are performed using algorithms developed by Correia (2016)

\section{A.2 Which factors affect credit supply?}

Jensen \& Johannesen (2016) show that Danish banks entering the 2007-2008 financial crisis with weaker balance sheets declined sharply their lending to retail customers, depressing their consumption. They use a proxy for liquidity in 2007 (loans over deposits) to measure balance sheet strength. Following this literature, for each year $t$ between 2007 and 2009 (credit crunch) we estimate the linear model:

$$
\phi_{b, t}=\phi_{t}+\gamma \cdot\left(\frac{\text { Loans }}{\text { Deposits }}\right)_{b, 2007}+\eta_{b, t}
$$

Results are presented in Column (1) of Table A.5: banks more reliant of wholesale funding-therefore with less "liquid" balance sheet-at the beginning of the credit crunch, decreased more their credit supply. We follow Jensen \& Johannesen (2016) and rely on 2007 data to construct the RHS variable. Results are robust to use 2006 values. Column (2) of the same table uses the capital adequacy ratio (the ratio of bank capital to risk-weighed assets) as an alternative measure of financial strength: better capitalized banks decreased less their credit supply during the credit crunch.

During the Europe sovereign debt crisis, the spread on bonds issued by Italian government (and other southern European countries) increased sharply. Investors responded by acquiring more of these assets, "crowding out" credit to private non-financial corporation (Broner et al. , 2014). Therefore, for each year between 2010 and 2013, we estimate the model:

$$
\phi_{b, t}=\phi_{t}+\gamma \cdot \Delta\left(\frac{\text { Sovereign }}{\text { Assets }}\right)_{b, t}+\eta_{b, t}
$$

where $\left(\frac{\text { Sovereign }}{\text { Assets }}\right)_{b, t}$ is the share of sovereign bonds on the total assets of bank $b$. Results are presented in column (3) of of Table A.5: banks increasing more their exposure to sovereign debt decreased their credit supply to corporate borrowers.

After an M\&A episode, acquired banks generally reduce (in the short-run) their supply of credit to pre-existing borrowers (Buono \& Formai, 2013). Following this intuition, we estimate the model:

$$
\phi_{i, t}=\phi_{i}+\phi_{t, p, s}+\gamma \cdot M A_{i, t}+\eta_{i, t}
$$

where $\phi_{i, t}$ is the credit supply shock experienced by firm $i$ and $M A_{i, t}$ is the share of $i$ 's previous period lenders which are being acquired by another financial institution. Results are presented in 
column (4) of Table A.5: credit supply is negatively affected by lenders' M\&A episodes.

The results presented in this section, being consistent with economic intuition and relevant literature, provide additional support to our measure of credit supply shocks.

\section{B Production with Heterogeneous Credit Constraints}

Firm $i$ operates in sector $s$ and province $p$. For simplicity, we omit the subscript $s$, although all parameters are industry-specific. In each year $t$, firm combines capital, labor and materials to generate revenues:

$$
Y_{i, t}=\exp \left\{\omega_{i, t}\right\} F\left(L_{i, t}, K_{i, t}, M_{i, t}, \beta\right)
$$

or value added

$$
V A_{i, t}=\exp \left\{\omega_{i, t}\right\} F\left(L_{i, t}, K_{i, t}, \beta\right)
$$

We focus the discussion on revenue production function. The value added case is a straightforward simplification. ${ }^{28}$ As it is common in the literature (Olley \& Pakes, 1996) we assume that productivity can be decomposed into a structural component and an error term:

$$
\omega_{i, t}=\tilde{\omega}_{i, t}+\epsilon_{i, t}^{Y}
$$

$\tilde{\omega}_{i, t}$ is correlated over time and it is known to the firm before starting production. Therefore, it affects inputs acquisition and other firm decisions. $\epsilon_{i, t}^{Y}$ is an iid shock, which takes place after input decisions have been made and do not convey information about future productivity. It is often referred as measurement error of output, or "pure luck".

\section{Capital accumulation}

Capital stock is accumulated according to the usual law of motion:

$$
K_{i, t}=I_{i, t}+\left(1-\delta_{t}\right) K_{i, t-1}
$$

\section{Prices}

Firms are price-takers on the input markets. Prices of materials are assumed to be shaped by national prices of inputs and by local inflation shocks (measured by local CPI):

$$
P_{p, t}^{M}=P_{t}^{M} \cdot P\left(c p i_{p, t}\right)
$$

we do not observe firm level or local level prices of intermediate inputs, so we need to assume a form for $P(\cdot) .{ }^{29}$

\section{Variable Profits and Utility Function}

\footnotetext{
${ }^{28}$ For a discussion see Ackerberg et al. (2015) and De Loecker \& Scott (2016).

${ }^{29}$ Namely, we assume that the price of intermediate inputs is an arithmetic average between the national price and the national price deflated by local CPI. See section 2.
} 
Variable profits are:

$$
\begin{aligned}
& \pi\left(K_{i, t}, L_{i, t}, \tilde{\omega}_{i, t}, w_{t}, P_{p, t}^{M}, \epsilon_{i, t}^{Y}\right)= \\
& \quad=\exp \left\{\omega_{i, t}+\epsilon_{i, t}^{Y}\right\} F\left(L_{i, t}, K_{i, t}, M_{i, t}, \beta\right)-w_{t} L_{i, t}-M_{i, t} P_{p, t}^{M}
\end{aligned}
$$

The firm maximizes owner's utility from the dividend stream $\operatorname{Div}_{i, t}$ :

$$
u\left(D_{i v_{i, t}}, \epsilon_{t}^{U}\right)+E\left[\sum_{\tau>t}\left(\frac{1}{1+R}\right)^{\tau-t} u\left(D i v_{i, \tau}, \epsilon_{\tau}^{U}\right)\right]
$$

\section{Credit Supply Shocks}

At the beginning of the period, firm $i$ is connected to a subset of the banks operating in the country, $\mathcal{B}_{i, t-1}$. Each bank "experience" a credit supply shock $\phi_{b, t}$. Firm $i$ receive a credit supply shock equal to $\phi_{i, t}=\sum_{b \in \mathcal{B}_{i, t-1}} \phi_{b, t} \cdot w c_{b, i, t-1}$ where weights are proportional to the share of credit received from firm $i$ from each lender in previous period. We assume $\mathcal{B}_{i, t}$ and $\left\{w c_{b, i, t-1}\right\}$ evolve exogenously, while the quantity of debt is endogenously chosen.

\section{Budget and Credit constraints}

Firm faces a budget constraint:

$$
\begin{array}{r}
\operatorname{Div}_{i, t}+K_{i, t}+B_{i, t-1}\left(1+r_{i, t}\right)+\operatorname{Adj}\left(L_{i, t}, L_{i, t-1}, K_{i, t}, K_{i, t-1}, J_{t}, \epsilon_{i, t}^{a d j}\right)= \\
=\pi_{i, t}+B_{i, t}+\left(1-\delta_{t}\right) K_{i, t-1}
\end{array}
$$

where $B_{i, t}$ is the quantity of euros borrowed, $\operatorname{Adj}(\cdot)$ are adjustment costs for labor and capital, $J_{t}$ is the set of all industry-wide state variables. Firm faces also a credit constraint

$$
B_{i, t} \leq K_{i, t-1} \cdot \Gamma\left(B_{i, t-1}, \phi_{i, t}, \tilde{\omega}_{i, t}, J_{t},\right)
$$

we also assume each input is affected by specific financially-generated constraints:

$$
\begin{aligned}
M_{i, t} & \leq K_{i, t-1} \cdot \Gamma^{M}\left(B_{i, t-1}, \phi_{i, t}, \tilde{\omega}_{i, t}, J_{t}\right) \\
K_{i, t} & \leq K_{i, t-1} \cdot \Gamma^{K}\left(B_{i, t-1}, \phi_{i, t}, \tilde{\omega}_{i, t}, J_{t}\right) \\
L_{i, t} & \leq K_{i, t-1} \cdot \Gamma^{L}\left(B_{i, t-1}, \phi_{i, t}, \tilde{\omega}_{i, t}, J_{t}\right)
\end{aligned}
$$

Furthermore, we assume the function $\Gamma^{M}$ is increasing in its second and third arguments.

The presence of general credit constraints does not imply that intermediate inputs are constrained. However, we want to allow for this possibility, since firms might need to pay in advance part of the material inputs and availability of credit (especially credit lines) might limit their ability to do so. Whether or not an input is effectively contained by availability of external funds depends on the relative cash cycle. For instance, capital investments might be more sensitive to credit availability than labor because they have to be paid fully in advance. However, while firms make financial and 
real decision in continuous time (or every day), our model discretize time in yearly periods, as it is commonly do by the literature because balance-sheets data are available at yearly frequency. Allowing for input-specific constraints is a way to partly reconcile the model with reality.

\section{Timing}

At the beginning of the period the firm observes $\tilde{\omega}_{i, t} \epsilon_{i, t}^{K} \epsilon_{i, t}^{a d j} \phi_{i, t}$ and all elements of $J_{t}$ (like $\epsilon_{t}^{u}$ and $\left.c p i_{p, t}\right)$. Then, it sets jointly $B_{i, t}$ and all inputs. It does not observe the error $\epsilon_{i, t}^{Y}$ until the end of the period. Divit, is set as residual from the budget constraint and it is consumed.

\section{Law of Motion}

The non transmitted shock $\epsilon_{i, t}^{Y}$ is pure luck and, therefore, it is i.i.d and independent of any other component of the model. Without loss of generality, we set $E\left[\exp \left\{\epsilon_{i, t}^{Y}\right\}\right]=1$. Following the tradition of the control function, we impose a Markovian law of motion for productivity. That is,

$$
E\left[\tilde{\omega}_{i, t} \mid \mathcal{I}_{t-1}\right]=E\left[\tilde{\omega}_{i, t} \mid \tilde{\omega}_{i, t-1}, \phi_{i, t-1}, J_{t-1}\right]
$$

where $\mathcal{I}_{t-1}$ is firm's information set at time $t-1$. Assumption 20 relaxes the classical Markovian structure by allowing credit supply to affect productivity dynamics. Furthermore, defining:

$$
\zeta_{i, t}:=\tilde{\omega}_{i, t}-E\left[\tilde{\omega}_{i, t} \mid \mathcal{I}_{t-1}\right]
$$

and

$$
\zeta_{i, t}^{\phi}:=\phi_{i, t}-E\left[\phi_{i, t} \mid \phi_{i, t-1}\right]
$$

we assume $\zeta^{\phi_{i, t}}$ is independent of all $\epsilon$ 's.

\section{Demand for intermediate inputs}

The optimal quantity of intermediate input is

$$
\begin{aligned}
& M^{*}\left(K_{i, t}, L_{i, t}, K_{i, t-1} \tilde{\omega}_{i, t}, J_{t}, B_{i, t-1}, P_{p, t}^{M}\right)= \\
& \quad \min \left\{M^{u n c}\left(K_{i, t}, L_{i, t}, \tilde{\omega}_{i, t}, P_{p, t}^{M}\right) ; K_{i, t-1} \cdot \Gamma^{M}\left(B_{i, t-1}, \phi_{i, t}, \tilde{\omega}_{i, t}, J_{t},\right)\right\}
\end{aligned}
$$

where $M^{\text {unc }}$ solves

$$
\frac{\partial F\left(L_{i, t}, K_{i, t}, M, \beta\right)}{\partial M} \exp \left\{\tilde{\omega}_{i, t}\right\}=P_{p, t}^{M}
$$

under assumptions above, ${ }^{30} M^{*}$ is increasing in productivity for each level of the other factors. Therefore, $\exists$ an unknown function $M^{-1}$ such that:

$$
\tilde{\omega}_{i, t}=M^{-1}\left(K_{i, t}, L_{i, t}, K_{i, t-1}, \phi_{i, t}, c p i_{p, t}, J_{t}\right)
$$

\footnotetext{
${ }^{30}$ We also need to assume that $M$ is chosen within a set $\mathcal{A}_{M}$ such that $F(K, L, \cdot)$ is increasing in its last argument for each value of $K$ and $L$. Then, $M^{u n c}$ is increasing in $\tilde{\omega}$ by Topkis theorem. This is trivially true for the Cobb Douglas case, as long as $K>0$ and $L>0$.
} 
which allows us to write

$$
Y_{i, t}=\exp \left\{\epsilon_{i, t}^{Y}\right\} F\left(L_{i, t}, K_{i, t}, M_{i, t}, \beta\right) \exp \left\{M^{-1}\left(K_{i, t}, L_{i, t}, K_{i, t-1}, \phi_{i, t}, c p i_{p, t}, J_{t}\right)\right\}
$$

therefore, for some unknown function $\tilde{\Psi}$

$$
Y_{i, t}=\exp \left\{\epsilon_{i, t}^{Y}\right\} \tilde{\Psi}\left(L_{i, t}, K_{i, t}, M_{i, t}, K_{i, t-1}, \phi_{i, t}, c p i_{p, t}, J_{t}\right)
$$

\section{B.1 Estimation of the Production Function}

We write the main equations in logarithmic terms. Variables in logs are indicated by lowercase letters. Revenues are:

$$
y_{i, t}=\tilde{\omega}_{i, t}+\epsilon_{i, t}^{Y}+f\left(l_{i, t}, k_{i, t}, m_{i, t}, \beta\right)
$$

where $f(\cdot)$ is known up to the parameter $\beta$, which we aim to estimate. Revenues, can also be written as

$$
y_{i, t}=\Psi\left(l_{i, t}, k_{i, t}, m_{i, t}, k_{i, t-1}, \phi_{i, t}, c p i_{p, t}, J_{t}\right)+\epsilon_{i, t}^{Y}
$$

for some unknown function $\Psi$. Following Ackerberg et al. (2015), we estimate the model in two stages. In the first stage we purge the output from the noise $\epsilon_{i, t}^{Y}$. We estimate $\Psi$ as $E_{t}\left[y_{i, t} \mid l_{i, t}, k_{i, t}, m_{i, t}, k_{i, t-1}, \phi_{i, t}, c p i_{p, t}\right] .^{31}$

From equation (20) we can write

$$
\tilde{\omega}_{i, t}=g_{t}\left(\tilde{\omega}_{i, t-1}, \phi_{i, t-1}\right)+\zeta_{i, t}
$$

with $g_{t}$ unknown.

By definition, we have

$$
E\left[\zeta_{i, t}+\epsilon_{i, t}^{Y} \mid \mathcal{I}_{t-1}\right]=0
$$

therefore,

$$
E\left[y_{i, t}-f\left(l_{i, t}, k_{i, t}, m_{i, t}, \beta\right)-g_{t}\left(\Psi_{i, t-1}-f\left(l_{i, t-1}, k_{i, t-1}, m_{i, t-1}, \beta\right), \phi_{i, t-1}\right) \mid \mathcal{I}_{t-1}\right]=0
$$

leading to the moment condition

\footnotetext{
$\left.31 E_{[} y_{i, t} \mid x_{i, t}, J_{t}\right]=\phi\left(x_{i, t}, J_{t}\right)$ for some unknown function $\phi$, which we approximate as a third order polynomial in $x_{i, t}$ plus year fixed effects. We follow this approximation procedure through the paper.
} 


$$
E\left[\begin{array}{cc}
l_{i, t-1} \\
\Psi_{i, t}-f\left(l_{i, t}, k_{i, t}, m_{i, t}, \beta\right)- & \Psi_{i, t-1} \\
+g_{t}\left(\Psi_{i, t-1}-f\left(l_{i, t-1}, k_{i, t-1}, m_{i, t-1}, \beta\right), \phi_{i, t-1}\right) & \Psi_{i, t-1} \\
m_{i, t-1} \\
. \cdot
\end{array}\right]=0
$$

Moments (26) allow joint estimation of the structural parameter $\beta$ and of the unknown function $g_{t} \cdot{ }^{32}$

We parametrize $f(\cdot)$ as either linear (Cobb-Douglas) or quadratic (Trans-Log) in logs. These two functions are a first- and second- order log-linear approximation of any smooth production function $F(\cdot)$. Since our results are extremely similar between the two, we do not believe it is useful to add higher order terms. Production functions are industry-specific. We drop sectors for which less than 300 firm-year observations are available, because of difficulties in estimating production function with few observations.

The control function approach allows to estimate production function parameters by controlling for simultaneity bias in the choice of inputs. ${ }^{33}$ Furthermore, the inclusion of local price shocks $c p i_{p, t}$ in the control function overcomes the non-identification results of Gandhi et al. (2011). In our baseline specification, we do not include endogenous exit decision in the model. Section 5.1 shows that such an inclusion does not significantly affect the main results of this paper.

If credit supply affects productivity, then it is correlated with $\zeta_{i, t}$. Moreover, $\phi_{i, t}$ is correlated over time: in fact, regression of $\phi_{i, t}$ on $\phi_{i, t-1}$ gives a coefficient of $\approx 0.5$ if no fixed effect is included and $\approx 0.2$ if firm fixed effects are included. Furthermore, it affects input acquisition, as documented by section 4. Therefore, if one excludes credit supply shocks from the model, past inputs are correlated with the productivity innovation, and there are no valid instruments to identify the parameter of interests.

\section{Results}

Table A.1 provides some descriptives for the Cobb-Douglas production function estimates. ${ }^{34}$ The mean $^{35}$ elasticity of value added to capital (to labor) is $\approx .17(\approx .64)$ for the whole economy and $\approx .19(\approx .62)$ for manufacturing. The mean elasticity of net revenue to capital (to labor) is $\approx .07$ $(\approx .14)$ for the whole economy and $\approx .04(\approx .13)$ for manufacturing. The mean elasticity of net revenue to intermediate inputs is $\approx .81$ for both manufacturing and all industries. ${ }^{36}$

\footnotetext{
${ }^{32}$ We follow De Loecker \& Warzynski (2012) and we perform this second stage in two steps. For each guess a parameter value $\beta_{\text {guess }}$, we can compute a corresponding $\omega_{i, t}\left(\beta_{\text {guess }}\right)$. Then, by regressing $\omega_{i, t}\left(\beta_{\text {guess }}\right)$ on a polynomial in $\omega_{i, t-1}\left(\beta_{\text {guess }}\right)$ and $\phi_{i, t-1}$ plus year fixed effects we get a sample analog of $\zeta\left(\beta_{\text {guess }}\right)$. We estimate $\beta$ by minimizing then sample analog of $E\left[\zeta\left(\beta_{\text {guess }}\right) \cdot\right.$ instrument $\left._{i, t-1}\right]$.

${ }^{33}$ That is, since more productive firms are likely to acquire more inputs, a simple regression of output on inputs does not recover the structural parameters of interest.

${ }^{34} \mathrm{As}$ it is shown in section 5 the relations between productivity and credit does not change if one consider CD or Trans-Log production function, therefore we do not find it useful to analyses in detail the more complicated case.

${ }^{35}$ We take averages weighted for number of observation in the sample of the main specification.

${ }^{36}$ Revenue production function estimates can be translated into quantity production function parameters. The mapping between the two depends on the competitive structure of the product market (De Loecker, 2011). If firms are
} 


\section{An alternative model}

A potential critique of this framework is that we include credit supply changes as factors of the level of the credit constraint. Indeed, one might prefer to include the level of the bank-factors affecting its ability and willingness to provide credit into the credit constraint function $\Gamma$. An additional potential problem is that, to perform the inversion of the error, the researcher need to observe the exact value of credit supply shocks. The credit shifter estimated as in section 3.1 might be considered a proxy of the real variation in credit constraints. For instance, the actual credit supply faced by a firm can be affected by new banks it connects to during the year. In a previous version of this paper, we provided an alternative model of production with credit constraints that address all these issues, at the cost of relying on a first-order log-linearization of the main estimating equations (see Carroll (2001) for a critique to this approach). This model provides an alternative firm-specific estimate of productivity growth: the impact of credit supply shocks on it is qualitatively and quantitatively similar to baseline estimates.

\section{Additional Materials on Credit Supply and Productivity Growth}

\section{C.1 TFP, TFPR and TFPQ}

This appendix clarifies that an empirical investigation based on data on revenues rather than quantities presents both challenges and opportunities. We follow De Loecker (2011) and consider a firm producing quantity $Q_{i, t}$ of a single differentiated good, at price $P_{i, t}$, and facing a CES demand. Let its physical production function be a Cobb-Douglas. Quantity produced (supply) is

$$
Q_{i, t}=\exp \left\{\omega_{i, t}^{q}+f\left(l_{i, t}, k_{i, t}, m_{i, t}, \beta^{q}\right)\right\}=\exp \left\{\omega_{i, t}^{q}+\beta_{l}^{q} \cdot l_{i, t}+\beta_{k}^{q} \cdot k_{i, t}+\beta_{m}^{q} \cdot m_{i, t}\right\}
$$

Quantity sold (demand) is:

$$
Q_{i, t}=\left(\frac{P_{i, t}}{P_{t}}\right)^{-\sigma} \exp \left\{\theta_{i, t}\right\}
$$

where $P_{t}$ is national deflator and $\theta_{i, t}$ reflects demand conditions, both endogenous (e.g. quality of the product offered) and exogenous (e.g. local economic shocks) with respect to firm activity. We follow Pozzi \& Schivardi (2016) and refer to $\theta$ as "market appeal". Then, the deflated revenues are:

$$
Y_{i, t}=\frac{P_{i, t} \cdot Q_{i, t}}{P_{t}}=Q_{i, t}^{\frac{\sigma-1}{\sigma}} \cdot \exp \left\{\theta_{i, t}\right\}
$$

price takers on the output market, then the quantity elasticities are equal to revenue elasticities. Under monopolistic competition (and consumers CES demand) for each input $x$ the relations between quantity and revenue elasticities is $\beta^{x, q u a n t i t y}=\beta^{x} \cdot \frac{\sigma}{\sigma-1}$ where $\sigma$ is the elasticity of demand. We compute sector level estimate of $\sigma$ following Pozzi \& Schivardi (2016) in order to calculate the mean quantity-elasticities for manufacturing, which are, respectively $\approx .05$ for capital, $\approx .17$ for labor and $\approx 1.06$ for intermediate inputs. 
therefore, taking logs:

$$
\begin{aligned}
y_{i, t} & =\frac{1}{\sigma} \cdot \theta_{i, t}+\frac{\sigma-1}{\sigma} \cdot \omega_{i, t}^{q}+\frac{\sigma-1}{\sigma} \cdot f\left(l_{i, t}, k_{i, t}, m_{i, t}, \beta^{q}\right)= \\
& =\frac{1}{\sigma} \cdot \theta_{i, t}+\frac{\sigma-1}{\sigma} \cdot \omega_{i, t}^{q}+\beta_{l} \cdot l_{i, t}+\beta_{k} \cdot k_{i, t}+\beta_{m} \cdot m_{i, t}
\end{aligned}
$$

with $\beta_{x}=\frac{\sigma-1}{\sigma} \cdot \beta_{x}^{q}$. The growth rate of productivity is:

$$
\Delta \omega_{i, t}=\frac{1}{\sigma} \cdot \Delta \theta_{i, t}+\frac{\sigma-1}{\sigma} \cdot \Delta \omega_{i, t}^{q}
$$

Therefore, an increase in a revenue-based measure of productivity can be generated either by an increase in technical efficiency or by an increase in market appeal of firm product. Productivityenhancing activities can impact both terms. For instance a process innovation is more likely to increase $\omega_{i, t}^{q}$ while a product innovation should mainly affect $\theta_{i, t}$, see Hall (2011) and Peters et al. (2017b).

The main empirical specification (equation 10) of this paper can be re-written as:

$$
\Delta \omega_{i, t}=\frac{1}{\sigma} \cdot \Delta \theta_{i, t}+\frac{\sigma-1}{\sigma} \cdot \Delta \omega_{i, t}^{q}=\psi_{i}+\psi_{p, s, t}+\gamma \cdot \phi_{i, t}+\eta_{i, t}
$$

Equation (27) highlights an important challenge for our study: to provide evidence that the results are not driven by correlation between output demand (or other local competitive conditions) ${ }^{37}$ and credit supply factors: evidence provided in section 5.1 and 6 are reassuring on this regard. At the same time, we have the opportunity to take into account other sources of productivity increase, besides technical efficiency (Hall, 2011). These encompass improvements in quality of the product offered and access to new markets or new niches that may result in an increase in markups. Measures of pure technical efficiency may ignore changes in product quality, which are found to explain the vast majority of the heterogeneity in firm size (Hottman et al. , 2016). Moreover, it is difficult to properly define quantity productivity in service industries, where products are intrinsically non-homogeneous. How to measure, for instance, the "quantity" produced by a law firm?

An additional concern is that under a more general (inverse) demand function, $P_{i, t}=D\left(Q_{i, t}, \theta_{i, t}, P_{t}\right)$, credit supply might alter pricing incentives and create an increase in measured productivity even without a change in technical efficiency $\omega_{i, t}^{q}$ or market appeal $\theta_{i, t}$. In fact, productivity growth can be also written as:

$$
\Delta \omega_{i, t}=\Delta p_{i, t}+\Delta \omega_{i, t}^{q}
$$

However, this is a not a worrisome concern. In section 4, we find that positive credit supply shocks increase input acquisition. Therefore, even if productivity does not respond to credit shocks, quantity produced also goes up. As long as demand is decreasing in price (inverse demand is decreasing in quantity), a firm has to set lower prices in order to sell the additional quantity produced. Then, a positive credit supply shocks decreases prices and, consequently, revenue productivity, for a given level of technical efficiency and product appeal. We show, instead, a positive effect of credit on productivity growth.

\footnotetext{
${ }^{37}$ For instance, if there is an overlap between the output market of the borrower and the lending market of the lender, then healthier lenders are also connected to firms receiving positive demand shocks.
} 


\section{C.2 Unobservable selection and coefficient stability (Oster, 2016)}

Oster (2016) develops a framework to evaluate the stability of OLS coefficients and $R^{2}$ when including additional controls. This framework builds on work by Altonji et al. (2005) and it quantifies the robustness of the coefficient of a linear regression to the presence of unobservable covariates. It formalizes a commonly used intuitive approach: if the researcher includes relevant controls in a linear regression and the coefficient associated with the variable of interest does not vary "much", then it is "unlikely" that omitted variables are significantly affecting the results.

In order to implement this approach in our setting, let us define $R_{u n}$ and $\gamma_{u n}$ as the R-squared and the coefficient of interest of the unrestricted regression (full set of fixed effects) and $R_{\text {con }}$ and $\gamma_{c o n}$ as their restricted counterpart (from regression with only province and sector and year fixed effect, but no interaction). They can be found in columns (1) and (5) of table 4 (for the revenue Cobb-Douglas case), see section 5.1. The formula at the end of section 3.2 of the 2016 working paper version of Oster (2016) defines as "approximated bias adjusted treatment effect" the coefficient

$$
\gamma\left(\delta, R_{\text {max }}\right)=\gamma_{u n}-\delta \cdot\left(\gamma_{c o n}-\gamma_{u n}\right) \cdot \frac{R_{\text {max }}-R_{u n}}{R_{u n}-R_{c o n}}
$$

where $\delta, R_{\max }$ are two parameters to be chosen by the researcher. $R_{\max }$ is the maximum R-squared that a regression including all the observable and unobservable variables can attain. We set $R_{\max }$ equal to 1 , that is the most conservative value. $\delta$ is a parameter governing the relative importance of unobservable variables with respect to the observable controls. It is common to set $\delta=1$, that is, to assume that observable and unobservable have the same correlation with the variable of interest. However, we choose $\delta=2$ in order to be very conservative. As suggested in section 3.4 of Oster (2016), we build bounding set for $\gamma$ using $\gamma_{u c}$ and $\gamma\left(\delta=2, R_{\max }=1\right)$ as extreme points. Results, which are presented in Table A.4, show that these bounding sets never contain 0. Therefore, our results on the effect of credit shocks on productivity growth (section 5) are "robust" to the presence of unobservable shocks.

\section{C.3 Measurement Error}

Most of the production function literature assume that inputs are measured without error. ${ }^{38}$ However, the complete absence of any measurement error is an utopia. Therefore, the reader might be concerned that the mismeasurement of inputs with respect to output is an important driver of our results. Section 5.1 deals with robustness of the findings with respect to misspecification of the production functions. A further concern is that that we find a residual effect of the credit supply shocks on productivity because we are not able to fully control for inputs. In fact, we can re-write equation (10) as:

$$
\Delta y_{i, t}=\psi_{i}+\psi_{p, s, t}+\Delta f\left(k_{i, t}, l_{i, t}, m_{i, t}, \beta\right)+\gamma \cdot \phi_{i, t}+\eta_{i, t}
$$

where the $\beta$ s are computed on a first stage. Given that $\left(k_{i, t}, l_{i, t}, m_{i, t}\right)$ are correlated, measurment error in the inputs might lead inconsistent estimates for $\gamma$. Table 2, where inputs are on the left hand side, mitigates these concern. Measurment error on the dependent variable ${ }^{39}$ worsen estimates precision, but does not lead to inconsistent estimates. Therefore, the finding that output respond more than inputs (except capital), which is the statistical finding informing the productivity results,

\footnotetext{
${ }^{38}$ There are few notable exceptions, such as Collard-Wexler \& De Loecker (2016).

${ }^{39}$ The difference of two classical measurment errors is still a classical measurment error.
} 
cannot be generated by classical mismeasurment.

The interaction of factor hoarding and adjustment costs may generate more pernicious forms of misurement errors and create spurious correlation between credit supply and productivity. For instance, as a consequence of a tightening in the credit constraint, a firm might immediately scale down production by acquiring less intermediate inputs and-let's say, disinvest part of the capital goods. However, because of employment protection legislation, firing workers might take some time even though these are factually out of production. Therefore, the researcher would observe a wagebill (or headcount) which overestimates the real workforce. Similarly, we observe only capital stock and not its utilization. If using capital is costly, for instance because of endogenous deterioration, firms might respond to negative credit supply shocks partially by changing utilization rate rather than investments. While these concerns are well grounded, and our empirical analysis would be more complete if we could observed capital utilization and hours worked, they cannot be a main driver of our results. In fact, these stories are based on delayed adjustments and they could create short-term productivity loss from negative shocks. Conversely, section 5.3 shows that effect of credit supply shocks last for, at least, few years.

\section{C.4 Marginal Revenue Product of Capital}

Under standard assumptions, if the production factors are allocated between firms in the most efficient way, then the marginal product of each input is equalized between producers within an industry. In fact, if the marginal products are not equalized, the overall production can be increased by moving inputs from low- to high-MRP.

If production functions are Cobb-Douglas, the marginal revenue product of capital (MRPK) is proportional to its average. Considering a sales-generating production function, as we do in this paper, MRPK is:

$$
M R P K:=\frac{\partial Y_{i, t}}{\partial K_{i, t}}=\beta_{k} \exp \left\{\omega_{i, t}\right\} \frac{L_{i, t}^{\beta_{l}} M_{i, t}^{\beta_{m}}}{K_{i, t}^{1-\beta_{k}}}
$$

In a frictionless world, such efficient allocation is achieved if firms face the same input prices (Hsieh \& Klenow, 2009). However, credit constraints, as other frictions, might lead to a departure from this efficient outcome: a credit constrained firm might be "hungry" for capital and exhibits high MRPK while being unable to invest as much as desired. In fact, the within-industry dispersion of MRPK has been used as an empirical measure of allocative inefficiency.

According to this intuition, when credit constraints get slacker, firms can acquire more capital (if it's profitable to do so) and MRPK should decrease. In section 4, we show that firms increase their investment when they are connected to lenders expanding their credit supply. However, credit expansions have also a positive effect on firm TFP (and other inputs). Therefore, as illustrated by equation (28) the sign of the overall effect is ambiguous.

Consequently, we estimate the effect of credit supply shocks on (log) MRPK and MRPK growth. Results are presented in Table A.3 for the Cobb-Douglas case (they are similar for Trans-Log production functions). We find that credit availability leads to an increase of firm MRPK. Therefore, firms look more hungry for capital exactly when their constraints are getting slacker, at least in the 
panel dimension. We detect a positive or null effect on MRPK growth, according to the specification.

This finding further illustrates the core argument of the paper: exogenous changes in credit availability do not only affect how much capital (and other input) is allocated to firms but they also impact the marginal productivity of inputs by altering TFP.

\section{Additional Materials on Interbank Shock}

\section{D.1 Placebo and robustness tests}

Estimation of (15) provides evidence that firms hit harder by the credit crunch decrease their relative productivity. What if banks relying more heavily on the interbank market were just matched to worst borrowers? To remove this concern, we run equation (15) including only years before the freeze of the interbank market; that is, $t \in[2004,2006]$. Results, shown in columns (1) - (4) of Table A.7, show that firms more exposed to the freeze of the interbank market did not have statistically different growth rates of productivity before the credit crunch.

We implement an additional placebo test. That is, we investigate the effect of a hypothetical freeze of the interbank market in 2003. For $t \in[2003,2005]$ we estimate the model:

$$
\Delta \omega_{i, t}=\psi_{p, s, t}+\gamma \cdot I N T B K_{i, 2002}+\eta_{i, t}
$$

Columns (5)-(8) of Table A.7 show that the placebo collapse is not a significant predictor of firms' subsequent productivity growth.

An additional concern is that firms hit harder by the collapse of the interbank market were more sensitive to business cycle fluctuation and, therefore, they suffered more during the recession following the financial turmoil. For each firm in the sample, we estimate its sensitivity to business cycle from equation:

$$
\Delta y_{i, t}=\psi_{i}+\alpha_{i} \cdot g r G D P_{t}+\epsilon_{i, t}
$$

where $\operatorname{gr} G D P_{t}$ is the growth rate of Italian GDP in year $t, \alpha_{i}$ is firm-specific sensitivity to business cycle fluctuation, and $y_{i, t}$ is the log of net revenue. The model is estimated using all available years before 2006. We find no statistically significant correlation between the estimated sensitivity to business cycle before 2006 and firm lenders reliance on the interbank market in 2006, see column (9) of Table A.7.

We also perform a test of balancing pre-crisis covariates across different quartiles of dependence from the interbank market, following Chodorow-Reich (2013) and Imbens \& Wooldridge (2009). Normalized differences are reported in the bottom panel of Table A.2. We do not reject the null of homogeneous distribution of observable characteristics, see section 5.1 for details.

\section{D.2 Credit Granted and Credit Supply}

This section investigates whether the exposure to the interbank market was a significant negative credit supply shock, as we argue in section 6 . For each firm $i$ active in industry $s$ and province $p$ over the years $t \in[2007,2009]$, we estimate the equations: 


$$
\begin{aligned}
\Delta \text { credit }_{i, t} & =\psi_{p, s, t}+\gamma \cdot I N T B K_{i, 2006}+\eta_{i, t} \\
\phi_{i, t} & =\psi_{p, s, t}+\gamma \cdot I N T B K_{i, 2006}+\eta_{i, t}
\end{aligned}
$$

Results are shown in Table A.6, which documents that firms more exposed to the collapse of the interbank market decrease more the credit received with respect to others operating in the same industry and location. An increase of dependence from the interbank market of $1 \%$, lead to a decrease of the growth rate of credit granted between a quarter and a fifth of a percentage point, see columns (2) and (4). Furthermore, columns (1) and (3) show that the measure of credit supply shocks $\phi_{i, t}$ does respond negatively to the interbank shocks. 


\section{Additional Figures}

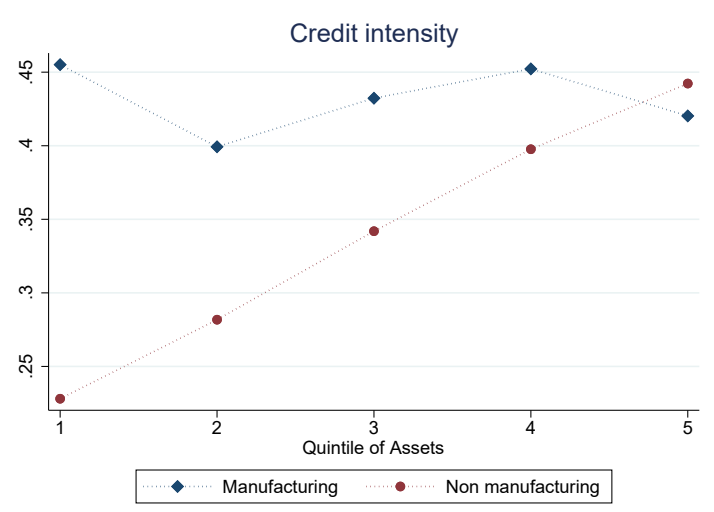

Figure A.1: Credit intensity per quintile of asset size. Credit intensity is the ratio of credit granted over net revenue and it is winsorized at top $2 \%$
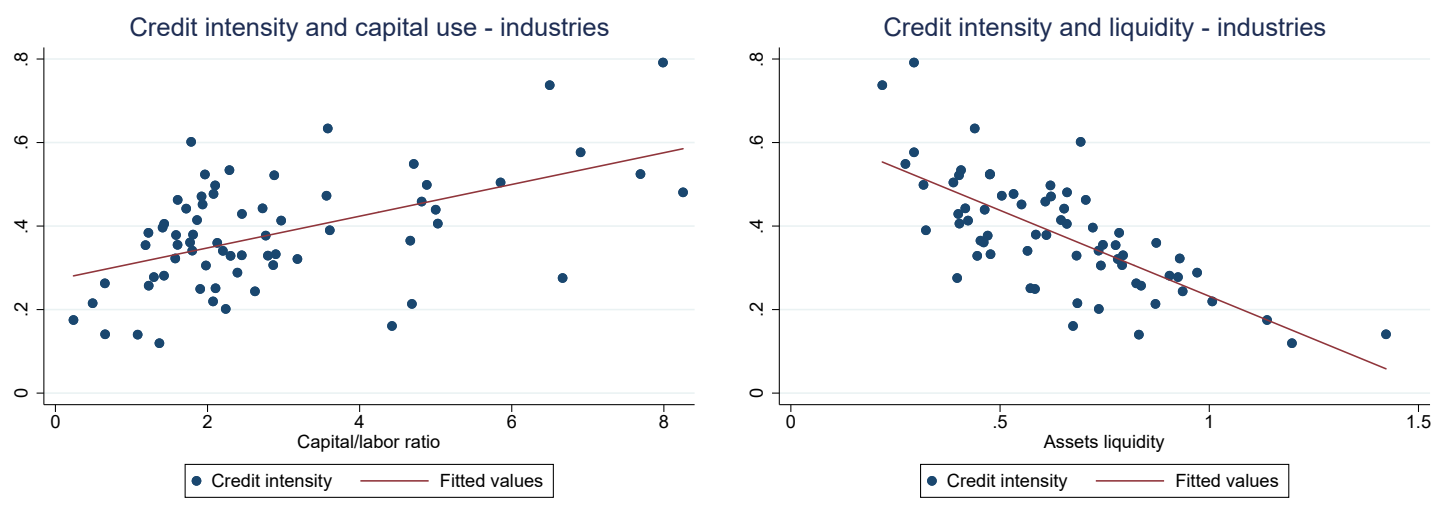

Figure A.2: Industry (2-digits) average credit intensity and capital to labor ratio (left panel) or liquidity (right panel). Credit intensity is the ratio of credit granted over net revenue and it is winsorized at top $2 \%$ before taking averages. Capital to labor ratio is the ratio of capital stock over total wagebill. Liquidity is the ratio of liquid assets over book value of capital.

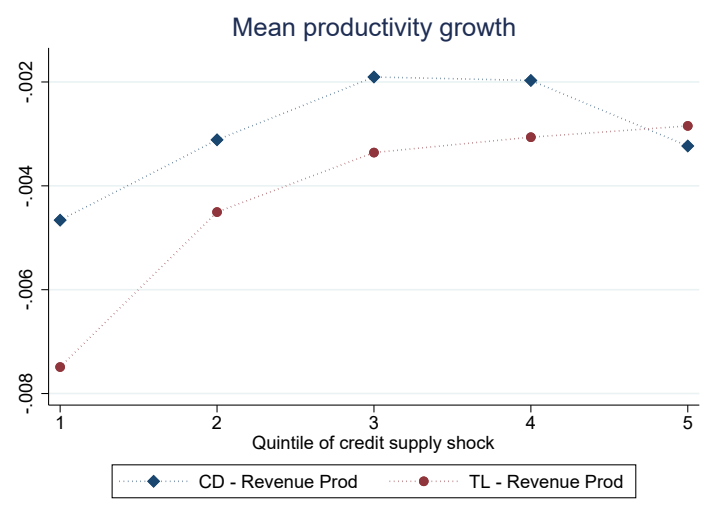

Figure A.3: Average productivity growth per quintile of credit supply shock 

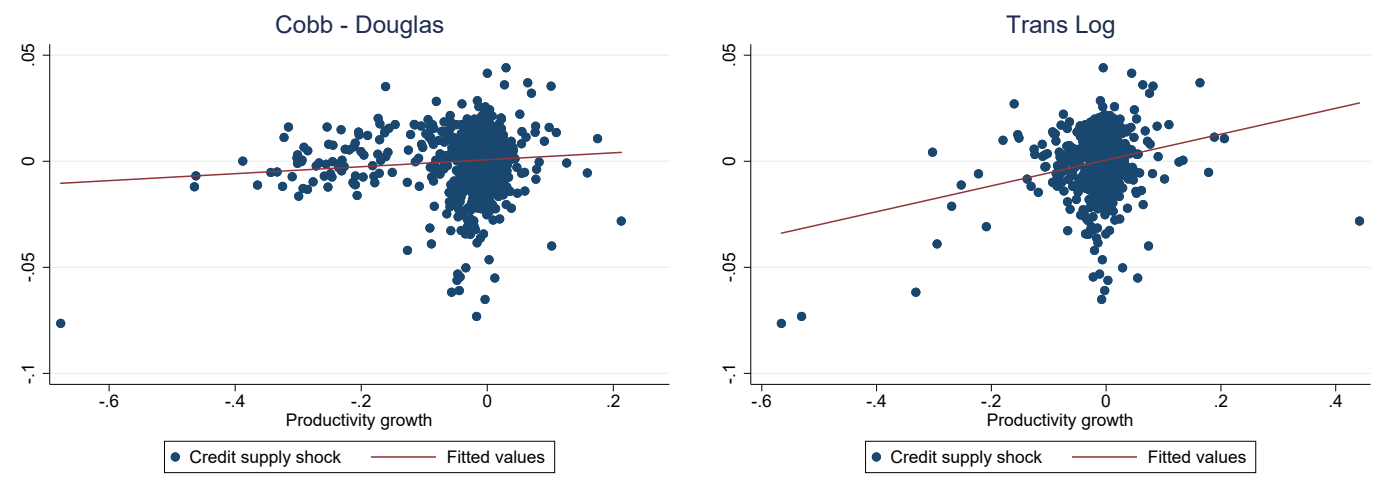

Figure A.4: Industry $\times$ year average revenue productivity growth and credit supply shocks. Fitted lines in both panels have a slop significantly larger than zero (1\% confidence).
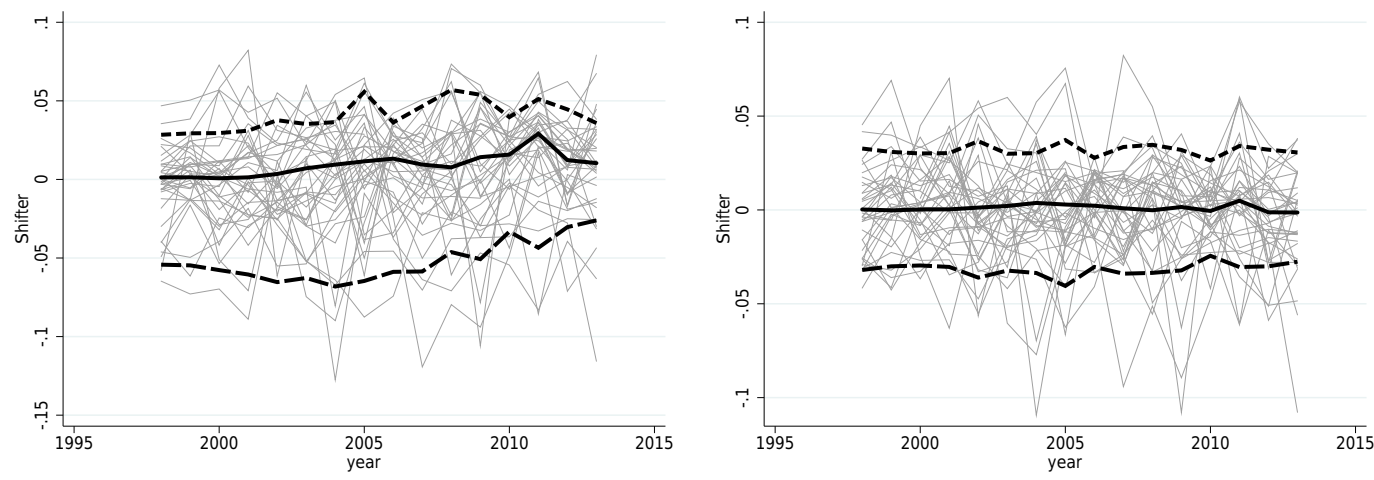

Figure A.5: Figures display evolution of Credit Supply Shock experienced by a 1.5\% random sample. Right panel shows residualized values after taking out FEs
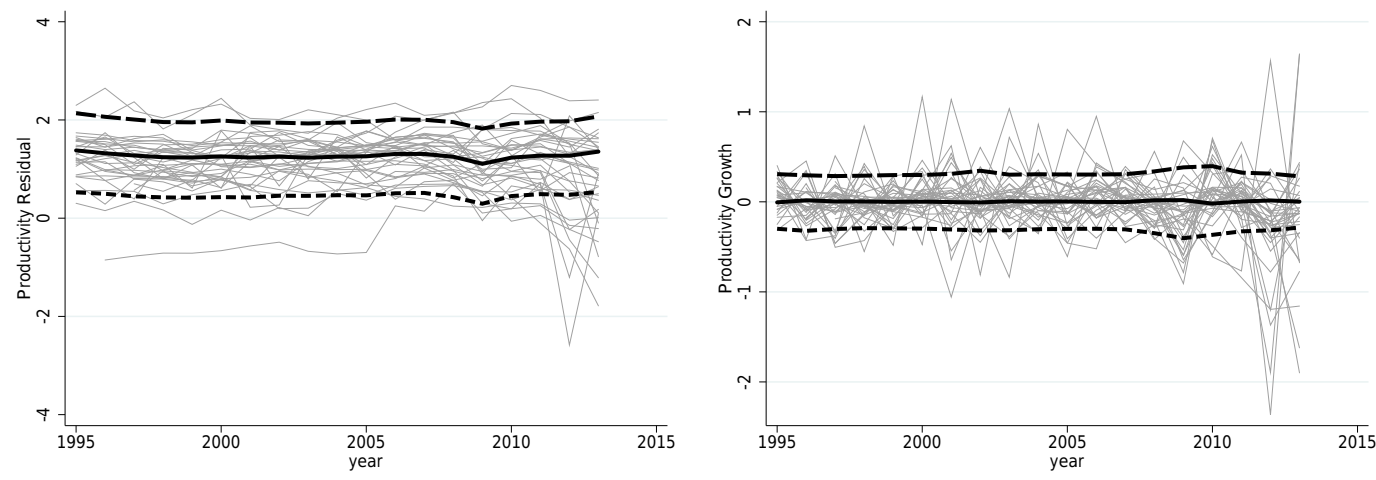

Figure A.6: Figures display evolution of Productivity (Cobb-Douglas, Value Added) for 1.5\% random sample. Right panel shows residualized values after taking out FEs 

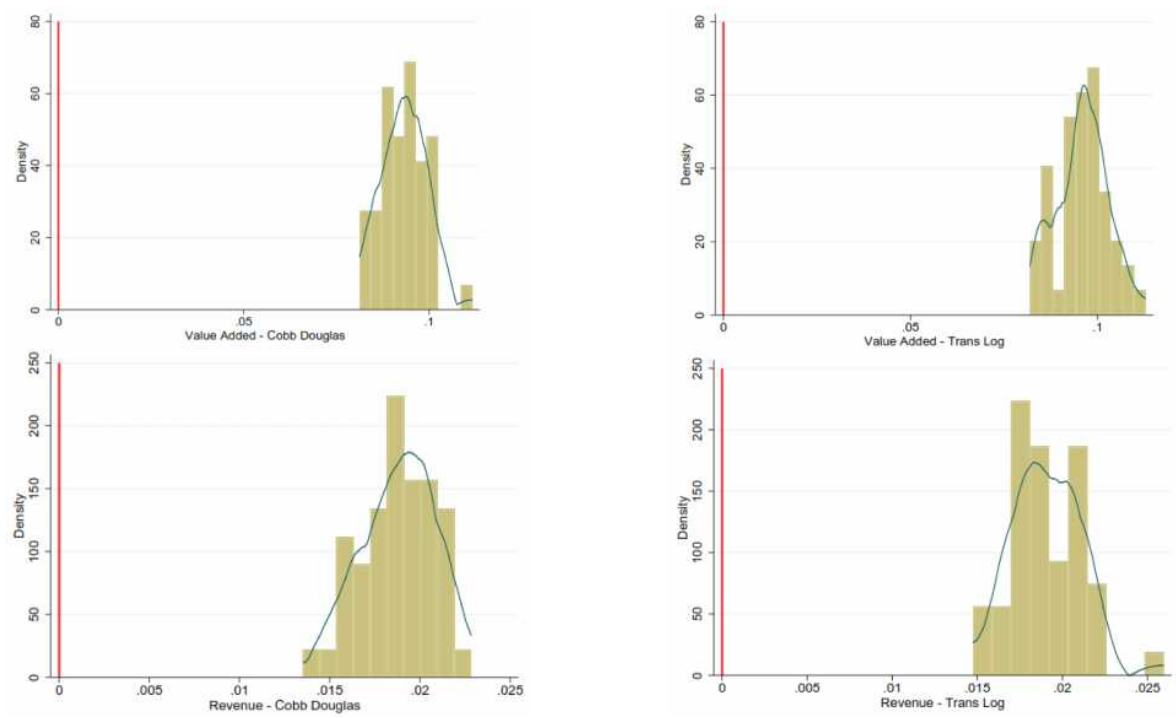

Figure A.7: Distribution of $\gamma$ from equation $\Delta \omega_{i, t}=\psi_{i}+\psi_{p, s, t}+\gamma \cdot \phi_{i, t}+\eta_{i, t}$. See section 5 for details. Distribution is computed from 50 (firm-level) bootstrapped sample. Industry level production function and firm level productivity growth is re-estimated for each bootstrapped sample. Estimates are all above zero (red vertical line) for all samples.
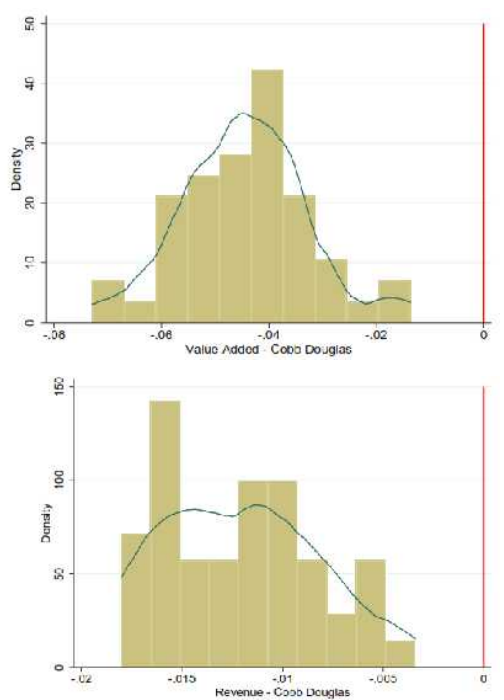
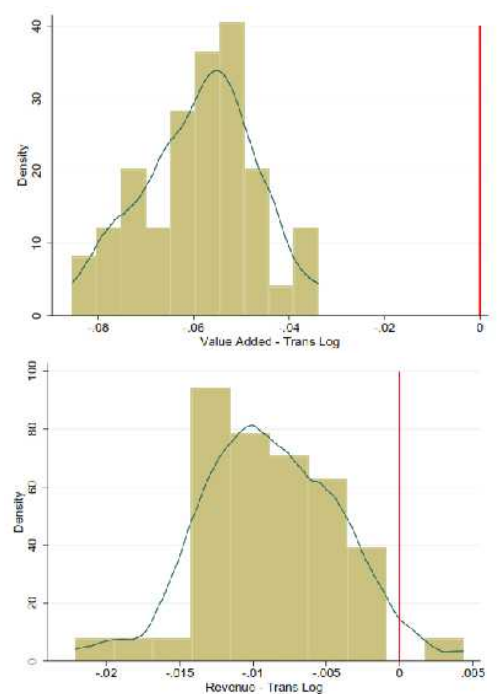

Figure A.8: Distribution of $\gamma$ from equation $\Delta \omega_{i, t}=\psi_{p, s, t}+\gamma \cdot I T B K_{i, 2006}+\eta_{i, t}$. See section 6 for details. Distribution is computed from 50 (firm-level) bootstrapped sample. Industry-specific production function and firmlevel productivity growth are re-estimated for each bootstrapped sample. Estimates are all below zero for all samples except one (one of the estimates related to the revenue- trans log productivity case). 


\section{Additional Tables}

Table A.1: Descriptive Statistics - Cobb Douglas Parameters

\begin{tabular}{|c|c|c|c|c|}
\hline VARIABLE & Mean & Std. Dev. & $\begin{array}{c}\text { Mean } \\
\text { (Quantity) }\end{array}$ & $\begin{array}{l}\text { Std. Dev. } \\
\text { (Quantity) }\end{array}$ \\
\hline \multicolumn{5}{|c|}{ All Industries } \\
\hline \multicolumn{5}{|c|}{ Value Added } \\
\hline$\beta_{l}$ & .64 & .16 & .85 & .25 \\
\hline$\beta_{k}$ & .17 & .14 & .22 & .19 \\
\hline \multicolumn{5}{|c|}{ Revenues } \\
\hline$\beta_{l}$ & .14 & .17 & .18 & .22 \\
\hline$\beta_{k}$ & .06 & .06 & .08 & .08 \\
\hline$\beta_{m}$ & .81 & .11 & 1.08 & .25 \\
\hline \multicolumn{5}{|c|}{ Manufacturing } \\
\hline \multicolumn{5}{|c|}{ Value Added } \\
\hline$\beta_{l}$ & .62 & .15 & .81 & .22 \\
\hline$\beta_{k}$ & .19 & .16 & .24 & .21 \\
\hline \multicolumn{5}{|c|}{ Revenues } \\
\hline$\beta_{l}$ & .13 & .05 & .17 & .07 \\
\hline$\beta_{k}$ & .04 & .02 & .05 & .03 \\
\hline$\beta_{m}$ & .81 & .1 & 1.06 & .12 \\
\hline
\end{tabular}

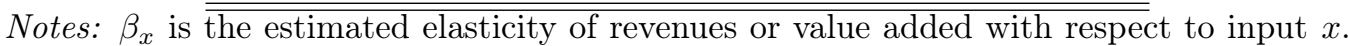
Estimation of the parameters is performed at sector level (2-digit), details are provided in section 3.2. Standard deviations represent sectoral variations and not estimation error. "Quantity" parameters are calculated by multiplying the estimate of sales-generating production function by the correction term $\frac{\sigma}{\sigma-1}$, where $\sigma$ is the elasticity of demand. The correction is exact if firms are monopolistic competitors, see De Loecker (2011). $\sigma$ is estimated from self-reported elasticity of demand, as in Pozzi \& Schivardi (2016). If, instead, firms are price-takers on the output markets, then the elasticity of revenues with respect to an input is the same as the elasticity of quantity. 
Table A.2: Balancing of observable firm characteristics

\begin{tabular}{lcccc}
\hline \hline & $1^{s t}$ Quartile & $2^{\text {nd }}$ Quartile & $3^{\text {rd }}$ Quartile & $4^{\text {th }}$ Quartile \\
& \multicolumn{5}{c}{ Unexpected credit supply shock in $t+1$} & \\
& & & & \\
$\omega$ VA - CD & -.01 & .08 & .08 & -.01 \\
$\omega$ VA - TL & -.03 & .02 & .04 & .01 \\
$\omega$ Rev - CD & .02 & 0 & 0 & -.01 \\
$\omega$ Rev - TL & -.01 & -.01 & .01 & -.01 \\
$\Delta \omega$ VA - CD & .03 & .02 & .03 & .05 \\
$\Delta \omega$ VA - TL & .03 & .02 & .03 & .06 \\
$\Delta \omega$ Rev - CD & -.01 & .02 & 0 & 0 \\
$\Delta \omega$ Rev - TL & -.01 & .01 & 0 & 0 \\
Value Added & .07 & .06 & -.01 & -.06 \\
Net Revenue & .03 & .07 & .01 & -.07 \\
Capital & .08 & .04 & -.03 & -.06 \\
Assets & .04 & .05 & -.01 & -.08 \\
Wagebill & .07 & .05 & -.03 & -.07 \\
Leverage & -.04 & .06 & .04 & -.07 \\
\hline
\end{tabular}

Lenders' reliance on the Interbank market in 2006

\begin{tabular}{|c|c|c|c|c|}
\hline$\omega \mathrm{VA}-\mathrm{CD}$ & -.1 & .03 & .08 & 0 \\
\hline$\omega \mathrm{VA}-\mathrm{TL}$ & .03 & .01 & 0 & -.04 \\
\hline$\omega$ Rev - CD & -.06 & -.03 & .05 & .04 \\
\hline$\omega$ Rev - TL & .02 & .04 & -.01 & -.05 \\
\hline$\Delta \omega \mathrm{VA}-\mathrm{CD}$ & .03 & -.02 & 0 & -.02 \\
\hline$\Delta \omega \mathrm{VA}-\mathrm{TL}$ & .03 & -.02 & -.01 & -.01 \\
\hline$\Delta \omega$ Rev - CD & 0 & -.02 & 0 & .01 \\
\hline$\Delta \omega$ Rev - TL & .01 & -.02 & -.02 & .03 \\
\hline Value Added & -.2 & -.04 & .13 & .09 \\
\hline Net Revenue & -.18 & -.01 & .12 & .05 \\
\hline Capital & -.18 & -.02 & .11 & .07 \\
\hline Assets & -.22 & -.01 & .14 & .06 \\
\hline Wagebill & -.21 & -.04 & .12 & .1 \\
\hline Leverage & -.12 & .24 & .12 & -.24 \\
\hline$\phi_{2006}$ & .03 & .12 & .04 & -.18 \\
\hline$\frac{\phi_{2006}+\phi_{2006}+\phi_{2004}}{3}$ & .06 & .06 & .04 & -.14 \\
\hline
\end{tabular}

"Normalized differences" computed by quartile of treatment variable. Top panel: treatment variable is $\zeta_{i, t+1}^{\phi}$, that is next year innovation to credit supply shock, as defined in equation (11). Bottom panel, treatment variable is $I T B K_{i, 2006}$, that is firm interbank exposure in 2006, as defined in section 6. "Normalized differences" are computed following Imbens \& Wooldridge (2009) as:

$$
N D=\frac{\bar{X}_{q}-\bar{X}_{-q}}{\sqrt{\frac{\operatorname{var}\left(X_{q}\right)+\operatorname{var}\left(X_{-q}\right)}{2}}}
$$

where $q$ and $-q$ denote observations belonging or not to the $q$ th quartile according to the distribution of the treatment variable. The rule-of-thumb threshold to reject homogeneous distribution of covariates is 0.25 (Imbens \& Wooldridge, 2009). Top panel: the sample includes all firm $\times$ year observations such that we can observe a credit supply shock in the following year. Bottom panel: sample includes all firms in 2006. $\omega_{i, t}$ is the estimated Hicks-neutral firm-idiosyncratic productivity term, see section 3.2. 
Table A.3: Credit Supply Shocks and Marginal Revenue Product of Capital

\begin{tabular}{lcccc}
\hline \hline VARIABLES & MRPK & MRPK & MRPK & MRPK \\
& $(\log )$ & $(\log )$ & $($ delta $\log )$ & $($ delta $\log )$
\end{tabular}

Output Measure Value Added Net Revenue Value Added Net Revenue $(1)$

$(2)$ (3)

(4)

All industries

\begin{tabular}{lcccc}
$\phi_{i, t}$ & $0.258^{* * *}$ & $0.170^{* * *}$ & $0.0606^{* * *}$ & -0.0146 \\
& $(0.0345)$ & $(0.0324)$ & $(0.0204)$ & $(0.0166)$ \\
Observations & 656,960 & 656,960 & 656,960 & 656,960 \\
R-squared & 0.915 & 0.917 & 0.186 & 0.221 \\
\hline \multicolumn{5}{c}{ Manufacturing } \\
& & & \\
$\phi_{i, t}$ & $0.294^{* * *}$ & $0.161^{* * *}$ & $0.0725^{* * *}$ & -0.0174 \\
& $(0.0442)$ & $(0.0446)$ & $(0.0239)$ & $(0.0197)$ \\
Observations & 347,990 & 347,990 & 347,990 & 347,990 \\
R-squared & 0.927 & 0.913 & 0.203 & 0.231 \\
\hline \hline
\end{tabular}

Results of estimating models:

$$
\begin{aligned}
\log M R P K_{i, t} & =\psi_{i}+\psi_{s, t, p}+\gamma \cdot \phi_{i, t}+\eta_{i, t} \\
\Delta \log M R P K_{i, t} & =\psi_{i}+\psi_{s, t, p}+\gamma \cdot \phi_{i, t}+\eta_{i, t}
\end{aligned}
$$

One observation is one firm for one year between 1998 and 2013 (unbalanced panel). Firm FEs and province $\times$ industry $\times$ year FEs are included. Singleton are dropped. $\phi_{i, t}$ is an idiosyncratic shock to firm credit supply, whose construction is detailed in section 3.1. A $1 \%$ increase in $\phi_{i, t}$ is the supply shock needed to increase the credit granted to firm $i$ by $1 \%$. MRPK is defined as $M R P K=\frac{\partial Y}{\partial K}$ where $Y$ is net revenue or value added and $K$ is the capital stock. To calculate MRPK we assume firm production function is log-linear in inputs (Cobb-Douglas). We rely on the production function parameters estimated in section 3.2. Standard errors, in parentheses, are clustered at firm level. ${ }^{* * *} \mathrm{p}<0.01,{ }^{* *} \mathrm{p}<0.05,{ }^{*} \mathrm{p}<0.1$ 
Table A.4: Credit Supply Shocks and Productivity Growth - bounding sets (Oster, 2016)

\begin{tabular}{lcccc}
\hline \hline $\begin{array}{l}\text { VARIABLES } \\
\text { (in delta Log) }\end{array}$ & Productivity & Productivity & Productivity & Productivity \\
$\begin{array}{l}\text { Functional Form } \\
\text { Output Measure }\end{array}$ & $\begin{array}{c}\text { Cobb-Douglas } \\
\text { Value Added } \\
(1)\end{array}$ & $\begin{array}{c}\text { Trans-Log } \\
\text { Value Added } \\
(2)\end{array}$ & $\begin{array}{c}\text { Cobb-Douglas } \\
\text { Net Revenue } \\
(3)\end{array}$ & $\begin{array}{c}\text { Trans-Log } \\
\text { Net Revenue } \\
(4)\end{array}$ \\
\hline \multicolumn{5}{c}{ All industries } \\
$\phi_{i, t}$ & {$[0.043 ; 0.095]$} & {$[0.057 ; 0.11]$} & {$[0.019 ; 0.066]$} & {$[0.026 ; 0.071]$} \\
Observations & 656,960 & 656,960 & 656,960 & 656,960 \\
\hline \multicolumn{5}{c}{ Manufacturing } \\
$\phi_{i, t}$ & {$[0.069 ; 0.115]$} & {$[0.097 ; 0.121]$} & {$[0.014 ; 0.030]$} & {$[0.032 ; 0.126]$} \\
Observations & 347,990 & 347,990 & 347,990 & 347,990 \\
\hline \hline
\end{tabular}

Bounding set for the estimates of model

$$
\Delta \omega_{i, t}=\psi_{i}+\psi_{s, t, p}+\gamma \cdot \phi_{i, t}+\eta_{i, t}
$$

One observation is one firm for one year between 1998 and 2013 (unbalanced panel). Bounding sets are built following Oster (2016), see appendix C.2 for details. 
Table A.5: Bank characteristics, M\&A and credit supply shocks

\begin{tabular}{|c|c|c|c|c|}
\hline $\begin{array}{l}\text { VARIABLES } \\
\text { (delta log) } \\
\text { Years }\end{array}$ & $\begin{array}{c}\text { Credit Supply } \\
\text { [2007,2009] }\end{array}$ & $\begin{array}{c}\text { Credit Supply } \\
{[2007,2009]}\end{array}$ & $\begin{array}{c}\text { Credit Supply } \\
\text { [2010,2013] }\end{array}$ & $\begin{array}{l}\text { Credit supply } \\
\text { All years }\end{array}$ \\
\hline $\begin{array}{l}\text { Unit of } \\
\text { observation }\end{array}$ & $\begin{array}{l}\text { Bank } \\
\text { (1) }\end{array}$ & $\begin{array}{l}\text { Bank } \\
(2)\end{array}$ & $\begin{array}{c}\text { Bank } \\
(3)\end{array}$ & $\begin{array}{l}\text { Firm } \\
(4)\end{array}$ \\
\hline$\left(\frac{\text { loans }}{\text { deposits }}\right)_{b, 2007}$ & $\begin{array}{c}-0.0189^{* * *} \\
(0.00533)\end{array}$ & & & \\
\hline$\left(\frac{\text { capital }}{R W A}\right)_{b, 2007}$ & & $\begin{array}{l}0.00133^{* *} \\
(0.000588)\end{array}$ & & \\
\hline$\Delta\left(\frac{\text { sovereign }}{\text { Assets }}\right)_{b, t}$ & & & $\begin{array}{c}-0.155^{* * *} \\
(0.0400)\end{array}$ & \\
\hline$M \& A_{i, t-1}$ & & & & $\begin{array}{r}-0.0117 * * * \\
(0.000657)\end{array}$ \\
\hline Observations & 1,635 & 1,635 & 2,034 & 652,692 \\
\hline R-squared & 0.086 & 0.076 & 0.010 & 0.521 \\
\hline
\end{tabular}

Table A.6: Exposure to Interbank Market, Credit Supply Shocks and Credit Granted

\begin{tabular}{lcccc}
\hline \hline VARIABLES & $\begin{array}{c}\text { Credit Supply } \\
\end{array}$ & $\begin{array}{c}\text { Credit Granted } \\
(\text { delta } \log ) \\
(2)\end{array}$ & $\begin{array}{c}\text { Credit Supply } \\
(1)\end{array}$ & $\begin{array}{c}\text { Credit Granted } \\
(\text { delta log }) \\
(4)\end{array}$ \\
\hline \multirow{4}{*}{$I T B K_{i, 2006}$} & $-0.144^{* * *}$ & $-0.192^{* * *}$ & $-0.164^{* * *}$ & $-0.241^{* * *}$ \\
& $(0.0278)$ & $(0.0400)$ & $(0.0257)$ & $(0.0545)$ \\
& & & & \\
Observations & 110,070 & 108,267 & 57,986 & 57,349 \\
R-squared & 0.191 & 0.093 & 0.197 & 0.089 \\
\hline \hline
\end{tabular}

Results of estimating models:

$$
\begin{aligned}
\phi_{i, t} & =\psi_{s, t, p}+\gamma \cdot \operatorname{ITB} K_{i, 2006}+\eta_{i, t} \\
\Delta \operatorname{cred}_{i, t} & =\psi_{s, t, p}+\gamma \cdot \operatorname{ITB} K_{i, 2006}+\eta_{i, t}
\end{aligned}
$$

One observation is one firm for one year between 2007 and 2009. Province $\times$ industry $\times$ year FEs are included. Singleton are dropped. The RHS variable $I T B K_{i, 2006}$ is the weighted average of firm's $i$ lenders' liability on the interbank market over assets in 2006. The first LHS variable is the credit supply shocks $\phi_{i, t}$, construction is detailed in section 3.2. The second LHS is the first difference of the log of the credit granted to firm $i$ by all financial intermediaries at the end of year $t$. Standard errors, in parentheses, are (two-way) clustered at firm and main-lender $\times$ year level. ${ }^{* * *} \mathrm{p}<0.01,{ }^{* *} \mathrm{p}<0.05,{ }^{*} \mathrm{p}<0.1$. 
Table A.7: Exposure to Interbank Market and Productivity Growth - Placebos

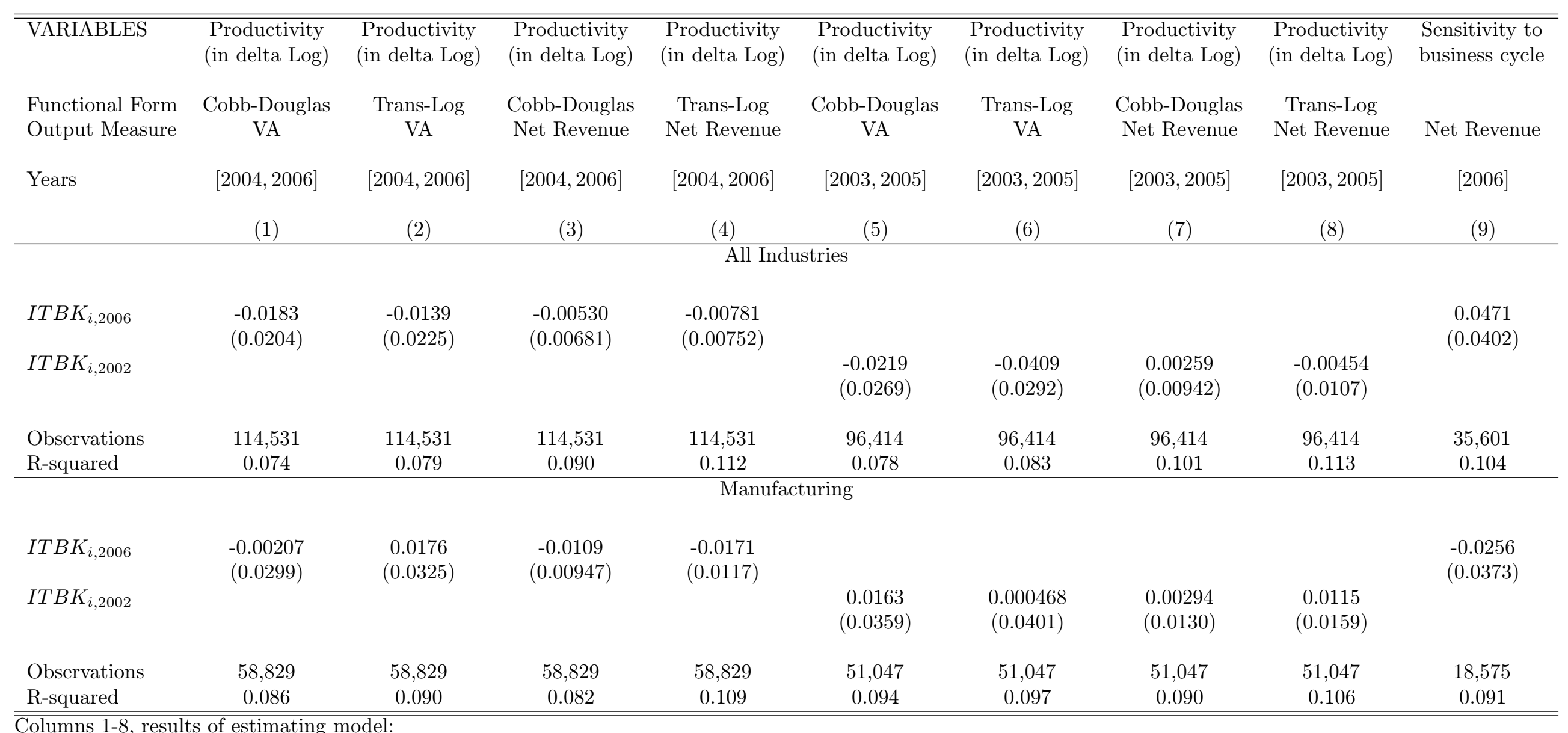

$$
\Delta \omega_{i, t}=\psi_{s, t, p}+\gamma \cdot \operatorname{ITB} K_{i, \tau}+\eta_{i, t}
$$

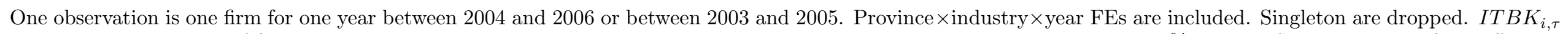

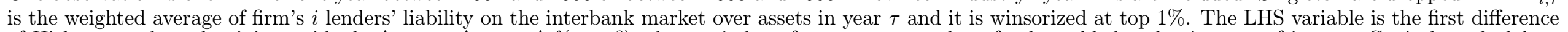

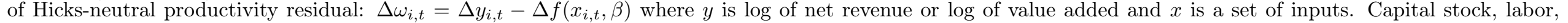

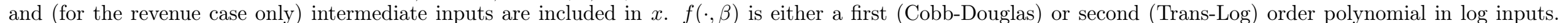

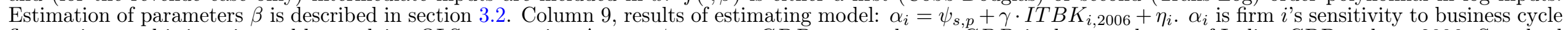

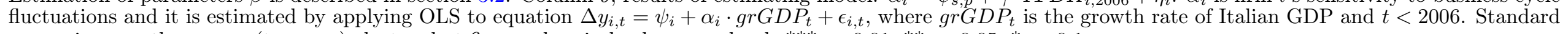
errors, in parentheses, are (two-way) clustered at firm and main-lender $\times$ year level. $* * * \mathrm{p}<0.01, * * \mathrm{p}<0.05,{ }^{*} \mathrm{p}<0.1$. 
Table A.8: Credit Supply Shocks and Productivity Growth: Robustness - Cobb-Douglas Value Added Productivity

\begin{tabular}{|c|c|c|c|c|c|c|c|c|c|}
\hline $\begin{array}{l}\text { VARIABLES } \\
\text { (delta Logs) }\end{array}$ & Productivity & Productivity & Productivity & Productivity & Productivity & Productivity & Productivity & Productivity & Productivity \\
\hline Model & $\begin{array}{l}\text { Baseline } \\
\text { (1) }\end{array}$ & $\begin{array}{c}\text { Firm } \\
\text { Controls } \\
(2) \\
\end{array}$ & $\begin{array}{c}\text { Important } \\
\text { Borrowers } \\
\quad(3) \\
\end{array}$ & $\begin{array}{c}\text { Pooled } \\
\text { Estimator } \\
(4)\end{array}$ & $\begin{array}{c}\text { Alternative } \\
\text { FEs structure } \\
(5)\end{array}$ & $\begin{array}{c}\text { Match } \\
\text { Controls } \\
(6)\end{array}$ & $\begin{array}{c}\text { Split } \\
\text { Sample } \\
(7)\end{array}$ & $\begin{array}{l}4 \text { Digits } \\
\text { Sector } \\
(8)\end{array}$ & $\begin{array}{c}\text { Endogenous } \\
\text { Exit } \\
(9)\end{array}$ \\
\hline$\phi_{i, t}$ & $\begin{array}{c}0.0946^{* * *} \\
(0.0155)\end{array}$ & $\begin{array}{c}0.106^{* * *} \\
(0.0175)\end{array}$ & $\begin{array}{c}0.0865^{* * * *} \\
(0.0172)\end{array}$ & $\begin{array}{c}\text { All Industries } \\
0.0436^{* * *} \\
(0.00963)\end{array}$ & $\begin{array}{c}0.0968^{* * *} \\
(0.0151)\end{array}$ & $\begin{array}{c}0.101^{* * *} \\
(0.0188)\end{array}$ & $\begin{array}{c}0.0932^{* * *} \\
(0.0164)\end{array}$ & $\begin{array}{c}0.0988^{* * *} \\
(0.0183)\end{array}$ & $\begin{array}{c}0.0898^{* * *} \\
(0.0156)\end{array}$ \\
\hline $\begin{array}{l}\text { Observations } \\
\text { R-squared }\end{array}$ & $\begin{array}{c}656,960 \\
0.172 \\
\end{array}$ & $\begin{array}{c}483,665 \\
0.191 \\
\end{array}$ & $\begin{array}{c}521,741 \\
0.185 \\
\end{array}$ & $\begin{array}{c}656,960 \\
0.021 \\
\end{array}$ & $\begin{array}{c}656,960 \\
0.104 \\
\end{array}$ & $\begin{array}{c}656,960 \\
0.172 \\
\end{array}$ & $\begin{array}{c}656,960 \\
0.172 \\
\end{array}$ & $\begin{array}{c}587,873 \\
0.267 \\
\end{array}$ & $\begin{array}{c}656,960 \\
0.175 \\
\end{array}$ \\
\hline$\phi_{i, t}$ & $\begin{array}{c}0.115^{* * *} \\
(0.0178)\end{array}$ & $\begin{array}{c}0.122^{* * *} \\
(0.0211)\end{array}$ & $\begin{array}{c}0.126^{* * *} \\
(0.0196)\end{array}$ & $\begin{array}{c}\text { Manufacturing } \\
0.0405^{* * *} \\
(0.0120)\end{array}$ & $\begin{array}{c}0.116^{* * *} \\
(0.0180)\end{array}$ & $\begin{array}{c}0.114^{* * *} \\
(0.0216)\end{array}$ & $\begin{array}{c}0.114^{* * *} \\
(0.0188)\end{array}$ & $\begin{array}{c}0.127^{* * *} \\
(0.0208)\end{array}$ & $\begin{array}{c}0.111^{* * *} \\
(0.0180)\end{array}$ \\
\hline $\begin{array}{l}\text { Observations } \\
\text { R-squared }\end{array}$ & $\begin{array}{c}347,990 \\
0.186\end{array}$ & $\begin{array}{c}262,308 \\
0.209\end{array}$ & $\begin{array}{c}280,346 \\
0.198\end{array}$ & $\begin{array}{c}347,990 \\
0.032\end{array}$ & $\begin{array}{c}347,990 \\
0.110\end{array}$ & $\begin{array}{c}347,990 \\
0.186\end{array}$ & $\begin{array}{c}347,990 \\
0.186\end{array}$ & $\begin{array}{c}309,887 \\
0.278\end{array}$ & $\begin{array}{c}347,990 \\
0.191\end{array}$ \\
\hline
\end{tabular}
FEs and province $\times$ industry $\times$ year FEs are included. Singleton are dropped. The RHS variable $\phi_{i, t}$ represents idiosyncratic shock to firm credit supply, and its construction is detailed in section 3.1. A $1 \%$ increase in $\phi_{i, t}$ is the supply shock needed to increase the credit granted to firm $i$ by $1 \%$. The LHS variable is the first difference of productivity residual: $\Delta \omega_{i, t}=\Delta v a_{i, t}-\beta_{k} \cdot \Delta k_{i, t}-\beta_{l} \cdot \Delta l_{i, t}$ where $v a$ is log of net value added, $k$ is $\log$ of capital stock and $l$ is labor (measured by log of wagebill). Estimation of parameters $\beta$ is described in section 3.2 . Column (2) add a set of lagged controls to baseline specification: polynomial in size (assets) and the ratios of value added, liquidity, cash flow and bank debt to assets. It excludes observation with missing or zero values for any control variable. Column (3) excludes any firm that, at any point in time, received more than $1 \%$ of the credit by any financial intermediary. Column (4) use pooled estimator (rather than "within") by dropping firm FEs. Column (5) includes firm FEs, province FEs, year FEs and industry FEs, but do not include province $\times$ year $\times$ industry FEs. Column (6) uses an alternative measure of credit supply shocks which control for match-specific covariates, see section 3.1. Column (7) uses, as an instrument, an alternative credit supply shocks estimated with a "split sample" procedure, in order to control for finite sample biases. Column (8) uses a 4-digits (rather than 2) industry definition both for the estimation of productivity parameters and for the FEs structure. It contains less observations because of the singleton dropping. Column (9) estimate productivity allowing for endogenous firm exit, as in Olley \& Pakes (1996). Standard errors, in parentheses, are (two-way) clustered at firm and main-bank $\times$ year level. $* * * ~ p<0.01, * *$ $\mathrm{p}<0.05, * \mathrm{p}<0.1$ 
Table A.9: Credit Supply Shocks and Productivity Growth: Robustness - Translog Revenue Productivity

\begin{tabular}{|c|c|c|c|c|c|c|c|c|c|}
\hline $\begin{array}{l}\text { VARIABLES } \\
\text { (delta Logs) }\end{array}$ & Productivity & Productivity & Productivity & Productivity & Productivity & Productivity & Productivity & Productivity & Productivity \\
\hline Model & $\begin{array}{l}\text { Baseline } \\
\text { (1) }\end{array}$ & $\begin{array}{c}\text { Firm } \\
\text { Controls } \\
(2) \\
\end{array}$ & $\begin{array}{c}\text { Important } \\
\text { Borrowers } \\
\quad(3) \\
\end{array}$ & $\begin{array}{c}\text { Pooled } \\
\text { Estimator } \\
(4)\end{array}$ & $\begin{array}{c}\text { Alternative } \\
\text { FEs structure } \\
(5)\end{array}$ & $\begin{array}{c}\text { Match } \\
\text { Controls } \\
(6)\end{array}$ & $\begin{array}{c}\text { Split } \\
\text { Sample } \\
(7)\end{array}$ & $\begin{array}{l}4 \text { Digits } \\
\text { Sector } \\
(8)\end{array}$ & $\begin{array}{c}\text { Endogenous } \\
\text { Exit } \\
(9)\end{array}$ \\
\hline$\phi_{i, t}$ & $\begin{array}{c}0.0259 * * * \\
(0.00491)\end{array}$ & $\begin{array}{c}0.0268^{* * * *} \\
(0.00563)\end{array}$ & $\begin{array}{c}0.0246^{* * *} \\
(0.00571)\end{array}$ & $\begin{array}{c}\text { All Industries } \\
0.0210^{* * *} \\
(0.00367)\end{array}$ & $\begin{array}{c}0.0244^{* * *} \\
(0.00492)\end{array}$ & $\begin{array}{c}0.0297^{* * *} \\
(0.00621)\end{array}$ & $\begin{array}{c}0.0261^{* * *} \\
(0.00521)\end{array}$ & $\begin{array}{c}0.0274^{* * *} \\
(0.00573)\end{array}$ & $\begin{array}{c}0.0242^{* * *} \\
(0.00452)\end{array}$ \\
\hline $\begin{array}{l}\text { Observations } \\
\text { R-squared }\end{array}$ & $\begin{array}{c}656,960 \\
0.195\end{array}$ & $\begin{array}{c}483,665 \\
0.202\end{array}$ & $\begin{array}{c}521,741 \\
0.207\end{array}$ & $\begin{array}{c}656,960 \\
0.007\end{array}$ & $\begin{array}{c}656,960 \\
0.100\end{array}$ & $\begin{array}{c}656,960 \\
0.195\end{array}$ & $\begin{array}{c}656,960 \\
0.195\end{array}$ & $\begin{array}{c}586,012 \\
0.267\end{array}$ & $\begin{array}{c}656,960 \\
0.182\end{array}$ \\
\hline$\phi_{i, t}$ & $\begin{array}{c}0.0323^{* * *} \\
(0.00649)\end{array}$ & $\begin{array}{c}0.0363^{* * *} \\
(0.00710)\end{array}$ & $\begin{array}{c}0.0343^{* * *} \\
(0.00765)\end{array}$ & $\begin{array}{c}\text { Manufacturing } \\
0.0304^{* * *} \\
(0.00483)\end{array}$ & $\begin{array}{c}0.0274^{* * *} \\
(0.00659)\end{array}$ & $\begin{array}{c}0.0335^{* * *} \\
(0.00809)\end{array}$ & $\begin{array}{c}0.0315^{* * *} \\
(0.00693)\end{array}$ & $\begin{array}{c}0.0361^{* * *} \\
(0.00820)\end{array}$ & $\begin{array}{c}0.0299^{* * * *} \\
(0.00644)\end{array}$ \\
\hline $\begin{array}{l}\text { Observations } \\
\text { R-squared }\end{array}$ & $\begin{array}{c}347,990 \\
0.180\end{array}$ & $\begin{array}{c}262,308 \\
0.191\end{array}$ & $\begin{array}{c}280,346 \\
0.185\end{array}$ & $\begin{array}{c}347,990 \\
0.012\end{array}$ & $\begin{array}{c}347,990 \\
0.093\end{array}$ & $\begin{array}{c}347,990 \\
0.180\end{array}$ & $\begin{array}{c}347,990 \\
0.180\end{array}$ & $\begin{array}{c}309,252 \\
0.277\end{array}$ & $\begin{array}{c}347,990 \\
0.164\end{array}$ \\
\hline
\end{tabular}

FEs and province $\times$ industry $\times$ year FEs are included. Singleton are dropped. The RHS variable $\phi_{i, t}$ represents idiosyncratic shock to firm credit supply, and its construction is detailed in section 3.1. A $1 \%$ increase in $\phi_{i, t}$ is the supply shock needed to increase the credit granted to firm $i$ by $1 \%$. The LHS variable is the first difference of productivity residual: $\Delta \omega_{i, t}=\Delta y_{i, t}-f\left(k_{i, t}, l_{i, t}, m_{i, t}, \beta\right)$ where $y$ is log of net revenue, $k$ is $\log$ of capital stock, $l$ is labor (measured by log of wagebill), $m$ is log of intermediate inputs, and $f(\cdot, \beta)$ is a second order polynomial. Estimation of parameters $\beta$ is described in section 3.2. Column (2) add a set of lagged controls to baseline specification: polynomial in size (assets) and the ratios of value added, liquidity, cash flow and bank debt to assets. It excludes observation with missing or zero values for any control variable. Column (3) excludes any firm that, at any point in time, received more than $1 \%$ of the credit by any financial intermediary. Column (4) use pooled estimator (rather than "within") by dropping firm FEs. Column (5) includes firm FEs, province FEs, year FEs and industry FEs, but do not include province $\times$ year $\times$ industry FEs. Column (6) uses an alternative measure of credit supply shocks which control for match-specific covariates, see section 3.1. Column (7) uses, as an instrument, an alternative credit supply shocks estimated with a "split sample" procedure, in order to control for finite sample biases. Column (8) uses a 4-digits (rather than 2) industry definition both for the estimation of productivity parameters and for the FEs structure. It contains less observations because of the singleton dropping. Column (9) estimate productivity allowing for endogenous firm exit, as in Olley \& Pakes (1996). Standard errors (in parentheses) are clustered at firm level. *** $\mathrm{p}<0.01, * * \mathrm{p}<0.05, * \mathrm{p}<0.1$ 